\title{
„BESSER, DEM GEMEINEN VOLK ANZUGEHÖREN": ZUR ROLLE DES CHORS IN DER SENECANISCHEN TRAGÖDIE
}

\author{
Thomas Gärtner
}

\section{Zusammenfassung}

Eine systematische Untersuchung des Verhältnisses, in welchem die Chöre der echt-senecanischen Tragödien zur jeweiligen dramatischen Handlung stehen, läßt zwei grundverschiedene Typen der Chorgestaltung erkennen: einerseits den unbeteiligt aus einer Position programmatisch gepriesenener Mittelmäßigkeit heraus das Unglück der hochgestellten Helden beobachtenden und analysierenden Chor, andererseits die konträre Spielform eines selbst am Leiden der Großen beteiligten und in der Bewältigung dieses Leidens absorbierten Chors. Beide Spielformen laufen Gefahr, verkannt zu werden in der modernen Forschung, die noch immer das philosophisch-didaktische Element in Senecas Schrifttum auch in den Tragödien in den Mittelpunkt rückt. Die analytische Ausprägung, die immer wieder auf das Axiom rekurriert, alles Hochstehende sei gefährdet, wird mißverstanden in dem Sinne, daß Seneca durch die Äußerungen des Chors zeigen wolle, Macht und Größe führe automatisch zu Hybris und Korruption; die leidende Variante wird ebenfalls fehlgedeutet, indem das, was in Wirklichkeit philosophisch sublimierte Leidensbekundung des Chors ist, als philosophisches Theorem aufgefaßt wird, welches der „Dichterphilosoph“ dem Chor zur Belehrung des Lesers in den Mund lege.

Aristoteles fordert in seiner Poetik, der Chor müsse als einer der Schauspieler begriffen werden und ein integraler Bestandteil der ganzen Tragödienhandlung sein ${ }^{1}$; ähnlich äußert sich Horaz in seiner Ars poetica ${ }^{2}$. Richtet man den Blick von diesen theoretischen Schriften auf die Praxis der senecanischen Tragödie, so kann man nur zu dem negativen Befund kommen, daß sich Seneca an derartige Anweisungen nicht gehalten hat. Der Chor erhält in seinen Tragödien oftmals überraschend wenig Profil; sein Auftreten oder Abgehen wird nicht erwähnt geschweige denn motiviert; ja in mehreren senecanischen Tragödien bleibt unklar, welche Personengruppe der Chor eigentlich repräsentiert und sogar welchem Geschlecht er angehört. Abgesehen von dieser mangelnden persönlichen Profilierung verhält sich der Chor aber auch gelegentlich in eklatanter Weise inkonsequent gegenüber dem dramatischen Geschehen: Etwa im Thyest hat er offenbar mit angehört, wie Atreus gegen seinen Bruder ein gräßliches, alle bisherigen Verbrechen überbietendes Mordkomplott schmiedet (zumindest gibt der Text keinen Hinweis, daß der Chor während dieser Szene den Schauplatz des Geschehens verlassen hätte) — und trotzdem singt er im dritten Chorlied einen Lobpreis auf die Bruderliebe. Wenn man diesen Chor im aristotelischen Sinne als eine an der Handlung teilnehmende Person ansehen wollte, müßte man ihm geistige Demenz unterstellen.

$\mathrm{Zu}$ diesem aristotelischen Postulat ist nun allerdings einschränkend hinzuzufügen, daß in der Poetik selbst schon ein Abweichen der zeitgenössischen Tragödienpraxis von dieser Regel beklagt wird: Bereits Euripides habe sich im Gegensatz zu Sophokles nicht mehr daran gehalten, und bei dem Tragiker Agathon seien die Chorlieder zu bloßen „Einschüben“ (sogenannten $\varepsilon \mu \beta o ́ \lambda \iota \mu \alpha)$ herabgesunken, die keine

\footnotetext{
${ }^{1}$ Arist. poet. 18 p. 1456 a $25-27$.

2 Hor. AP 193-195.
} 
andere Funktion haben, als die Pause zwischen den Szenen zu füllen ${ }^{3}$. Diese spätere griechische Praxis (die wir infolge der Tatsache, daß die hellenistische Tragödie fast vollständig verloren ist, kaum verifizieren können) hat Friedrich Leo mit dem senecanischen Verfahren in Verbindung gebracht. Jedoch läßt sich eine solche Verbindungslinie zwischen einem weitgehend aus Aristoteles erschlossenen Verfahren der hellenistischen Tragödie und Seneca nicht aufrechterhalten: Denn der Chor füllt bei Seneca eben nicht nur die Pausen zwischen den Akten, sondern agiert stellenweise durchaus in der Bühnenhandlung mit. Es finden sich einige Beispiele dafür, daß der Chor nach klassischer Praxis das Auftreten von Schauspielern ankündigt, an Wechselgesängen teilnimmt oder Gespräche mit anderen Personen (z.B. ankommenden Boten) führt. Kurz: es handelt sich beim senecanischen Chor eben nicht nur um eine musikalische Gruppe, welche die Aktpausen überbrückt (wie es offenbar in der hellenistischen Tragödie der Fall war), sondern auch um eine im dramatischen Geschehen agierende Person nach klassischem Vorbild, der allerdings persönliches Kolorit weitgehend entzogen ist und zwar in solchem Maße, daß nicht einmal mehr geachtet wird auf die Stimmigkeit zwischen dem, was der Chor gerade sagt, und dem, was er aufgrund des bisherigen Handlungsverlaufs eigentlich wissen müßte.

Solche Unstimmigkeiten werden gesammelt und in aller Schärfe herausgestellt in der Berliner Dissertation von Otto Zwierlein ${ }^{4}$. Zwierlein sucht diese und andere Unstimmigkeiten im Sinne des Titels seiner Arbeit („Die Rezitationsdramen Senecas“) dahingehend auszuwerten, daß die senecanische Tragödie von ihrem Autor nicht als Bühnendrama, sondern als Rezitationsliteratur konzipiert ist. Inkonsequenzen wie die oben angeführte im Thyest sind nach Zwierlein unerträglich, wenn ein Zuschauer im Theater den Chor ständig während der Planung des Mordkomplotts auf der Bühne sieht und anschließend aus seinem Munde ein Lied über die Bruderliebe hört; wenn der Zuhörer einer Rezitation dagegen den Chor nach seinem letzten vorausgehenden Gesang allmählich aus dem Gedächtnis verloren hat und dann bei seinem erneuten Eingreifen nicht als eine vor Augen stehende Bühnenperson, sondern nur als eine literarische Konvention der Tragödiengattung wahrnimmt, sind solche Widersprüche gemäß Zwierlein hinzunehmen ${ }^{5}$. Die durch Zwierleins Dissertation wiederbelebte philologische Diskussion um den literarischen Charakter der Seneca-Tragödien wird bis in die Gegenwart kontrovers geführt. Da wir keine Selbstzeugnisse Senecas über den von ihm intendierten Zweck seiner Tragödien besitzen, beschränkt sich die Kontroverse notwendig auf die schwierige Frage, ob die uns überlieferten Tragödien mit ihren zweifellos vorhandenen Abweichungen vom klassisch-griechischen Usus noch einigermaßen mit den ihrerseits nicht leicht faßbaren Bedingungen und Möglichkeiten römischer Theaterpraxis vereinbar sind.

Im folgenden soll von dieser Kontroverse um die Aufführbarkeit abgesehen und nur die Frage gestellt werden, in welcher Weise der einerseits formal persönliche, aber andererseits doch in der skizzierten Weise entpersönlichte Chor an der Handlung der senecanischen Tragödien teilhat ${ }^{6}$. Die Untersuchungsbasis bilden sieben in ihrer

\footnotetext{
3 Arist. poet. 18 p. 1456 a $27-32$.

${ }^{4}$ Zwierlein 1966.

${ }^{5}$ Zwierlein 1966, 21 f. Anm. 25 verweist auf Arist. poet. 24 p. 1460 a 11 ff., wo ausgeführt wird, daß

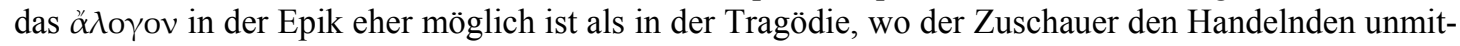
telbar vor Augen hat.

6 Literatur wird gesammelt bei Grewe 114-119; Kugelmeier 1999, 139-144; Hiltbrunner 989-991; Liebermann 202 Anm. 173. Heranzuziehen ist auch die von Castagna edierte italienische Aufsatzsammlung.
} 
Echtheit nicht umstrittene Tragödien (der Hercules Oetaeus und die Octavia werden in einem Exkurs herangezogen); die Phoenissen, ein nur als fragmentarisches Konzept ohne Chor erhaltenes Stück, müssen naturgemäß zunächst beiseite bleiben. Der Gang der Untersuchung wird zwei grundverschiedene Gestaltungen der Chorrolle und eine Mischform ans Licht bringen.

\section{Hercules}

Der He r c u le s beginnt mit einem Zornmonolog der Götterkönigin Juno, die ihren Stiefsohn Hercules vernichten will, indem sie ihn zum Wahnsinn treibt. Der Chor nimmt von diesem Monolog keine Notiz und besingt stattdessen den Sonnenaufgang und wie die verschiedenen Menschen ihrem jeweiligen Tagwerk nachgehen. Die aufreibenden öffentlichen Tätigkeiten höhergestellter Persönlichkeiten schildert der Chor mit offenkundigem Unbehagen.

J. D. Bishop 1966 vermutet hinter den mit typisierendem hic-ille geschilderten Lebensformen die dramatischen Personen Hercules und Lycus, welche in Bishops Deutung in bedenklicher Weise auf eine Stufe gestellt werden (vgl. auch Bishop 1964 b, 181 f.); Bishops Deutung wird fortgeführt von Amy R. Rose 1980, 137 („Hercules resembles the tyrant Lycus in many details“) mit Anm. 9. Entsprechend dieser Gesamtauffassung sucht dieselbe Autorin in einer späteren Abhandlung das erste Chorlied im Sinne einer hercules-kritischen Deutung auszuwerten durch die Aufzeigung fragwürdiger Parallelen zwischen dem hier gezeichneten Naturbild und späteren Schilderungen von Hercules' Arbeiten: „Every image in the dawn song finds its reversal or distortion in Hercules' world, and incorporates allusions to that perversion through language“ (Rose 1985, 102). Allgemein zum motivischen Hintergrund des ersten Chorlieds im Hercules vgl. jetzt die Abhandlung von Rita degl'Innocenti Pierini. Zu Maders (1990) Deutung der Chorposition im Hercules vgl. unten S. 4.

Gepriesen werden demgegenüber die wenigen, die ihr - in Anbetracht des bevorstehenden Todes kurzes - Dasein in friedvoller Stille auskosten. Solange das Schicksal den Menschen leben läßt, solle er in stiller Freude die ihm vergönnte Zeit genießen. Aber die Menschen verhalten sich unverständlicherweise anders und streben ihrem Tod geradezu entgegen. Als Beispiel hierfür wird der Gang des Hercules in die Unterwelt genannt ${ }^{7}$ : Insofern jedem Menschen sein Todestag festgesetzt ist, stelle es einen Akt aus übergroßer Tapferkeit erwachsender Übereilung 8 dar, wenn man wie Hercules von sich aus in die Unterwelt strebe. Am Schluß des Lieds bekundet der Chor noch einmal deutlich sein eigenes Ideal von einem bescheiden friedlichen Daseins, dem „glanzlosen Glück eines kleinen Haushalts“ (Sordida parvae fortuna domus $^{9}$ ).

Daß aus diesem Lebensideal, welches der Chor selbständig und in bewußter Antithese zur Lebens-

\footnotetext{
${ }^{7}$ Hercules wird eindeutig als Beispiel für die dem Ideal des Chors entgegengesetzte Lebensweise eingeführt (vgl. Zwierlein 1988, 334: „Das erste Chorlied verwirft die vita activa zugunsten eines beschaulichen, zurückgezogenen Lebens“). Die Deutung von Motto / Clark 1981, 113 („,The point is that, although the common man seems to the Chorus better off than those elevated in fortune ... nevertheless all mankind serves as time's chattel ... Every man is a laboring Hercules in miniature and yet mere fodder for all-consuming death") kehrt die im Text gegebene logische Ordnung um und bewertet die anderen Lebensweisen relativ zu der des Hercules.

8186 f. Nimium, Alcide, pectore forti/ Properas maestos visere manes. Vgl. im dritten Chorlied 867 Quid iuvat durum properare fatum?.

9 Sen. Herc. 200.
} 
weise des Hercules entwickelt, keine moralisierende Kritik d e s A u t o r s S e n e c a an seiner Figur Hercules zu sehen ist, sondern „vielmehr ... die Folie, vor der die in beherztem Mannesmut in Kauf genommene Gefährdung eines aktiven Lebens stoischer Prägung, das sich allen Widrigkeiten entgegenstellt, umso deutlicher hervortritt“, sagt mit Recht Zwierlein 1984, 24 (zustimmend hierzu auch Mader 1990, 20). Aus der Sicht der dramatischen Handlung ist dieses Lebensideal in der Tat eine Folie; auf der Ebene der Chorreflexion — die hier im Mittelpunkt der Betrachtung steht — ist es zugleich Ausgangspunkt und Instrument einer hintergründigen Analyse der dramatischen Handlung. Diese Analyse führt zu dem Ergebnis, daß die sich im Hadesgang des Hercules bekundende Größe diesen faktisch (nicht schuldhaft) in den Untergang stürzt. Die Reflexionen des Chors mit ihrer Fixierung auf den Todesgedanken laufen letztlich nicht ins Leere, sondern erreichen ihr Ziel im letzten Chorlied beim Tod der Kinder des Hercules. Insofern kann man nicht sagen, daß „the choral arguments acquire philosophical significance in proportion as they are refuted“ (Mader 1990, 25). Maders Auffassung, im Hercules verkehre sich die übliche Konstellation der senecanischen Tragödie (der Chor als positive Folie zu einer aus stoischer Sicht negativen Hauptperson) derart, daß der Chor als negative (epikureische) Kontrastfolie einem positiv gezeichneten Helden gegenüberstehe (Mader 1990, 25), scheitert daran, daß sämtliche im Sinne der unten ausgeführten Typologie analytisch ausgerichteten Chöre (in den Stücken Hercules, Medea, Phaedra, Oedipus, Thyest) dieselbe „epikureische“ Grundhaltung einnehmen und aufgrund des Unglücks der hochstehenden Helden i m m e r faktisch Recht behalten.

Von der schlimmen Bedrängnis der Familie des abwesenden Hercules durch den Usurpator Lycus, die im zweiten Akt geschildert wird, scheint der Chor in seinem zweiten Lied wiederum nichts zu wissen: Er reflektiert über die Ungerechtigkeit der Fortuna, welche Eurystheus in Frieden regieren läßt, während Hercules (der bis jetzt noch überhaupt nicht aufgetreten ist) schwere Mühen bestehen muß; unter anderem muß er den bereits im ersten Chorlied erwähnten Gang in die Unterwelt bestehen, wozu ihm der Chor alles Gute wünscht. Seine Erfolgsaussichten werden durch einen Vergleich mit dem thrakischen Sänger Orpheus, der ebenfalls als Lebender in die Unterwelt gelangte, verdeutlicht.

Im dritten Akt kehrt Hercules zu seiner Familie zurück und wendet sich unverzüglich gegen den Usurpator Lycus; unterdessen berichtet Hercules' Begleiter Theseus ausführlich vom bestandenen Abenteuer in der Unterwelt. Das dritte Chorlied hat wiederum dieselbe Unternehmung zum Gegenstand; die zahllose Population der Unterwelt, in die sich Hercules wagte, wird beschrieben; der Chor wünscht sich, erst möglichst spät dorthin zu gelangen und feiert die Heimkunft des Helden; den Abschluß macht ein metrisch abgesetztes, relativ kurzes Preislied auf den zurückgekehrten Helden.

Die herausgearbeitete Dominanz des Todesmotivs entspricht den übrigen Chorliedern des Hercules. Der Festgesang auf Hercules (875 ff.), der als eigentlicher Zweck der Ode angekündigt wurde (829), wirkt fast wie ein Anhängsel. Damit widerlegt sich das inhaltliche Argument, welches Sutton 1986, 41 dazu bestimmt, das Lied einem Nebenchor zuzuschreiben: „Since the emotional tone of this passages differs so much from that of the play's other choral odes, it is especially plausible that it might be performed by a chorus having a different identity. One thinks of a laurelgarlanded band of youthful merry-makers“" (vgl. auch dies. 1984, 305).

Erst nach der vierten Szene, welche die Ermordung der Kinder des Hercules durch ihren von Juno zum Rasen gebrachten Vater zum Gegenstand hat, läßt sich der Chor dazu herbei, auf das aktuelle Geschehen in Theben einzugehen. Er bittet um eine Teilnahme sämtlicher Elemente an einer kosmischen Trauer über das geschehene Unglück; ferner betet er zum Schlafgott, dieser möge den (inzwischen eingeschlafenen) Hercules von seinem Wahnsinn heilen. Das letzte Chorlied wird beschlossen durch eine Art Abgesang, welcher die Seelen von Hercules' Kindern in die Unterwelt, den Ort der größten Heldentat ihres Vaters, hinabgeleitet. 
Damit hat auch der Chor den Schlußpunkt der äußeren Handlung des Hercules, die Tötung der Kinder, erreicht. Dieser Zielpunkt ist durch die wiederholten Erwähnungen von Hercules' Hadesgang, Totenreich und Tod im allgemeinen in den vorausgegangenen Chorliedern gewissermaßen bereits angesteuert. Im dritten Chorlied (noch vor der eigentlichen Wahnsinnsszene im vierten Akt) hat der Chor bei seiner Schilderung der Unterweltspopulation bereits auf die Seelen umgekommener Kinder hingewiesen ${ }^{10}$. Der Chor erreicht also den äußeren Zielpunkt der dramatischen Handlung in einer Weise, die gegenüber dem in den einzelnen Akten geschilderten äußeren Geschehensablauf einerseits zwar parallel, aber andererseits weitgehend unabhängig ist ${ }^{11}$ : Die Wirklichkeit, die auf der Ebene des äußeren Geschehens faktisch erreicht wird, nämlich der Tod der Kinder, wird vom Chor auf einer reflexiven Ebene parallel zum dramatischen Geschehen erreicht, wobei der Ausgangspunkt auf der Ebene der Chorreflexion der von übergroßem Heldenmut zeugende Unterweltsgang des Hercules ist; das Thema „Unterwelt" und „Tod“ wird in allen folgenden Chorliedern fortgeführt, um im letzten endlich auf die getöteten Kinder des Hercules spezialisiert zu werden.

Mit Hercules selbst wird die ständige Präsenz des Todesmotivs in den Chorliedern in Verbindung gebracht von Zintzen, besonders $163=252$ (die Verse 186-191 ,lassen sich ... vorausweisend auf die wirkliche Katastrophe des Herakles beziehen ... Gemeint ist nicht der physische Tod, sondern die Vernichtung seiner Größe, sozusagen der Tod des mythischen Herakles"); $189=270$ (über das dritte Chorlied: „Dies sind die Gedanken des stoischen Philosophen, der den Sieg und die Taten des Herakles konfrontieren möchte mit der Forderung des meditari mortem“); $195=274$ („Nicht die Götter, sondern der Held selbst stürzt sich in das Verhängnis, das er nur dann hätte vermeiden können, wenn er in stoischer praemeditatio sich der Gefährdung durch seine eigene Größe bewußt geworden wäre"); 208 $=283($,Dieser Herakles ist ... nicht einfach ein Opfer der Fortuna, die alles Hohe stürzt; er selbst trägt zu diesem Sturz bei, weil er in einer Selbsttäuschung die Gefahren seiner das normale Menschenmaß übersteigenden Macht nicht erkannt hat“); ähnlich die Deutung von Motto / Clark 1981, 114: „In consenting to „go to Hell“" Hercules appears merely to be courting his own death, hastening his own dire end". Doch von einem siegreichen Hercules, dem zudem e in göttliches Fortle be n versprochen is t (vgl. astra promissa Herc. 23 i m M unde Ju nos), eine praemeditatio mortis zu fordern, geht wohl selbst für einen stoischen Dramatiker zu weit, und wenn denn Hercules tatsächlich ständig an seinen eigenen Tod gedacht hätte, so hätte dies am Haß der Juno, die sein Unglück herbeiführt, kaum etwas geändert: Denn Juno haßt Hercules ja in erster Linie als ihren Stiefsohn, nicht wegen seiner übergroßen Leistungen oder wegen seiner angeblichen Hybris (vgl. Motto / Clark 1981, 111: „Hercules is persecuted by Juno for what he is, not for what he does“). Daß man Juno nicht als Wiederherstellerin einer gerechten Weltordnung, sondern nur als ihrerseits von persönlichen Affekten bestimmte und destruktiv wirkende Kraft ansehen kann, macht Lawall 1983, besonders $6-10$, aus der literarischen Tradition der Juno-Darstellung bei Ovid und Vergil wahrscheinlich. Heldmann 56 spricht zu Recht von „dem gewaltigen, aber berechtigten Selbstverständnis des Herkules (die Tugend der Bescheidenheit darf man hier nicht erwarten!)“. Die Formulierung Heldmanns wird aufgegriffen von Hiltbrunner 1007, der im folgenden einige Zugeständnisse an die Theorie eines schuldigen Hercules macht. Englische Vertreter solcher Hybris-Theorie werden gesammelt bei Motto/ Clark 1981, 102; als besonders radikaler Vertreter zu nennen ist der Hercules-Kommentator Fitch, vgl. Zwierlein 1988, 333-335. Die Forschungsgeschichte wird jetzt dargeboten in einem Kommentar zum senecanischen Hercules von Margarethe Billerbeck, 30-38, wo die (von Billerbeck in bezug auf Seneca zu Recht abgelehnte) Vorstellung eines selbstverschuldeten Wahnsinnsanfalls des Hercules bis auf Lessing zurückverfolgt wird. Vgl. auch Nesselrath $312 \mathrm{Anm}$. 10, der - gegen Zwierlein 1984 - problematische Züge des senecanischen Hercules vor dem Hintegrund des euripideischen hervorzuheben tendiert.

Zu berücksichtigen sind in der Debatte um die Wertigkeit der dramatischen Person des sene-

\footnotetext{
10 Sen. Herc. 852-854.

11 Vgl. Bishop 1964 b, 43: „... the odes construct a logical sequence parallel to but not necessarily in step with the dramatic action“".
} 
canischen Hercules vor allem zwei Punkte:

1. Daß Hercules von Juno in Wahnsinn versetzt wird gerade am Opferaltar, unmittelbar nachdem er seinen göttlichen Helfern für seine Erfolge gedankt hat (900 ff.) und insbesondere um Frieden auch für den Götterhimmel gebetet hat (926 ff.), wäre ein grotesker Fehlgriff seitens eines Dramatikers, der die Abstrafung des Hercules für seine Frevel gegen eine göttliche Weltordnung darstellen wollte (vgl. Zwierlein 1984, 22 f. und Motto / Clark 1981, 111).

2. Die in den Chorreflexionen immer wieder berührte Tat des Hercules, sein Hadesgang, und die sich daraus ergebenden Pervertierungen der göttlichen Weltordnung geschahen „im Auftrag“ (iussus) der Juno. Mit diesem Argument entschuldigt sich Hercules ausdrücklich für sein Tun beim Sonnengott Phoebus (595 ff.). Solche Worte hätte ihm ein Dramatiker, der zeigen will, daß sein Handeln die Maßstäbe eines geordneten Weltgefüges ignoriert, schwerlich in den Mund gelegt.

Daß Hercules an anderen Stellen Prahlereien in den Mund nimmt, welche schlecht zu der an diesen beiden Stellen bekundeten Gottesfürchtigkeit passen, kann nicht bestritten werden. Nur wäre es Seneca, wenn er Hercules durchgehend als maßlosen Frevler hätte zeichnen wollen, sicher gelungen, Indizien eines gemäßigten, die Naturordnung repektierenden Wesens wie die beiden aufgezählten zu eliminieren.

Die Relevanz des von Zintzen als Motto gewählten Chorverses Alte virtus animosa cadit $(201)^{12}$ wird geleugnet von Dingel 114 f.: „Das ist eine der in Senecas Tragödien so häufigen Weisheiten des Chors, die keine objektive Äußerung darstellen, sondern als subjektives Urteil Objektivität nur vorspiegeln, indem sie lediglich den Vordergrund treffen. Zwar hat Hercules in der Tat virtus animosa, und in der Tat fällt er tief, aber - das ist das Entscheidende, und das Chorlied verschweigt es - er kann daran nichts ändern“. Wenn diese Reflexion über die Gefährdung der Großen wirklich so subjektiv und vordergründig wäre, müßte man dennoch erklären können, warum sie in sechs der acht echten Seneca-Tragödien (mit Ausnahme der Troerinnen und der fragmentarisch ohne Chorpartien erhaltenen Phoenissen) verwendet wird, um das Verhältnis des Chors zu den handelnden Personen zu bestimmen.

Wenn man nun versucht, den Chor des Hercules abschließend zu charakterisieren, so stößt man auf Charakteristica, welche in vielen Fällen senecanische Chöre kennzeichnen: einerseits einen reflexiven Tiefgang, der nicht von den dramatischen Ereignissen des Stücks, sondern von früheren Geschehnissen (in diesem Fall Hercules' Hadesgang) seinen Ausgangspunkt nimmt. Diese kontemplative, auf die Vergangenheit gerichtete Haltung verbindet der Chor mit einer Hervorhebung seiner eigenen niedrigen, von den prominenten Trägern der dramatischen Handlung weit entfernten Stellung. Mit dieser bescheidenen, untergeordneten Stellung verbindet der Chor eine gewisse Sicherheit, nicht von ähnlichen Schicksalsschlägen betroffen zu werden wie die Mächtigen, deren Handeln und Leiden in der Tragödie geschildert wird. Neben die reflexive Distanziertheit von der dramatischen Handlung tritt also eine sich aus der niederen Stellung ergebende äußere Unabhängigkeit.

Ähnliche Züge zeigen auch die Chöre anderer senecanischer Tragödien, die im folgenden zu behandeln bleiben:

\section{M e d e a}

Der offensichtlich aus der korinthischen Bevölkerung rekrutierte Chor der $\mathrm{M}$ e d e a ist der Hauptfigur feindlich gesonnen. Das erste Lied steht der dramatischen Handlung recht nahe: es feiert die neue Hochzeit Jasons mit der Korintherin Creusa und schließt mit einer boshaften Anspielung auf Medea ${ }^{13}$. Der Gegenstand des zweiten ${ }^{14}$

\footnotetext{
12 Auf die Gemahlin des Hercules übertragen in HO 406 Alte illa cecidit quae viro caret Hercule.

13 Vgl. die Abhandlung von Alessandro Perutelli. Daß das erste Chorlied der sich in den beiden folgenden Oden bekundenden zentralen Chorreflexion, welche J a s o n s Geschick zum
} 
ist das ungeheure Wagnis der Argonautenfahrt des Jason. Dieses der eigentlichen dramatischen Handlung der Medea vorausliegende Ereignis hat in den Chorliedern der Medea eine ähnliche Funktion wie der Hadesgang im Hercules: In beiden Fällen handelt es sich um eine heroische Aktion, welche das Normal-Menschliche weit übersteigt und somit dem jeweiligen Chor den Reflexionshintergrund abgibt, vor dem er seine eigene Mittelmäßigkeit und Distanziertheit herausstellen kann. Im zweiten Chorlied der Medea geht es um die Wagnisse, die mit der Argonautenfahrt verbunden waren: Die in der Antike topische Schiffahrts- und Zivilisationskritik liefert hier ein reichhaltiges Motivarsenal, mit Hilfe dessen der Chor die Vision eines glücklichen Urzeitalters heraufbeschwört, in dem noch jeder an seine eigene Scholle gebunden war - wobei diese Vision übrigens in einem sonderbaren Mißverhältnis steht zu der abschließenden anachronistischen Hommage an den Britannienfeldzug des Kaisers Claudius. Der einzige Gewinn, welcher mit der beschwerlichen Argonautenfahrt erzielt wurde, ist nach den zynischen Worten des Chors nichts anderes als das Goldene Vließ und die entführte Medea, „die ein noch schlimmeres Übel als das Meer ist, eine würdige Belohnung für das erste Schiff"15.

Bishop 1964 a stellt die Vorstellung von Medea als malum in einseitiger Weise in das Zentrum seiner Interpretation der Chorlieder der ganzen Tragödie. Zu solcher Auffassung vgl. Pratt 84: „Medea, like the sea, is a superhuman, irrational force that threatens and destroys“; 163: „the Argo theme showing the cosmic proportions of Medea's passion“. Ähnlich jetzt auch Grewe 127: „Die moralische Verurteilung der Argofahrt dient in erster Linie der Verurteilung Medeas“. Speziell im zweiten und dritten Chorlied steht, wie im vorigen und im folgenden gezeigt, die Problematik von Jasons heroischer Größe im Mittelpunkt; die Bemerkung über Medea ist nur ein boshafter Seitenhieb, wie er sich auch am Ende des ersten Chorlieds findet. Auch die Deutung von Schmitz 147 f., welche die ,Verletzung der Naturgesetze durch die Fahrt der Argonauten“ mit „,der Verwirrung der gesetzmäßigen Ordnung des Weltalls durch Medeas Zaubermacht“" in Verbindung bringt, überzeugt nicht: Jasons tragisches übergroßes Heldentum hat nichts mit den dämonischen Praktiken Medeas zu tun.

Im dritten Chorlied der Medea wird anfangs kurz auf die Gefährlichkeit Medeas hingewiesen, deren Zorn sich in der vorausgehenden Auseinandersetzung mit Jason gezeigt hat. Der weitaus größte Teil des Lieds ist wiederum der Argonautenfahrt gewidmet: Der Chor bittet die Meeresgötter um Schonung für den Argonauten Jason. Die offenkundige Gefahr, welche für Jason besteht, wird vom Chor also weniger ${ }^{16}$ in seiner verlassenen Frau Medea gesehen, die Böses gegen ihn plant (wie aus der dramatischen Handlung der Medea seit dem in der ersten Szene gebotenen Zornmonolog der Titelheldin deutlich wird), als vielmehr in den Meeresgöttern, welche Rache für die Verletzung ihres Herrschaftsbereichs durch die Argonauten einfordern. Ähnlich wie im Hercules wird der Zielpunkt der Handlung, die Bestrafung Jasons durch die

Gegenstand hat, inhaltlich fern steht, zeigt, daß man nicht mit Bishop 1964 b, 44 das erste Chorlied einer senecanischen Tragödie prinzipiell zur „directive ode“ erklären kann.

14 Sonderausgabe und Kommentar zum zweiten und dritten Chorlied der Medea bietet Biondi, 1984 (vgl. auch dens. 1981).

15 Sen. Med. 362 f.

16 Gil 133 sieht in diesem Übergang keine Vertiefung der Begründung, sondern eine bloße Addition zweier Schuldaspekte: „Das sich anschließende Chorlied (Med. 579-669) stellt das Fehlverhalten beider Hauptfiguren — Medea und Jason — gegenüber: die ungezügelte, zur Raserei gesteigerte Leidenschaft Medeas und die von Jason verursachte Verletzung der Naturgesetze“ (vgl. auch a.a.O. $137 \mathrm{zu}$ den ,zwei Schuldebenen der Tragödie“). Damit wird jedoch die gedankliche Anknüpfung im Text ignoriert: Die Bedrohung Jasons durch die rasende Medea läßt den Chor die Meeresgötter um Milde für Jason bitten. Der „tiefere“ Grund für Jasons Gefahr liegt im Zorn der verletzten Gottheiten. 
Ermordung seiner Kinder, in den Chorliedern auf einer tieferen Reflexionsebene angesteuert, wobei die Reflexionen ansetzen bei einer Handlung, welche dem dramatischen Geschehen zeitlich vorausliegt, nämlich der Argonautenfahrt.

Schwierigkeiten mit dieser „tieferen Ebene“ zeigen sich bei Liebermann 199-202. Das zweite Chorlied sei „nahezu als ablösbare Einlage“ zu verstehen (199). Zum dritten Chorlied heißt es: „Die Motivierung als Strafe für Iasons Schuld, die in der Teilnahme am Argonautenzug bestünde, schießt deutlich über; sie kommt sonst im Stück nicht zum Tragen. Daß Medea gar eine Art höherer Mission erfüllte, ist ganz abwegig [trotzdem sieht jetzt Grewe 131 „Medea als Handlangerin Neptuns“; ähnlich ist Medea bei Bishop 1964 b, 254 ,an instrument of divine retribution on Jason“ und bei Gil 133 ein „Instrument der Katastrophe“; vgl. auch Fyfe 87 „Medea appears as nature's instrument of justice“; Henderson 101 sagt sogar: Medea ,prepares herself to avenge the violence done to $h$ e $r$ cosmos“"]. Immerhin deutet sich, nimmt man das zweite und dritte Lied zusammen, eine Alternative an, die im Gegenteil der Vermessenheit, in der Bescheidung begründet wäre. Doch sie fällt nicht in den Bereich des Stückes und seiner Möglichkeiten; sie ist gewissermaßen auf einer zweiten Ebene angesiedelt“" (200 f.). Andere Interpreten suchen beide Ebenen im Sinne zweifacher Verschuldung gewaltsam miteinander zu parallelisieren, vgl. Fyfe 88, wo ,the idea of Jason's broken faith with Medea ... and his role in the breaking of nature's convenants" in wohl nur sprachlich überzeugender Weise zusammengestellt wird; vgl. auch a.a.O. 89: Seneca ,focuses on the hybristic nature of Jason's act in sailing the Argo and suggests that, in so doing and in his use of Medea, he has released elemental forces which cannot be controlled“. Dagegen betont Mazzoli 107 den Gegensatz zwischen der audacia des Argonauten Jason im Chorlied und der Aporie der Medea in der dramatischen Handlung.

Alle Schwierigkeiten und Widersprüche lösen sich jedoch auf, wenn man die in der Chorreflexion gegebene Erklärung für Jasons Unglück nicht als eine $\mathrm{S} \mathrm{c} \mathrm{h} \mathrm{u} \mathrm{l} \mathrm{d} \mathrm{z} \mathrm{u} \mathrm{w} \mathrm{e} \mathrm{i} \mathrm{s} \mathrm{u} \mathrm{n} \mathrm{g}$ auffaßt, welche eine alternative Handlungsmöglichkeit aufzeigt, wie er sein Unglück hätte vermeiden sollen (daß Jason auf die Argonautenfahrt hätte verzichten sollen, liegt in der Tat nicht im „Bereich des Stückes"), sondern als eine f a k t i s c h e Analyse über den Hintergrund seines Unglücks. Jason gerät ins Unglück wie die übrigen — ebenfalls heroisch großen - Teilnehmer an der Argonautenfahrt. Prinzipiell richtig verstanden wird die Vertiefung des Geschehens durch die Chorreflexion schon bei Regenbogen, wo es über das zweite Chorlied der Medea heißt (Kl. Schr. 440 f.): „Der Eröffnung dieser Hintergründe dient das zweite Chorlied, das den Blick in alle Weiten und Fernen kaiserzeitlicher Länderkunde hinausleitet ... Eines ist dabei noch übersehen; daß nämlich der Römer [Seneca] ... das Einzelgeschehen aus seiner Vereinzelung löst und in einen großen Zusammenhang von Schicksal, Schuld und Sühne rückt, damit wieder eine Grenze aufhebend und den sozusagen moralischen Hintergrund großartig vertiefend. Das geschieht in dem dritten Chorlied, das an den Anfang die Mahnung setzt: rumpe nec sacro violente sancta/ foedera mundi. Nichts anderes hat die Argofahrt bedeutet; und nun (616) exigit poenas mare provocatum. So hat Tiphys büßen müssen, so Orpheus, Herkules und all die anderen. Ist nun auch für Jason die Stunde der Vergeltung gekommen? Hat er selbst aus Kolchis sich das Unheil geholt? Jam satis, divi, mare vindicastis; parcite iusso schließt das Lied mit dem Gebet des Chors. Solche Einordnung vertieft auch sonst bei Seneca den Hintergrund der Tragödien: so im Oedipus (709) der Blick auf die monstra Cadmeiae terrae ....". Daraus, daß der thebanische Geschlechterfluch des Oedipus mit der Argofahrt der Medea auf eine Stufe gestellt wird, geht hervor, daß die Begriffe „Schuld und Sühne“, „büßen“, „Vergeltung“ letztlich nicht im Sinne eines subjektiv schuldhaften Vergehens gemeint sein können: Jason ist wegen der Argofahrt genausowenig „subjektiv schuldig“ wie Oedipus wegen des thebanischen Geschlechterfluchs oder Hercules wegen des ihm auferlegten Hadesgangs. In diesen Umständen manifestiert sich aber jeweils die das Normalmaß übersteigende Größe der Helden, welches phänomenologisch immer — oder jedenfalls sehr häufig — mit Unheil für diese Helden selbst einhergeht. Diese Erkenntnis bekundet sich in dem weitausgreifenden, dem Argonautenkatalog vorangestellten Relativsatz 607-615 Quisquis audacis tetigit carinae/ Nobiles remos .../ .../ .../.../.../.../ Exitu diro temerata ponti/ Iura piavit.

Im Falle des Oedipus lassen sich diese Verhältnisse am Text des letzten Akts eindeutig belegen: Seinen Entschluß zum Selbstmord formuliert Oedipus mit den Worten anime, quid mortem times?/ Mors in no c e n te m sola Fortun a e eripit (933 f.). Wenige Verse später heißt es in den Überlegungen über die richtige Art des Selbstmords tam magnis breves/ P o e $n$ as sceleribus solvis? (936 f.) und nach dem Vollzug der Blendung de bitas po e n a s t u li (976); Iocasta sagt Fati ista culpa est: ne mo fit fato no ce ns (1019), was auch für sie selbst gelten muß; trotzdem ermuntert sie sich wesentlich später zum Selbstmord mit den Worten socia cur scelerum dare/ Po enas recusas? (1024f.). Subjektive Unschuld 
und die Sühnung objektiver Befleckung etwa durch Selbstmord schließen einander nicht aus, vgl. Zwierlein 1984, 38 ff. Der Aspekt der subjektiven Unschuld tritt in den Vordergrund, wenn sich der Held vor dem Hintergrund einer höheren Macht wie fatum oder fortuna sieht, der des Büßen-Müssens dagegen, wenn es um die menschliche Bewältigung der objektiven Befleckung geht. Insofern bedeutet es auch im Falle der Medea keinen Widerspruch, wenn Jason einerseits subjektiv unschuldig ist und andererseits für die objektive Normen überschreitende Argonautenfahrt „,büßen“ muß.

$\mathrm{Zu}$ beachten sind im übrigen gewisse Unterschiede in der Bewertung der einzelnen Argonauten: Hercules und Meleager wird durch das anaphorisch aufgegriffene Stravit (634. 643) eine ansatzweise persönliche Verantwortung für ihr Geschick (die jedoch jeweils außerhalb der Argonautenfahrt liegt) zugeschrieben; von solcher Verantwortung wird der Knabe Hyllas emphatisch distanziert (646 ff.). Auch bei Aiax Oileus (660 f.) und bei Nauplius (658 f.) scheint eine gewisse persönliche Schuld dazuzukommen. Jason wird als iussus (669) dagegen ausdrücklich distanziert von Pelias, qui ... iussit (664), und als der Schonung würdig befunden. Gerade dieser Schluß des Lieds entlastet Jason völlig und macht deutlich, daß er trotz seiner führenden Rolle bei der Argonautenfahrt keinerlei subjektive Schuld hat. Dagegen sieht Gil 130 im zweiten Chorlied die stoische Beleuchtung von Medeas Auspruch (280) Totiens nocens sum facta, sed numquam mihi; gerade im Aspekt von Jasons bei der Argonautenfahrt bekundeten Wagemut (audere, audax) liege aus stoischer Sicht eine Kritik (131).

Zwierlein 1978, 38 ff. zeigt, daß sich bei Seneca gegenüber Euripides die Tragik auf die Figur Jason verschiebt. Die Objektivität der Zwangslage Jasons zeigt sich besonders in der Übereinstimmung 138 f. (Medea spricht) debuit ferro obvium/ Offerre pectus 434-436 (Jason spricht) si vellem fidem/ Praestare meritis coniugis, leto fuit/ Caput offerendum. Diese Akzentverschiebung gegenüber Euripides wird u.a. durch die Chorlieder deutlich, in denen letztlich zugunsten Jasons Partei genommen wird (vgl. Zwierlein 1978, 47 f.). Es besteht kein Grund, diese Parteinahme als nur „äußerlich“ zu betrachten; so Gil 135, der den Sinn des Lieds darin sieht, dem Leser die „Kriterien zu liefern, um die Schuldhaftigkeit beider Hauptfiguren stoisch zu beurteilen“. Der Chor der „Medea“ ist Jason durchaus freundlich gesonnen (ebenso wie der Chor des „Hercules“ gegenüber dem Titelhelden dieses Stücks, der ebenfalls um Erfolg für diesen betet), und doch erkennt er den letzten Grund von Jasons Gefährdung in dessen in der Argonautenfahrt bekundeter heroischer Übergröße. Wenn man diese phänomenologische Beurteilung mit stoisch-philosophischen Kategorien vermengt, gerät man unweigerlich in Widersprüche, insofern ein stoisch gesinnter Chor dem aus stoischer Sicht fehlenden Helden nicht mehr wohlgesonnen sein kann. In welche Widrigkeiten die Annahme einer subjektiven Schuld Jasons führen kann, zeigt übrigens auch Dingel 108 Anm. 27: „Das wäre dann wiederum ein Beispiel dafür, wie die Götter selbst an einer Schuld mitwirken; vgl. 2 f., wo von der Hilfe Minervas [bei der Argonautenfahrt] gesprochen wird“.

Schwer zu rechtfertigen ist die völlige Eliminierung der Chorreflexion durch Jens-Uwe Schmidt 1998, 162: „Da die Götter aber auf den Anruf des Chors [im dritten Chorlied] überhaupt nicht reagieren, entweder weil sie ihn nicht hören wollen und daher unbarmherzig, ja sogar ungerecht zu sein scheinen, oder weil sie der Bitte nicht entsprechen können und damit ihre Ohnmacht zeigen, wird dieses Deutungsmuster offensichtlich zurückgewiesen und statt dessen hervorgehoben, daß die nachfolgenden Ereignisse nur von Medea her, ihrer Situation, ihrem Schicksal und Wesen verständlich werden“. Mit dem offenkundigen Scheitern des Gebets ist jedoch m.E. nicht die Falschheit des darin gegebenen, zur dramatischen Handlung alternativen Deutungsansatzes denknotwendig verbunden; im Gegenteil wird die Anschauung über den unerbittlichen Zorn der Meeresgötter durch das faktische Ende Jasons eher bestätigt: Die Aufzählung der unglücklichen Geschicke aller übriger Argonauten bereitet geradezu vor auf das Scheitern der Bitte um Schonung für Jason (vgl. Bishop 1964 b, 267: ,the prayers are in fact foil for the hopelessness"). Im übrigen findet sich dasselbe mythologische Deutungsmuster bereits im zweiten Chorlied, wo die übergroße Kühnheit der Argonauten nur als Tatsache behauptet wird und somit nicht (im Sinne Schmidts) durch ein erfolgloses Gebet diskreditiert wird.

Weder der Hadesgang des Hercules noch die Argonautenfahrt Jasons ist als schuldhafte Handlung aufzufassen, welche das Hercules bzw. Jason schließlich zustoßende Unglück auf einer hintergründigen Ebene als ,gerechte Strafe“ erscheinen lassen könnte: Denn beide Helden unternahmen diese Aktionen nicht aus persönlichem Übermut, sondern weil sie dazu angewiesen wurden, Hercules von Juno bzw. Eurystheus, Jason von Pelias. In beiden Stücken wird dieser Umstand hervorgehoben: Im Hercules bittet der Titelheld den Sonnengott Phoebus um Verzeihung dafür, daß er 
Kreaturen der Unterwelt ans Licht der Oberwelt geführt hat: „Verzeih mir, Phoebus, wenn dein Gesicht etwas Unerlaubtes sah: Ge zw ung en e rma $\beta$ en (i us $s u s$ ) habe ich die Geheimnisse der [Unter]welt ans Licht getragen ${ }^{17 ،}$. In der Medea betet der Chor im dritten Lied für Jason, die Götter mögen ihm aus demselben Grund verzeihen: „Schon genug habt ihr, Götter, das Meer gerächt: Schont den, der zu seinem Handeln g e z w u n g e n wurde (Parcite $i$ u $s$ s $o)^{18^{\prime \prime}}$. In beiden Fällen liegt also eine Handlung vor, die Sphären bestimmter Götter verletzt, ebenweil sie über das $\mathrm{Ma}$ des Normalmenschlichen hinausgeht, aber in beiden Fällen liegt auch ein Auftrag von höherer Seite vor, welcher Hercules bzw. Jason dazu zwingt, ihr Heldentum in solcher die Naturordnung verletzender Weise zu bewähren. Von einer subjektiven Schuld kann also in beiden Fällen keine Rede sein.

Anders Grewe 132 f.: ,So wie bei Hercules Befehle Anlaß für sein Tun waren, er aber in Senecas Darstellung durch seine Haltung bei der Ausführung der Befehle schuldig und so zum Opfer seiner eigenen Hybris wird, so verschuldet auch der der senecaische Iason seinen Untergang selbst. Sein Wunsch nach Ruhm, Macht und Sicherheit ließen ihn den Auftrag seines Oheims annehmen; seine Unfähigkeit, diesen allein auszuführen, ließen ihn Medea um Hilfe bitten und seine Erschöpfung in Korinth ließ ihn auf das Angebot des Königs, seine Tochter Creusa zu heiraten, eingehen.“ Ähnlich schon Maurach 136 Anm. 23 = 310 f. Anm. 23: „Obwohl Jason auf Befehl handelte ..., ist er damit nicht der Verantwortung entzogen ...“; im Zusammenhang mit dem dritten Chorlied spricht Maurach sogar vom „,Fluch der bösen Tat“".

Das „Gezwungensein“ des Hercules zu seinen Taten und insbesondere zum Hadesgang wird andererseits stark in den Mittelpunkt gerückt von Dingel 110. Daß Dingels Verständnis des Hercules als ,eines Helden, der von der Gottheit z u r Grö $\beta$ e g e z w u n g n und dann um dieser Größe willen in seiner irdischen Existenz vernichtet wird“"(a.a.O. 109 f.) zu weit geht, zeigt eine Äußerung wie Et, si placerent tertiae sortis loca,/ Regnare potui (609 f.), die beweist, daß sich Hercules im Kraftbewußtsein seiner Taten durchaus gefällt und sich vorstellen kann, diese auch über das ihm anbefohlene Maß weiterzuführen. Daß er dies faktisch nicht tut, beweist, daß er kein von Hybris erfüllter Frevler ist; daß er aber solche Gedanken hat, zeigt, daß er sich auch nicht im Sinne Dingels zu seinen Taten nur gezwungen fühlt. In umgekehrter Weise gegenüber Dingel wird wiederum die Hybris des Hercules in einseitiger Weise aus seinen Äußerungen gefolgert von Rose 1985, 115 : „Hercules blames Juno for his action of presenting a pollution to the sight of the celestials ... This s o u n d s $1 \mathrm{ike}$ the apology of a pious man compelled to do wrong, except that Hercules soon b e tra y s his pride in the accomplishment and his willingness to do more"; ähnlich wie Rose argumentiert übrigens die vor Eifersucht rasende — und daher kaum objektiv urteilende — Deianira in HO 433 f.: Terris videri sceleribus causam suis/ Fecit novercam. Daß das Beauftragtsein des Hercules zu seinen Taten keine bloße Schutzbehauptung ist, beweist die Übereinstimmung mit der Prologrede der Juno, die geradezu zugibt, Hercules durch ihre immer größeren Aufträge — die ihn nach Junos Absicht vernichten sollten — zu seiner jetzigen Größe gebracht zu haben, vgl. 33-36 superat et crescit malis/ Iraque nostra fruitur; in laudes suas/ Mea vertit odia; dum nimis saeva impero,/ Patrem probavi, gloriae feci locum. Was speziell den Hadesgang anbetrifft, so sagt Juno, der Anblick des an die Oberwelt geschafften Höllenhunds habe sie vor ihrem eigenen Befehl erschaudern lassen (63 Timui imperasse). Unmittelbar hieran schließen sich die Befürchtungen über einen möglichen Himmelssturm des Hercules an. Daraus folgt, daß, wenn Hercules tatsächlich einen solchen Himmelssturm plante, die Schuld daran nur zu einem geringen Teil der Hybris des Hercules zuzuschreiben wäre, hauptsächlich aber der Götterkönigin Juno, die Hercules durch ihre immer größer werdenden Aufträge erst in solche Dimensionen hinaufgeführt hat. Auf das tatsächliche Vorhaben eines Himmelssturms ergibt sich in dem senecanischen Stück kein Hinweis; in HO $32 \mathrm{f}$. nec peto ut monstres iter;/ P e r $m$ i t t e tantum, genitor: inveniam viam bekundet sich übrigens geradezu Respekt vor der Autorität des göttlichen Vaters, vgl. auch HO 1302-1304 non minus (sc. quam gigas) caelum mihi/ Asserere potui — dum patrem verum imputo,/ Caelo peperci und das Gebet $1696 \mathrm{ff}$.

Damit ist schon durch die Äußerungen Junos im Prolog eine Art Absicherung gegeben, daß die überdimensionale Größe des Hercules nicht als Ausfluß seiner persönlichen, zur Hybris

17 Sen. Herc. 595-597.

18 Sen. Med. $668 \mathrm{f}$. 
drängenden Natur, sondern nur als — paradoxe — Folge von Junos Haß angesehen werden kann. Der senecanische Hercules — dies soll nicht bestritten werden - hat charakterliche Züge, die dazu führen, daß er diesen sich aufschaukelnden ,Wettkampf“ mit Juno — auch in rhetorischer Hinsicht — gern und sogar mit Begeisterung annimmt, vgl. im Munde der Juno 42 l a e t us imperia excipit (ganz auf der Linie des senecanischen Hercules liegt auch die pointierte Äußerung in HO 62 f.: institit virtus mihi/ Iunone peior). Dies zeigt sich etwa in der als Apostrophe an Juno gerichteten Frage, was sie ihm denn nun nach dem Hadesgang weiter auftrage (615); diese Frage korrespondiert geradezu mit den Befürchtungen der Juno im Prolog, macht aber andererseits auch deutlich, daß weitere, die Naturordnung vielleicht noch mehr pervertierende Unternehmungen des Hercules wiederum letztlich Juno zuzuschreiben wären. Daß Hercules diesen „Wettkampf“ im Grunde seiner Persönlichkeit wünscht, zeigt auch seine Ablehnung, Juppiter um das Ende seiner Mühen zu bitten (924 ff.). $\mathrm{S} \mathrm{chuldig} \mathrm{am} \mathrm{Tod} \mathrm{seiner} \mathrm{Familie} \mathrm{und} \mathrm{an} \mathrm{seinem} \mathrm{eigenen} \mathrm{im} \mathrm{Stück} \mathrm{dargestellten} \mathrm{Unglück} \mathrm{macht}$ den Hercules diese heroische Haltung, mit der er den von Juno angezettelten "Wettkampf" annimmt und weiterführen will, aber schwerlich.

Die herausgearbeitete Entlastung des Hercules durch den Befehl der Juno läßt sich interpretatorisch nur umgehen, wenn man Juno als Symbol für Hercules' eigenen Furor auffaßt (so Lefèvre 1995, 173 f., Doxographie a.a.O. 173 Anm. 23); diese interpretatorische Entpersönlichung der dramatischen Figur Juno erkennt Mader 1990, 19 als fast notwendige Folge der „hercules-kritischen“ Deutungsrichtung. Daß Juno „keine 'autonome', von außen in das Geschehen eingreifende Instanz, sondern das Symbol des Furor" sei, will Lefèvre 1995, 174 durch die Selbstaufforderung der Juno zum furor (108 f.) beweisen; mit dem gleichen Argument könnte man indes auch die senecanische Medea zu einer Symbolfigur erklären, die sich ebenfalls am Ende ihrer Prologrede zur Raserei anstachelt (51 f.). Die Prologreden im Hercules und in der Medea sind in vielerlei Hinsicht vergleichbar: Es ist schwer einzusehen, warum die jedes Maß sprengende, Hercules ins Verderben führende Eifersucht der Juno anders (nämlich symbolisch) gedeutet werden sollte als die entsprechend wirkenden Affekte Medeas.

Die Tatsache, daß die Meeresgötter auf die Argonauten böse sind, illustriert der Chor durch eine Exempla-Reihe all derjenigen Argonauten, welche in ihrem späteren Leben Unglück erfahren. Für sich selbst zieht der Chor aus dem Unglück der ersten Seefahrer folgende Konsequenz: „Der vorher bekannte Weg ist noch niemandem teuer zu stehen gekommen. Wandle auf dem Weg, wo es sicher war für das frühere Volk, und durchbrich nicht in gewalttätiger Weise die hochheiligen Satzungen der Weltordnung“19. Wieder findet der Chor wie im Hercules den letzten Grund des Leidens der Großen eben in deren Groß-Sein; die Konsequenz, die er daraus zieht, ist wiederum ein Bekenntnis zur gefahrlosen Niedrigkeit und Mittelmäßigkeit. Daraus erklärt sich zugleich auch seine innere Distanz vom dramatischen Geschehen. Vom vierten Chorlied, welches nur eine kurze, teils physiognomische Ekphrasis der nach Vergeltung drängenden Titelheldin enthält, kann im hier vorliegenden Zusammenhang abgesehen werden.

\section{P h a e d r a}

Ein vergleichbares Bild wie in der Medea bietet sich auch in der $\mathrm{P} h$ a e d r a : Nach dem ersten Akt, in welchem die Titelheldin ihrer Amme die Liebe zu ihrem Stiefsohn Hippolytus gestanden hat, singt der Chor von der Allmacht des Liebesgotts Cupido.

Lefèvre 1969, besonders 155 ff. = 370 ff., sieht in den Chorliedern objektive Darstellungen der subjektiven Verfehlungen der einzelnen Personen, welche nach Lefèvres Gesamtdeutung der Phaedra allesamt (Phaedra, Theseus und Hippolytus) im subjektiven Sinne schuldig sind: 159 = 374: ,Andererseits objektiviert sich dem stoischen Betrachter dieser Vorgang [daß der Mensch seinen Affekten

19 Sen. Med. 603-606. 
unterliegt] aufgrund des Handelns aller Menschen derart, daß er — und das ist die Deutung der Chorlieder - darin gleichsam eine höhere Notwendigkeit sieht". Im ersten Chorlied geht es nach Lefèvre um die Liebe als Schuld der Phaedra, welche jedoch nicht als deren subjektive Verfehlung, sondern als objektives Übel dargestellt werde: „der Chor konstatiert nur, daß der Eros überhaupt ein Übel ist“ $(156=371)$. Solche Deutung des Chorlieds wird begründet durch das Herausgreifen einiger Vokabeln, mit denen Cupido beschrieben wird (impotens 276, lascivus 277, furor 279).

Neuerdings ausführlich gedeutet werden die Chorlieder der Phaedra von Jens-Uwe Schmidt 1995. Nach Schmidt haben die Chorlieder die spezielle Funktion, Denkmuster mythischen Weltverständnisses ad absurdum zu führen (a.a.O. 286 und 320); eine ähnliche Position nimmt Schmidt auch zum dritten Chorlied der Medea ein, vgl. oben S. 9. Zum ersten Chorlied der Phaedra heißt es a.a.O. 287: „Dadurch, daß Seneca die Macht des Venus-Knaben im menschlichen Bereich sich speziell im mythischen Kontext entfalten läßt, ordnet er zugleich die dramatischen Ereignisse in jenes Weltverständnis ein, das den Zuschauer Mythen und Dichter gelehrt haben, wie etwa Vergil oder Ovid die Allmacht der Venus und ihres Knaben. Da dieses Weltverständnis das einzige ist, das Phaedra für ihre Leidenschaft anführen konnte [185 ff.], wird mit der Enthüllung der Katastrophe, die Amors „Feuer“ auslöst, zugleich die Gültigkeit dieses ganzen Deutungsmusters, so vertraut es dem Zuschauer sein mag, in Frage gestellt“. Jedoch ist die Kernaussage des Chorlieds die Universalität der Macht des Cupido, und dieser Aspekt wird vor allem durch die Vielzahl und Verschiedenheit der Beispiele verdeutlicht, welche zwar teilweise, aber bei weitem nicht ausschließlich der mythischen Sphäre entstammen. Insofern ist der Erklärungsansatz seinem Wesen nach verallgemeinernd-phänomenologisch und nicht speziell mythisch. Richtig erkannt wird der argumentative Charakter des Chorlieds bei Johanna Brandt: Sie gliedert (a.a.O. 58 f.) zwei Hauptteile ab, einen mythologischen (274-329) und einen auf die Natur bzw. auf empirische Beobachtung gegründeten (331-351). „Es kommt nicht eigentlich darauf an, daß diese Mythen als Realität anerkannt werden - auch in ihrer Eigenschaft als Mythen erfüllen sie an dieser Stelle ihre Funktion: Als Erfindungen der Menschen, die ganz bestimmte Erfahrungen und eine bestimmte Weltsicht in eigener Weise spiegeln, geben sie eine weit verbreitete Vorstellung von der großen Macht des amor wieder" (a.a.O. 60 f.). Später ist die Rede von einem „,induktiv abgeleiteten Naturgesetz“ (a.a.O. 61).

Als methodisches Problem an den Deutungen von Lefèvre und Schmidt bleibt hervorzuheben, daß beide als Senecas Absicht hinter den Chorlieder etwas anderes, von deren Wortlaut Abweichendes vermuten (Lefèvre die subjektive Schuld hinter dem nur objektiv Dargestellten; Schmidt die Unmöglichkeit der mythologischen Deutungsmuster hinter den mythischen Aussagen). Man muß - dies sei ausdrücklich konzediert - die Stellungnahmen des Chors nicht als Kommentar des Autors verstehen, aber man kann es schwerlich zum methodischen Prinzip erheben, den Kommentar des Autors in einer moralisierenden Wertung zu sehen, die in den Chorliedern eben so gerade nicht steht. Daß sich die Chorlieder der Phaedra, besonders das erste, nicht als stoische Stellungnahmen verstehen lassen, betont zurecht gegen Lefèvre Curley 68: „, the Chorus is the aspect of the play most securely entrenched in the traditions of tragedy" - und damit stoischer Moralphilosphie am fernsten; vgl. auch Curley 74 zum letzten Chorlied, wo das Thema der Hinfälligkeit des Großen behandelt wird: ,... the order perceived is that of popular wisdom and traditional poetic topoi ... evil is seen as an integral part of the universe, as one aspect to be accepted and understood as part of the whole. There is no Stoic attempt to portion off one completely good facet (e.g. the soul of the ,sapiens") from a world of different objects (,adiaphora“); nor is there the tendency to characterize forces as completely evil (e.g. „furor")“. Im folgenden sagt Curley über die Chorreflexionen (,the traditional generalizations of mythic, poetic, and popular lore“): ,Although no philosophic solutions are proferred, the fact that the central issues have been raised to the level of philosophy means that the solutions of traditional lore no longer suffice" (a.a.O. 75). Eine ähnliche Überlegung liegt offenkundig dem methodischen Ansatz von Jens-Uwe Schmidts Interpretation zugrunde. Wenn der Chor wirklich keine „philosophische Lösung“ bietet, sondern in Form des Theorems vom Sturz der Mächtigen allenfalls eine phänomenologische Erklärung, die überdies noch durch eine erhebliche Willkür und Ungerechtigkeit der zugrundegelegten Weltordnung belastet ist, so mag darin impliziert sein, daß sich jeder einzelne Rezipient der Tragödien nach einer besseren Erklärung umsehen soll; schwerlich liegt darin die Rechtfertigung, ein alternatives Lösungskonzept „hinter“ dem Text zu suchen (mit Hilfe der aus anderen Schriften bekannten philosophischen Ansichten Senecas) und als definitive „senecanische Lösung“ anzusehen.

Auf den zweiten Akt, in welchem Phaedra Hippolytus ihre Liebe offenbart und dieser entsetzt das Weite sucht, folgt ein Lied über die Schönheit des Hippolytus, welche sich vertieft zu einer Betrachtung über die Vergänglichkeit und Bedrohtheit solcher 
jugendlichen Schönheit.

Zum zweiten Chorlied vgl. Lefèvre 1969, $157=372$ : „So wie im ersten Canticum Phaedras Geschick o b j e k t i v verstanden wurde, erscheint hier das Schicksal, das Hippolytus ereilen wird, als objektive Macht - die subjektiven Verfehlungen bzw. Grundhaltungen, die sich jeweils in den Dialogen offenbaren, werden in den Chorliedern nicht erwähnt. So wie Amor schon an sich ein Übel bedeutet (Phaedra), bringt Schönheit schon an sich den Menschen zu Fall (Hippolytus)“. J.-U. Schmidt 1995, 298 f. sieht im zweiten Chorlied vor allem eine Wiederaufnahme einer Mahnung der werbenden Amme an Hippolytus (774 dum licet, utere 446 Aetate fruere: mobili cursu fugit), deren Fragwürdigkeit herausgestellt werde: „Seneca benutzt das 2. Stasimon dazu, dem Zuschauer durch den Widerspruch zwischen den Ereignissen und den vom Chor wieder aufgenommenen Ermahnungen der Amme auch die Untauglichkeit der epikureischen Anleitungen zur Sicherung des menschlichen Lebens eindringlich vor Augen zu führen“ (a.a.O. 299). Diese Deutung übersieht aber, daß im Chorlied die Vergänglichkeit der Schönheit nur eine argumentative Vorstufe bildet für den neuen Aspekt der Bedrohtheit der Schönheit (777 ff.). Dieser neue Aspekt (der keine Entsprechung hat in der Argumentation der Amme) ist derjenige, welcher für den Fortgang des Dramas und der Chorreflexion von Bedeutung ist.

Den Abschluß des Lieds macht ein Wunsch des Chors: „Für wenige Menschen blieb Schönheit straflos (blicke nur durch die Jahrhunderte). Möge an dir ein besserer Gott vorbeigehen, ohne daß du zu Schaden kommst, und möge deine edle Schönheit einst das Bild entstellenden Greisenalters zeigen“20. Dieser Schluß entspricht genau dem Ende des dritten Chorlieds der Medea, wo um Schonung für Jason gebeten wird: „Ihr habt das Meer bereits genug gerächt, [Meeres-]Götter: Schont ihn, der nur einen Auftrag ausführte“21. In beiden Fällen wird einerseits auf das häufig zu beobachtende Unglück vergleichbarer Existenzen (der Argonauten bzw. schöner Menschen) verwiesen und andererseits für eine Hauptperson des jeweiligen Dramas (Jason bzw. Hippolytus) um Schonung gebeten. Damit wird in beiden Fällen das diesen Personen bevorstehende Unheil geradezu prophezeit. Zugleich wird aber auch eine gewisse Erklärung für dieses zukünftige Unheil geliefert: In beiden Fällen waren diese Personen durch ein Übermaß an einer bestimmten Eigenschaft ausgezeichnet: Jason als Argonaut durch übermäßige heroische Kühnheit und Hippolytus durch übermäßige Schönheit. In beiden Fällen führt dieses Übermaß zu einer Gegenreaktion der Götter. Im Falle des Jason erklärt sich diese durch eine Verletzung der Sphäre der Meeresgötter. Im zweiten Chorlied des Hippolytus wird ein solches Motiv der rächenden Gottheit nicht spezifiziert, doch dürfte man der Aussagetendenz des Lieds recht genau entsprechen, wenn man auch hier eine ähnliche Verletzung göttlicher Sphären durch ein Übermaß annimmt. Sicher nicht zufällig ist die Schönheit des Hippolytus im hier besprochenen Lied mehrfach durch Vergleiche mit Göttern beleuchtet worden.

Auch hier liegt der Gedanke an eine subjektive Schuld fern. Schönheit an sich kann unmöglich sträflich sein, aber auch eine Kritik am Verhalten des Hippolytus liegt nicht vor; anders Brandt 127: „Sollte der Schluß des Chorlieds ... eine Warnung und Mahnung an Hippolytus sein, sich auf diese Gefährdung einzustellen, sie zu erkennen und zu akzeptieren und nicht einfach zu ignorieren und zu fliehen?“. Die einzige Hoffnung, die der Chor hat, besteht eben in der Gnade eines „,besseren Gotts“. Hippolytus selbst kann nichts tun, um seine Lage zu verbessern: Sogar die Flucht in die Einsamkeit vermag ihn nicht vor Gefahren zu schützen (777 ff.).

Dieser Wunsch des Chors auf einen „,besseren Gott“ wird durch die folgende Szene der Phaedra geradezu widerlegt. Theseus kehrt von seinem Gang in die Unterwelt

\footnotetext{
20 Sen. Phaedra 820-823.

21 Sen. Med. 668 f.
} 
heim, glaubt der von der Amme ausgeheckten Intrige Phaedras, welche die amoröse Verfehlung Hippolytus zuschiebt, und bittet seinen Vater, den Meeresgott Neptun, um den Tod seines Sohns Hippolytus. Das dritte Chorlied besteht aus einer Klage darüber, daß göttliche Mächte sich nicht um das Tun der Menschen kümmern, sondern die Fortuna planlos walten lassen ${ }^{22}$; so gerät der Keusche ins Unglück, und der Unzüchtige floriert.

Lefèvre 1969, 158 = 373 sieht im dritten Chorlied eine objektive Verbrämung der subjektiven Schuld des Theseus: „Wieder wird die Handlung ungeachtet der subjektiven Kausalität objektiv gedeutet. Während das erste Canticum Phaedras und das zweite Hippolytus' Schicksal in objektive Zusammenhänge rücken, bezieht sich der Chor in seinem dritten Lied auf Theseus, der unmittelbar zuvor ... Hippolytus verflucht hat. Da er die Unschuld seines Sohns vollkommen verkennt, fordern sein Handeln und Hippolytus' daraus resultierendes Leiden geradezu das Thema der Sinnlosigkeit von Fortunas Walten hinaus“. J.-U. Schmidt 1995, 310 deutet das dritte Chorlied folgendermaßen: „Die dramatischen Ereignisse haben dem Zuschauer ja gerade vor Augen geführt, daß es nicht die Fortuna, sondern menschliche Unzulänglichkeiten sind, die die libido entstehen und zumal über den sanctus siegen lassen, und daß die fraus nicht durch Fortuna, sondern durch menschliche Schwächen zumal im Herrscherhaus regiert und daß allein durch diese pudor und decus ihres wahren Wertes beraubt werden“. Doch zielt die Überlegung des Chors vor allem auf die vorausgesehene Katastrophe des Hippolytus, und ob dieser gemäß Schmidts Deutung mitschuldig wird ,durch das Unmaß seiner Empörung und Hilflosigkeit"“ (a.a.O. 298), bleibt doch zweifelhaft; im Chorlied figuriert er unter der Kategorie sancti (981) bzw. casti (986). Die Frage des Chors „Warum läßt Gott die Keuschen ins Unglück stürzen und die Unzüchtigen florieren?“ würde gemäß Schmidts Deutung in der dramatischen Handlung in recht unbefriedigender Weise entkräftet durch den Befund, daß die Unzüchtigen durch ihre Verkommenheit Schuld haben, aber zugleich auch die Keuschen mitschuldig sind durch ihre „Empörung und Hilflosigkeit“.

Damit korrigiert der Chor mit aller Deutlichkeit seine am Ende des letzten Lieds ausgesprochene Hoffnung auf einen ,besseren Gott“", der Hippolytus schützen möge. Es ist geradezu, als ob der Chor bereits vorauswisse ${ }^{23}$, daß der Meeresgott Neptun die Absicht seines durch die Intrige der Phaedra getäuschten Sohns Theseus nicht nur nicht verhindert, sondern sogar in grausamer Weise erfüllt.

Diese Erfüllung und den furchtbaren Tod des Hippolytus durch einen dem Meer entsteigenden Stier hat der Botenbericht im vierten Akt zum Gegenstand. Das folgende letzte Chorlied greift den Gedanken der planlos wütenden Fortuna wieder auf, wendet ihn aber in einer Richtung, die aus den anderen Tragödien schon sattsam bekannt ist: Die Geschosse des Geschicks wenden sich gegen die Hochstehenden, während die Tiefergestellten (zu denen sich der Chor wohl wieder selbst rechnet) verschont bleiben.

Lefèvre 1969, 159 = 374 sieht auch hier eine im Text nicht nachzuweisende Nuance subjektiver Verschuldung im Mittelpunkt: „Wiederum wird das ganze Geschehen objektiv kommentiert. Aber diese Perspektive kann sinnvollerweise nur aus den subjektiven Verfehlungen des einzelnen resultieren. Denn diese beliebte stoische Maxime, die Seneca auch sonst in seinen Tragödien populär ausgeführt hat, will sagen, daß der einzelne desto leichter fehle, je höher seine soziale Stellung ist"“. J.-U. Schmidt 1995, 314 versteht den Wortlaut des Chorlieds ebenfalls ohne moralisierende Nuance, glaubt aber, gerade durch das Fehlen dieses moralischen Aspekts, der in der dramatischen Handlung

22 Zum Motiv vgl. Eur. Hek. 488-491. Hier wie dort eine Apostrophe an Zeus bzw. Juppiter (Sen. Phaedr. 960) und die Feststellung, daß die Fortuna die menschlichen Angelegenheiten lenkt (Sen. Phaedr. 978-980).

23 Diesen Eindruck formuliert Lefèvre 1969, $157=372$ : „Hier spricht nicht jemand, der Schlimmes a $\mathrm{h} \mathrm{n} \mathrm{t,} \mathrm{wie} \mathrm{es} \mathrm{in} \mathrm{der} \mathrm{attischen} \mathrm{Tragödie} \mathrm{so} \mathrm{oft} \mathrm{begegnet,} \mathrm{sondern} \mathrm{einer,} \mathrm{der} \mathrm{genau} \mathrm{w} \mathrm{e} \mathrm{i} \beta$, wie alles kommen wird“. 
zum Ausdruck komme, diskreditiere sich das vom Chor gegebene „Deutungsmuster“ (a.a.O. 314): „Die Wiederaufnahme dieser Themen [schützende Kraft der Einsamkeit und Gefährdung des Hohen] aus der Analyse der Amme (204-215) hebt den Widerspruch heraus: Die Schläge und Katastrophen im Bereich der 'Großen' lassen sich gerade nicht als Auswirkungen eines 'göttlichen Neides' oder der Willkür der Fortuna verstehen. Deutlich wird also der Zuschauer auch hier durch den Chor herausgefordert, die angebotene Deutung mit den Ursachen der auf der Bühne erlebten Katastrophen zu vergleichen. Dabei kann er über die wahren Ursachen des Unheils kaum im unklaren bleiben, wo er mit angesehen hat, wie die Hochstehenden und Mächtigen selbst sich und ihre Mitmenschen in Untergang und Leid stürzen“. Doch sind die Worte der Amme in 204-215, welche hohe Stellung unzweifelhaft mit moralischer Korruption in Verbindung bringen, eindeutig auf Phaedra gemünzt und im dortigen Zusammenhang völlig berechtigt. Dagegen bezieht sich das Chorlied, wie die Verse 1144 ff. eindeutig zeigen, primär auf die Tragik des Theseus, der freilich seinerseits nach Schmidt (a.a.O. 308) „,nicht ... bloßes Opfer von Phaedras Täuschung ..., sondern weitgehend mitverantwortlich ... für deren Gelingen" ist. Eine derartige - durch Interpretation erschlossene - Schuld einer Figur durch ein — hinter dem vordergründigen „Deutungsmuster“ des Chorbilds gleichfalls erschlossenes Weltbild abzustützen, ist methodisch zumindest anfechtbar.

Besonders interessant ist ein nur kurz am Ende angedeutetes Motiv: Pallas, die Patronin des Theseus, die ihren Schützling aus der Unterwelt befreit hat, bleibt ihrem Onkel, dem Totengott Dis, nichts schuldig: Einerseits hat sie ihm zwar Theseus entrissen, aber andererseits hat jetzt dessen Sohn Hippolytus statt seiner die Unterwelt aufgesucht; so „,bleibt dem unterirdischen Tyrannen [Dis] die Zahl konstant“" (Constat inferno numerus tyranno ${ }^{24}$ ). Diese wenigen Verse enthalten gleichsam in nucleo die Chorreflexion des senecanischen Hercules: Hercules hat seine übermenschliche Größe gezeigt, indem er als Lebender in die Unterwelt herabgestiegen ist und von dort wieder zurückgekehrt ist ${ }^{25}$. Damit ist er in seinem Heldentum gewissermaßen übereilig gewesen (so sang der Chor im ersten Lied des Hercules), indem er als Lebender das antizipierte, was jedem Menschen in seiner Todesstunde bevorsteht. Am Schluß des Stückes müssen seine Kinder in dieselbe Unterwelt hinab, die ihr Vater siegreich bezwungen hat. In beiden Stücken (im Hercules wie in der Phaedra) scheint die Reflexion des Chors darauf hinauszulaufen, daß die im Hadesgang manifestierte übermenschliche Größe des Vaters in irgendeiner geheimnisvollen, nicht näher explizierten, jedoch offenkundig nicht schuldhaften Weise ${ }^{26}$ dazu beiträgt, daß seine Kinder bzw. sein Sohn schließlich am Ende des Stückes seinen Platz in der Unterwelt einnehmen müssen ${ }^{27}$. Daß der Chor selbst auf eine Heldengröße, die solche

\footnotetext{
24 Sen. Phaedra 1153. In seiner Verfluchung des Hippolytus hatte Theseus dasselbe Motiv bereits berührt (947 Adeatque manes iuvenis iratos patri).

25 Die Verbindung zwischen Hercules und Theseus wird auch gezogen von Jo-Ann Shelton 1978, 45 mit Anm. 18. Allerdings impliziert Sheltons Kommentar zu 1135 f. Ite infaustum genus, o pueri,/ Noti per iter triste laboris (die Worte, ,indicate precisely what Hercules' time in the Underworld has accomplished: he has only made it easier for his family to find its way there", Shelton a.a.O. 47) eine direkt-schuldhafte Kausalität, die sich weder faktisch-mythologisch noch durch Senecas Formulierungen verifizieren läßt.

26 Davis 1983, 124 sieht in Phaedr. 1149-1153 eine ,accusation“ gegen Theseus und belegt dies durch die wenig später folgenden Worte der Phaedra (1165 f.): gnatus et genitor nece/ Reditus tuos luere. Doch damit wird nur die rhetorische Pointe o numquam tuis/ Tuto reverse (1164 f.) begründet, die darauf hinausläuft, daß Theseus' Heimkunft in zwei Fällen seinen unmittelbaren Verwandten faktisch Verderben brachte, und nichts über die Schuldhaftigkeit der jeweiligen Unternehmung besagt. Genausowenig wie man behaupten könnte, seine Unternehmung in Kreta habe schuldhaft den Tod des Aigeus herbeigeführt, läßt sich aus den Worten der Phaedra (oder des Chors) folgern, daß sein Hadesgang schuldhaft den Tod des Hippolytus verursacht.

27 Natürlich hat der Hadesgang in beiden Fällen ganz verschiedene Motive (Hercules muß den Höllenhund Cerberus in die Oberwelt holen, und Theseus will zusammen mit seinem Freund Pirithous die
} 
Folgen hat, gern verzichtet, ist leicht nachzuvollziehen.

\section{O e d i p u s}

Das erste Chorlied des O e d i p u s ist - sicherlich nicht ohne Einfluß der sophokleischen Tradition - der Pest in Theben gewidmet.

Den Unterschied zur sophokleischen Version charakterisiert Marx 7 folgendermaßen: „Bei Seneca berichtet der Chor ü b e r die Situation, bei Sophokles ruft er a u s der Situation“. Dem sophoklei-

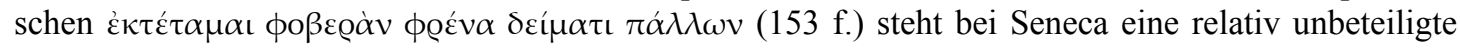
Apostrophe gegenüber: Occidis, Cadmi generosa proles,/ Urbe cum tota. Erst später spricht der Chor einmal kurz in der ersten Person (124 f., vgl. auch 159). Richtig wird dieser Unterschied in neuerer Zeit hervorgehoben von Lefèvre 1980, 302: „Bei Seneca spricht jemand, der nicht von den Ereignissen tangiert ist, sondern sie aus der Distanz des Beobachters kommentiert ... Wo in dem griechischen Stück Betroffenheit herrscht, kennt das römische nur Kommentar ...“ (im Anschluß an Marx). Übertrieben erscheint jedoch Lefèvres Deutung des ersten Chorlieds als eines inneren Monologs des Oedipus (a.a.O. 304), der als „monoman“ bezeichnet wird (303; vgl. auch Lefèvre 1981, 251). Es trifft zwar zu, daß der senecanische Oedipus im Prolog viel stärker mit sich selbst beschäftigt ist als der sophokleische; dies hängt jedoch damit zusammen, daß er — ganz im Gegensatz zu seinem sophokleischen Vorgänger - von vorneherein durchdrungen ist von der Vorahnung, daß das momentane Unglück Thebens etwas mit seinem persönlichen Schicksal (und insbesondere den ihm von Phoebus prophezeiten Verbrechen Vatermord und Inzest) zu tun hat. Insofern jeder Rezipient des Stückes weiß, daß diese Vorahnungen berechtigt sind, wird niemand die Haltung des Oedipus als pathologisch monoman ansehen, zumal das Verantwortungsbewußtsein des Oedipus für die Stadt trotz allem deutlich hervortritt: Er empfindet es als belastend, daß er als einziger von der Pest verschont wird (28 ff.), und wünscht sich, seinem Vaterland im Tod vorangehen zu können und nicht als letzter sterben zu müssen (71 ff.). Insofern trifft die Aussage „Beim Anblick des Massensterbens denkt er nicht an das Volk, sondern nur an sich“ (Lefèvre 1980, 303) nicht zu.

Ähnlich wie das Hochzeitslied in der Medea ist also auch im Oedipus das erste Chorlied noch durchaus der dramatischen Handlung verbunden und nicht in reflexive Tiefen abgetaucht. Gleich am Anfang des Lieds wird jedoch schon der Weingott Bacchus angesprochen, und zwar als Feldherr der Thebaner in einem mythischen Eroberungsfeldzug gegen die Inder. Diese Apostrophe wird im zweiten Chorlied, welches der Seher Tiresias ankündigt als ein Zwischenspiel, das die Zeit seiner Totenbeschwörung überbrücken soll, ausgeweitet zu einem Gebet um die Hilfe des Bacchus, welches zugleich in panegyrischer Weise die Leistungen des Gottes feiert.

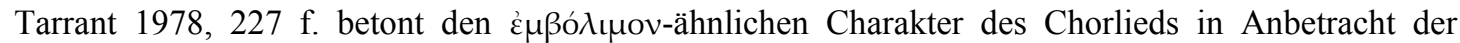
Einleitung des Tiresias. Singulär an dieser Einleitung ist in der Tat der durch den temporalen dum-Satz explizit bekundete Charakter des Lieds als Überbrückung eines nicht in unmittelbarer dramatischer Handlung wiedergegebenen Zeitabschnitts. Wenig überzeugend erscheint die „metatheatralische“

Totengöttin Proserpina als Ehefrau für diesen gewinnen, vgl. im Munde Phaedras 93 ff.), und die Vorstellung eines „Ausgleichs der Zahl“ läßt sich auf Hercules nicht übertragen, da er im Gegensatz zu Theseus nicht in der Unterwelt ,inhaftiert“ war. Doch erscheint davon abgesehen die mythologische Parallelität zwischen den senecanischen Tragödien Hercules und Phaedra bemerkenswert: In beiden Fällen bahnt sich in der zurückgelassenen Familie des Helden bereits während dessen Abwesenheit Unglück an, und nachdem der Held glücklich zurückgekehrt ist, führt er in unschuldhafter Weise den Tod seiner Kinder bzw. seines Sohns herbei. In beiden Fällen folgt der enormen heroischen Leistung des Hadesgangs (um eine solche handelt es sich auch bei Theseus, obwohl er schließlich von Hercules aus seiner Haft befreit werden muß, vgl. die Worte der Amme 222-224: Ne crede Diti: clauserit regnum licet/ Canisque diras Stygius observet fores:/ Sol us negatas invenit Theseus vias) ein tragisches Unglück im familiären Bereich. 
Interpretation des Bacchus-Lieds von Curley 119 f., der hinter Bacchus den griechischen Dionysos als Gott des Theaters sieht. Curleys Deutung beruht auf zwei sehr fraglichen Voraussetzungen, (1) das Bacchus-Lied sei als Dithyrambus aufzufassen und (2) Seneca schwebe hier die aristotelische Herleitung der Tragödie aus dem Dithyrambus vor.

Auf dieser göttlichen Ebene bewegt sich auch das dritte Chorlied, an dessen Anfang es ausdrücklich heißt, nicht Oedipus persönlich sei verantwortlich für die gegenwärtige Notlage, sondern die Götter: „Nicht du bist der Grund für so große Gefahren, nicht das gegenwärtige Geschick bedrängt die Thebaner, sondern vielmehr folgt ihnen der alte Zorn der Götter“ ${ }^{\prime 28}$. Diese Einleitung des Chorlieds mit „nicht ... sondern ...“ (non ... sed ...) macht also die Tendenz explizit, welche den meisten senecanischen Chorliedern gemeinsam ist: eine Abstraktion von der in den jeweils vorausgehenden Szenen praesentierten dramatischen Handlung, wobei man „Abstraktion“ ganz wörtlich im Sinne eines „Wegziehens“ verstehen darf: Das Geschehen wird von seiner vordergründigen Kausalität (in diesem Fall der beständig fortschreitenden Selbstenthüllung des Oedipus) „,weggezogen“ auf eine andere, dem äußeren Geschehen fremde Reflexionsebene.

Die Antithese „nicht du, sondern der Zorn der Götter“ wird gelegentlich so gedeutet, daß der Chor in opportunistischer Weise die Auskunft, welche Oedipus' Vater Laius in der von Tiresias durchgeführten Totenbeschwörung über den Grund der thebanischen Pest gab, zugunsten von Oedipus umkehrt.

Davis 1993, 54 f. 104 f. Vgl. auch Müller $456=388$ f.: „Nicht du bist schuld, sondern alter Götterzorn, so meint der Chor und zählt als Beweise des Götterzorns monstra der thebanischen Geschichte auf. Genau wie Ödipus seine Lage verkennt, so schiebt auch der Chor das Problem ins Unbestimmte und ahnt nicht, daß das schlimmste in der Reihe der thebanischen monstra Ödipus ist"; ferner Mastronarde 309: ,... though Laius claims non ira deum, sed scelere raperis (630-1), that makes no difference to the chorus, who in 712 reaffirm Tiresias' interpretation of ira numinum (331, 333)“; Gil 184: „Den Worten des Berichtes [Creons] wird offen widersprochen“; Curley 120 f.: „The Chorus reverses this judgment completely ... Whom are we to believe, Laius or the Chorus?"; Davis 1991, 151: ,The chorus is concerned at this point to exonerate Oedipus“ (irrig ist übrigens auch die Deutung a.a.O. 154, ,when the chorus asserts in the third ode that the pattern of terrible events which constitutes the history of Thebes points to the veteres deum irae and not Fate they are mistaken" — damit wird das entscheidende Attribut haec zu fata übersehen). Dem ist folgendes entgegenzuhalten: Derselbe Chor blickt so weit in die Zukunft, daß er ahnt, daß der Krieg zwischen den Sparten nicht der einzige Bruderkampf in der thebanischen Geschichte bleiben wird (748-750). Soll man diesem geradezu prophetisch in die Zukunft blickenden Chor den stumpfen Opportunismus zumuten, der in der Äußerung läge „,nicht Du, Oedipus, bist der Grund für die Pest, sondern es handelt sich doch nur um eine gottgesandte Krankheit“? Der Chor meint in Wirklichkeit: „Nicht du und das jetzige Geschick (die Pest) sind der Urgrund allen Übels, sondern uns verfolgt ein alter Götterzorn“. Wer den Einleitungssatz der Ode so versteht, wird die Worte Tempore ex illo nova monstra semper/ Protulit tellus (724 f.) automatisch so deuten, daß die jetzigen Ereignisse um Oedipus eben das neueste monstrum bilden. In die richtige Richtung geht Schmitz 38 f.: „Der Hinweis des Chores auf den mythischen Götterzorn, der das thebanische Königshaus seit jeher verfolge, mutet zunächst wie eine vordergründige, die Beschuldigung des Oedipus durch seinen Vater Laius ignorierende Verteidigung des Königs durch das loyale Volk an. In den mythischen Exempla, die der Chor zu seiner Beweisführung heranzieht, sind jedoch einzelne Ausprägungen des Mythos so deutlich auf das Oedipus vorherbestimmte Schicksal ausgerichtet, daß dem Hörer oder Leser angedeutet wird, daß sich auch Oedipus in die unheilvolle Geschichte des thebanischen Königsgeschlechts einreiht ... Auf diese Weise schließen sich die beiden, scheinbar einander widersprechenden Erklärungen des gegenwärtigen Unheils Thebens, scelus des Königs und veteres irae deum, zusammen“. Mit der Satzstruktur Non tu tantis causa periclis,/ Non haec Labdacidas petunt/ Fata, sed veteres deum/Irae secuntur (709-712), welche die vordergründig evidente Gültigkeit der ersten beiden Glieder durch das dritte außer Kraft

28 Sen. Oed. 709-712. 
setzt, vgl. Tro. 38-40 Non cautus ignes Ithacus aut Ithaci comes/ Nocturnus in vos sparsit aut fallax Sinon:/ Meus ignis iste est, facibus ardetis meis und HO 1467-1469 Sed non cruentae sceleribus nuptae iaces/Nec fraude matris: Nessus hos struxit dolos/Ictus sagittis qui tuis vitam expulit.

Laius hatte seine Heimatstadt Theben apostrophiert: „Mein Vaterland, du wirst nicht vom Zorn der Götter, sondern von einem Verbrechen heimgesucht" ${ }^{29}$. In dieser Orakel-Auskunft ist der „Zorn der Götter“ aber nur eine Metapher für eine zufällig durch ungünstige Witterungsverhältnisse zustandekommende Pest (dies beweisen die folgenden Worte), und die Auskunft bedeutet soviel wie „In der thebanischen Pest bekundet sich nicht zufällige Krankheit, sondern befleckende Versündigung [nämlich des Oedipus]“. Wollte der Chor diese Schuldzuweisung an Oedipus umkehren, müßte er einfach sagen „Nicht du, sondern der Zorn der Götter ist schuld an der gegenwärtigen Notlage“. Was der Chor aber tatsächlich sagt, ist komplizierter: „Nicht du bist der Grund für so große Gefahren, nicht das gegenwärtige Geschick bedrängt die Thebaner, sondern vielmehr folgt ihnen der alte Zorn der Götter“. D.h. es wird nicht nur von der Person des Oedipus, sondern überhaupt von der gegenwärtigen Notlage abstrahiert, und das bedrängende Unglück der Pest wird in einen weitläufigeren mythisch-historischen Zusammenhang gestellt. Es liegt also eigentlich keine Umkehrung der Schuldzuweisung des Laius vor, sondern vielmehr eine Vertiefung der Perspektive: Laius hatte gesagt „die Pest hat nicht bloßen Götterzorn, der sich in einer zufälligen Krankheit bekundet, zur Ursache, sondern die Verbrechen des Oedipus“, und der Chor geht noch einen Schritt weiter: „nicht die jetzige, unter Oedipus zustandegekommene Notlage ist der letzte Grund der Übel, sondern ein alter Zorn der Götter gegen Theben“. Dabei ist der Begriff „Zorn der Götter“ jetzt nicht mehr wie in Laius' Worten als metaphorische Umschreibung einer Krankheit, sondern wörtlich im Sinne eines auf der Stadt ruhenden Geschlechterfluchs zu verstehen.

Dieser ,,alte Zorn der Götter“" wird illustriert durch eine Exempla-Reihe prominenter Thebaner, die ins Unglück gerieten, beginnend mit dem mythischen Stadtgründer Cadmus; man erinnert sich an die Exempla der unglücklichen Argonauten im dritten Chorlied der Medea. Die durch die Chorlieder eröffnete Meta-Ebene im Oedipus könnte man plakativ mit dem Titel „Theben und die Götter“ bezeichnen: Wie es in den ersten beiden Chorliedern um Theben und seine Schutzgottheit Bacchus geht, so steht im dritten der prominente Thebaner immer wieder treffende Zorn der Götter im Mittelpunkt (wobei übrigens auch schon auf den noch bevorstehenden Bruderkampf zwischen Eteocles und Polynices vorausgedeutet wird). Dadurch unterscheidet sich der Oedipus in seiner durch die Chorgesänge eröffneten Hintergrund-Dimension von der Medea: Jasons Unglück scheint sich dort nach Ansicht des Chors durch den sich auf ihn persönlich (als Anführer der Argonauten) richtenden Zorn der Meeresgötter zu erklären, wohingegen das Geschick des Oedipus auf der Ebene der Chorreflexion durch das kollektiv-genealogische Verhältnis seiner Stadt Theben bzw. der Labdaciden zu den Göttern verständlich gemacht wird. Aber gleichermaßen im Oedipus wie in der Medea wird das tragische Unglück einer Hauptperson (Oedipus bzw. Jason) erklärt durch die Zugehörigkeit dieser Person zu einer Gruppe von Menschen, deren Verhältnis zu den Göttern problematisch ist (das thebanische Herrschergeschlecht bzw. die Argonauten), und so in eine das eigentliche Stück transzendierende mythologische Perspektive eingeordnet.

Abgeschlossen werden die Reflexionen im Oedipus in einer weiteren Chor-

29 Sen. Oed. 630 f. 
partie nach dem Botenbericht über die Blendung des Titelhelden, welche teilweise fälschlich als fünftes akttrennendes Chorlied aufgefaßt wird ${ }^{30}$. Dort wird das Thema jedoch von der historisch-politischen Ebene des Verhältnisses der Stadt Theben zu den Göttern in abstrakt-philosophische Sphären verlagert: Das Schicksal des Menschen ist durch eine feste Kausalität determiniert, und wenn der Mensch sich vor seinem Geschick fürchtet (wie Oedipus vor der Erfüllung des Phoebus-Orakels), so führt ihn gerade diese Furcht seinem Geschick zu.

Das vierte Chorlied, welches dem Moment der Selbsterkenntnis des Oedipus unmittelbar folgt, bietet die Standardlösung, mit welcher senecanische Chöre sich gegen Unglück, wie es die Personen der dramatischen Handlung erfahren, zu schützen suchen: nämlich eine durch immer andere Metaphern umschriebene nicht das Maß überschreitende Mittelmäßigkeit der eigenen Existenz. Diese Lösung formuliert der Chor ausdrücklich als seine persönliche Lebenswahl: „wenn es mir gestattet sein sollte, mein Geschick nach meinem eigenen Ermessen zu gestalten, ..."31. Damit wird die im dritten Chorlied ausgesprochene Erkenntnis, daß hinter dem Geschick des Oedipus letztlich der auf dem thebanischen Königshaus liegende Götterfluch steht, gewissermaßen auf alles Hochstehende verallgemeinert und ein positives Gegenideal entwickelt, in dem jedoch keinerlei Kritik oder Schuldzuweisung an Oedipus impliziert ist.

Zu Recht hält Müller $460=394$ den Worten Fata si liceat mihi/ Fingere arbitrio meo entgegen: „Aber man kann es sich nicht formen." Daß Oedipus seinen Status als König von Theben nachträglich nicht mehr aufgeben kann, wird an einer Stelle des Dramas sogar explizit gesagt: Creon erwidert Oedipus in der Kontroverse um Creons angebliche Illoyalität, Oedipus könne, selbst wenn er dies wolle, von der Königsherrschaft nicht mehr zurücktreten (681 Tibi iam necesse est ferre fortunam tuam); vgl. unten den Exkurs „Die Möglichkeit eines bescheidenen Exulantendaseins in den Phoenissen“ (S. 35 f.). In der Kondizionalprotasis Fata si liceat mihi/ Fingere arbitrio meo tritt übrigens auch deutlich der Aspekt der subjektiven Meinungsbekundung des Chors zu Tage: Es ist nicht einmal die Norm impliziert, daß ein anderer sich, wenn er denn freie Wahl hätte, auch so entscheiden müsse (in Med. 604-606 dagegen wagt der Chor immerhin einen Imperativ). Ähnlich Mader 1990, 19 zum ersten Chorlied des Hercules: „The 'standard of normality' is not necessarily an absolute yardstick, but represents rather the subjective norms to which the chorus subscribes".

\section{Thy es t}

Als letztes Stück der ersten Gruppe von Seneca-Tragödien zu behandeln bleibt der T h y e s t : Im Prolog wird der aus der Unterwelt heraufgeholte Schatten des Tantalus von einer Furie dazu gezwungen, seinen unheilvollen Einfluß auf das argivische Königshaus und seine Nachfahren auszuüben. Das erste Chorlied verrät keinerlei Kenntnis von diesem Geschehen, ja es wirkt im Lichte des vorausgegangenen Prologs geradezu verfehlt und abwegig, wenn der Chor darum bittet, eine Argos wohlgesonnene Gottheit möge die Reihe ständig neuer Verbrechen, welche sich durch das argivische Königshaus zieht, abbrechen. Die Betrachtungen des Chors erhalten eine historische Dimension durch die Exempla von Myrtilus und dem im Prolog aufgetretenen Tantalus.

Von der im zweiten Akt im Gespräch zwischen Atreus und einem Diener entwickelten furchtbaren Intrige gegen Thyest zeigt der Chor in seinem zweiten Lied

\footnotetext{
30 Sen. Oed. 980 ff.; vgl. Zwierlein 1987, 71.

${ }^{31}$ Sen. Oed. 882 f.
} 
wiederum keinerlei Kenntnis. Er meint, das argivische Königshaus sei endlich zur Ruhe gekommen und entwickelt einen bildlichen, deutlich von stoischer Philosophie geprägten Königsbegriff: Der wahre König sei nicht der, welcher gewaltigen äußeren Einfluß ausübe, sondern der, welcher über seine eigenen Affekte, besonders Furcht und Begierde, gebiete. Im Anschluß an diese philosophische Umwertung fällt es dem Chor nicht schwer, erneut sein Ideal von der bescheidenen Mittelmäßigkeit zu entwickeln: „An dunklem Orte stehend möge ich sanfte Ruhe genießen ... Wenn meine Tage so ohne Getöse vorübergegangen sind, möge ich sterben als ein Greis aus dem Volke“"32.

Dieses Ideal erhält im folgenden dritten Akt ein bedeutungsvolles Echo ${ }^{33}$ : Denn der durch das vorgetäuschte Angebot des Atreus, an der argivischen Königsherrschaft teilzuhaben, angelockte Thyest hat sich inzwischen nach seinen eigenen Worten recht gut an die Bescheidenheit seines Exulanten-Daseins gewöhnt und möchte diese gefahrlose Niedrigkeit eigentlich nicht aufgeben; sein Sohn Tantalus sucht ihn jedoch dazu zu überreden, das großzügige Angebot des Atreus doch nicht abzulehnen, und zwar u.a. mit dem stoischen Theorem, man dürfe zwar die Herrschaft nicht um ihrer selbst willen erstreben, aber sie andererseits, wenn sie angeboten wird, auch nicht ablehnen ${ }^{34}$ (hinter dieser Argumentation steht die stoische

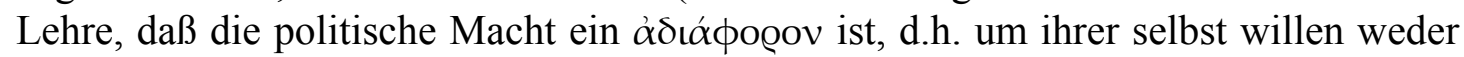
erstrebens- noch vermeidenswert). Durch die Unterredung zwischen Thyest und seinem Sohn vor der Ankunft im Königspalast wird dem der senecanischen Darstellung folgenden Leser oder Zuschauer, der von den intriganten Absichten des Atreus weiß, unmißverständlich vor Augen geführt, daß die Lieblingsmaxime der senecanischen Chöre in diesem Fall den Thyest vor schlimmem Unglück hätte bewahren können - wenn er denn an der Durchsetzung dieser Maxime konsequent festgehalten hätte ${ }^{35}$. Andererseits zeigt das stoisch geprägte Argument des Tantalus aber auch, daß Thyest — selbst aus stoisch-rigoroser Sicht - nicht fehlt, indem er eine ihm angebotene Herrschaft annimmt.

Zum Problem der Bewertung der Thyest-Figur (positive Gegenfigur zu Atreus oder nicht?) vgl. Seidensticker 107 f. Anm. 79; Lefèvre 1985, 1270-1272; Boyle 227 Anm. 34; Frings 29-36, besonders 29 f. Anm. 67, wo die wichtigsten Forschungspositionen gesammelt sind. Die extreme Polarität der verschiedenen Auffassungen über die Figur des Thyest formuliert Staley 234: „Thyestes has been seen as a Stoic saint or as a Stoic sinner“.

Die begrenzte Anwendbarkeit einer biographistischen Deutung der Thyest-Figur, wie sie Pöschl vertritt, zeigt sich schon in der Diskrepanz, daß Thyest beim Wiedereingreifen in das politische Geschehen nach seiner Verbannung sogleich ins Unglück stürzt, Seneca aber in dieser Phase seiner Laufbahn den größten Erfolg hatte. Zustimmung findet Pöschls Auffassung jetzt bei Lefèvre 1997, 131, der den Thyest ,in die Zeit von Senecas Rückzug aus der Politik“ setzt; der Seneca der Octavia äußert sich in der Tat in ähnlicher Weise wie Thyest über sein früheres Exil (vgl. besonders Oct. $385 O$ quam iuvabat $\sim$ Thyest. 449 o quantum bonum est), worin jedoch nicht mehr als eine Reminiszenz des Imitators an das echt-senecanische Stück liegen muß.

\footnotetext{
32 Sen. Thyest. 394-400.

33 Davis 1989, 429 sucht die Charakteristik des im dritten Akt auftretenden Thyest in fragwürdiger Weise vom Ideal des zweiten Chorlieds zu distanzieren, z.B., indem er die berechtigten Vorahnungen Thyests als Verstoß gegen das Prinzip der Affektlosigkeit auffaßt.

34 Sen. Thyest. 471 f. Nec abnuendum est, si dat imperium deus,/ Nec appetendum est. Vgl. die Worte des Atreus in 536 Quis influentis dona fortunae abnuit?.

35 Insofern zeigt der dramatische Handlungsgang gerade die faktische Richtigkeit der Choranalyse (anders D. \& E. Henry 139: ,The events of the play have trampled on the ideal picture which Thyestes and the Chorus had set up“).
} 
Zum Problem der Thyestfigur: Sicher ist Thyest als mythische Gesamtfigur kein stoischer Weiser und kann auch von einem Dramatiker nicht zu einem solchen stilisiert werden. Dennoch braucht man seine der stoischen Lehre verpflichteten Äußerungen am Anfang des dritten Akts nicht als Heuchelei anzusehen. Denn gerade im intimen Gespräch mit seinem Sohn, vor der Begegnung mit Atreus, hat Thyest keinerlei Anlaß zu heucheln. Die Haltung, die er in diesem Gespräch vertritt, verwirklicht er nicht, und gerade darin liegt die Tragik. Wenn sich Atreus, der Chor oder sogar Thyest selbst gelegentlich in der Richtung äußern, daß Thyest genau so verkommen sei wie Atreus (194 ff. 221 ff. 271 f. 640. 917 f. 1087 ff. 1104 ff.; übrigens agiert der Totenschatten Thyests auch im Prolog des Agamemnon als Erzverbrecher), so schließt dies nicht aus, daß Thyest an einem Punkt seines Lebens einmal zu einer stoischen Auffassung gelangen konnte (die er dann doch nicht verwirklicht). Zudem sind die verschiedenen Äußerungen über Thyest stark von den rhetorischen Belangen der Einzelszene geprägt, und Senecas Kompositionsweise ist zu sehr auf die Einzelszene angelegt, als daß man aus verstreuten Äußerungen über eine bestimmte Person deren Gesamtcharakteristik erschließen könnte. Knoche WdF 484 charakterisiert Thyest als „Mann, dem das Leiden den Blick für wahr und unwahr geschärft, noch nicht geläutert hat". Damit wäre Thyest nach stoischer Terminologie ein тооко́ $\pi \tau \omega v$ (vgl. Pratt 104 f.), aber selbst diese Qualifikation muß man in Anbetracht seiner mythischen Biographie als zweifelhaft ansehen. Der Sinn der „philosophischen“ Äußerungen Thyests wird nicht aus dem mythologischen Wesen dieser Figur, sondern nur aus den Zielen der senecanischen Komposition verständlich: Das Lebensideal des Chors erhält eine schlagende Bestätigung, indem in der dramatischen Handlung deutlich wird, daß es eine Figur hätte retten können — dies ist der Grund, warum Seneca das Gespräch zwischen Thyest und seinem Sohn darstellt, nicht etwa der Umstand, daß die stoische Haltung gut zur mythischen Gestalt Thyests passen würde.

Dabei kehrt sich Thyest von dieser stoischen Haltung an keiner Stelle innerlich ab: Von der Schlußszene des dritten Akts, wo sich Thyest von Atreus schließlich die Königskrone aufsetzen läßt, kann man schwerlich mit Recht sagen, daß Thyest ,succumbs to a world he has castigated as deluding“ und daß so die „naivety and impotence“ seiner philosophischen Haltung deutlich werde (Boyle 215). Denn bis zu seiner vorletzten Äußerung (539 f.) beharrt er auf seinem Standpunkt und reklamiert es sogar in typisch stoischer Paradoxologie als seinen besonderen Ruhm, die Herrschaft abzulehnen. Schließlich akzeptiert er doch in Anbetracht von Atreus' Drohung, seinerseits von der Herrschaft zurückzutreten (541), aber er betont, nur den Namen der Königsherrschaft anzunehmen, auf die zugehörige Macht aber keinen Wert zu legen (542 f.). Man könnte diese Äußerungen natürlich als ein geheucheltes Trug-Manöver ansehen (so Mader 2000, 168: „an ironic pseudo-compromise“; „The distinction between name and substance ... is intentionally absurd"), müßte sich dann aber fragen, was Thyest mit solch fingierter Selbstdarstellung bezweckt. Zudem macht die Vorschaltung der Thyest-Tantalus-Szene, wo Thyest ja im intimen Gespräch mit seinem Sohn - und noch in Abwesenheit des Atreus - keinerlei Grund zur Verstellung hat, sehr wahrscheinlich, daß die „bekehrte“ philosophische Haltung Thyests eben doch ernstgemeint ist. Das Gespräch zwischen Thyest und seinem Sohn Tantalus bildet gewissermaßen ein Gegenstück zu den Domina-Nutrix-Szenen in den Stücken Medea, Phaedra und Agamemnon und besonders zur Atreus-Satelles-Szene im Thyest (vgl. Picone 71): In den zuletzt genannten Szenen wird jeweils die pathologische Verfassung einer Person im Zwiegespräch mit einem Vertrauten beleuchtet; in der Thyest-Tantalaus-Szene treten dagegen die im Exil gewonnen Einsichten Thyests ans Licht, die sich fatalerweise nicht durchsetzen.

Genausowenig kann man aus den ersten Worten Thyests zu Beginn des zweiten Akts, wo er die argivische Macht apostrophiert (404) und das ihm entgegenströmende Volk bereits vor sich sieht (411), folgern, daß „Thyestes clearly longs for the world of fame and power“ (Boyle a.a.O. 216, der die abwegigen Unterstellungen des senecanischen Oedipus gegen Creon [682 f. Certissima est regnare cupienti vial Laudare modica et otium ac somnum loqui, „,as Oedipus observed“] zum Leitprinzip seiner Thyest-Interpretation erhebt). Im Gegenteil bilden die Verse 404-411 nur eine Folie, welche die klischeehaften Wünsche heimkehrender Verbannter (vgl. 405 Miserisque summum ac maximum exulibus bonum) den neugewonnenen Einsichten Thyests (412 ff.) entgegenstellt.

Ebensowenig überzeugt Boyles Interpretation der Unterredung Thyests mit Tantalus, wo aus der vorwiegend negativen Formulierung des Ideals vom einfachen Leben (455-470) gefolgert werden soll, daß „Thyestes is fascinated by the life of power and drawn irresistibly to it“" (a.a.O. 216). Die negative Formulierung ist natürlich, insofern Thyest die Leiden der hohen Position selbst erfahren hat, und entspricht im übrigen auch der Ausdrucksweise des senecanischen Chors (vgl. 381 ff.; 396; 399). Ferner formuliert auch Hippolytus in der Phaedra sein Ideal vom einfachen Leben vorwiegend negativ (486 ff.), ohne daß man dieser Figur deshalb ein latentes Machtstreben unterstellen könnte.

Aus dem Text ergibt sich kein Anzeichen dafür, daß die „stoische“ Haltung Thyests nicht echt oder nur aufgesetzt wäre. Insofern ist die Beurteilung Thyests als „,a proficiens who does not reach the 
goal of rationality“ (Pratt 104) fragwürdig: Das „goal of rationality“ hat Thyest vollständig erreicht, nur - und das ist das einzige, was man ihm vorwerfen kann, und zugleich seine Tragik - setzt er diese Rationalität in seinem Handeln weder gegenüber seinem Sohn Tantalus (im ersten Teil des dritten Akts) noch gegenüber seinem Bruder Atreus (im zweiten Teil des dritten Akts) konsequent um. Das Tragische an der Thyest-Figur ist gerade, daß er vollkommene philosophische Erkenntnis (die so genau der Maxime des Chors entspricht, daß Thyest selbst in media turba latere möchte, $533 \mathrm{f}$.) erlangt hat, diese auch innerlich festhält, aber doch an zwei entscheidenenden Punkten nicht umsetzt, sondern sich dem Gang des Geschehens - ohne Aufgeben seiner Überzeugung - äußerlich unterordnet (ebenso wie er seine vielfach bekundeten, berechtigten Zweifel an der Ehrlichkeit von Atreus' Angebot nicht in Handlung umsetzt). Damit vergibt er zwei Möglichkeiten, sich aus den Fängen des Atreus zu befreien: Er hätte zunächst, anstatt Tantalus nachzugeben, einfach in die Verbannung zurückkehren und dann im Gespräch mit Atreus die Herrschaft konsequent ablehnen können. Insofern trifft die Auffassung, daß die schwarzen Züge sich im Charakter des Thyest schließlich doch gegen die weißen behaupten (Lefèvre 1997, 130), nicht das Entscheidende.

Insbesondere im Gespräch mit seinem Sohn gibt Thyest seine Haltung nicht eigentlich auf, sondern zögert bis zuletzt, begreift dann aber plötzlich, daß es zu spät ist für Vorsichtsmaßnahmen (487 f. Serum est cavendi tempus in mediis malis:/ Eatur). Daß er letztlich doch nicht entsprechend seinen eigenen „stoischen“ Maximen handelt, erscheint in keiner Weise als durch Gier bedingt und somit auch kaum schuldhaft. Anders Lefévre 1985, 1275: „Thyestes handelt wider Wissen und Gewissen: Auf dem Wege zur Macht, will Seneca sagen, stehen Lüge und Selbsttäuschung“; 1279 (zustimmendes Referat von Knoche WdF 484): Thyestes unterliegt „schließlich in dem Kampf zwischen der Vernunft und der Gier nach den glänzenden Gütern“; Boyle 216: „Dissidence between personal appetite on the one hand and moral knowledge and moral responsibility on the other seems central to Thyestes' dramatisation“. Schon die Terminologie von Seidensticker 104, der in bezug auf den dritten Akt von „Verführungsszenen“ spricht, scheint irreführend. Die Einschätzung des Atreus, regna nunc sperat mea:/ Hac spe subibit gurgitis tumidi minas/... (289 ff.), ist einfach verkehrt; der Wirklichkeit entspricht dagegen sein Alternativplan: si nimis durus preces/Sper$n$ et $T$ h y e s t e s, liberos eius rudes/ Malisque fessos gravibus et faciles capi/ Prece commovebo (299-302), vgl. die Worte Thyests zu seinen Kindern in 489: Ego vos sequor, non duco; Thyest selbst läßt sich in keiner Weise überzeugen oder überreden.

Auch das von Frings 32 als entscheidend angesehene Motiv, ,die Rücksicht auf die Interessen der Kinder, auf die die Herrschaft einmal übergehen soll“", findet sich nur als Argument des Tantalus (444), wird aber von Thyest sogleich bestritten mit der Sentenz non capit regnum duos und am Ende der Szene sogar in seiner Wertigkeit für Thyests Entscheidung umgekehrt (485 f.): Pro me nihil iam metuo: vos facitis mihi/ Atrea timendum.

Treffend wird die der eigentlichen Haltung Thyests zuwiderlaufende Entscheidung von Heldmann 181 f. mit Tro. 349 ff. zusammengestellt, wo Agamemnon von seiner philosophisch wohlbegründeten Opposition gegen die Opferung der Polyxena abläßt in Hinblick auf die von Tiresias zu verkündenden $\mathrm{fata}^{36}$. Auch hier gibt der Sprecher seine eigene wohlfundierte Haltung in keiner Weise auf, sondern ordnet sich rein äußerlich dem Fortgang des dramatischen Geschehens unter. Damit ist in beiden Stücken eine fundierte Gegenposition entwickelt, bei deren Verwirklichung das Geschehen einen anderen Verlauf genommen hätte (ohne Opferung der Polyxena bzw. Thyestmahl). Trotzdem liegt keine willentliche Fehlentscheidung Agamemnons bzw. Thyests vor. Für den Chor im Thyest bedeutet dies: Die Chorreflexion zeigt einen Weg auf, auf dem Thyest unbeschadet hätte entkommen können; sie bietet aber keine Handhabe, ihm eine subjektive Schuld an seinem letztlichen Geschick zu geben. Die Annahme einer offerierten Königsherrschaft ist unter stoischem Gesichtspunkt keine Fehlhandlung, wenn man sich von den Gütern der Herrschaft nicht innerlich abhängig macht und hierauf ergeben sich bei Thyest keinerlei Hinweise.

Seltsamerweise wird auch die philosophisch wohlfundierte Position, welche Agamemnon in den Troerinnen gegen die Opferung der Polyxena einnimmt, von der modernen Forschung moralisch abgewertet - ähnlich wie die Haltung Thyests im Gespräch mit seinem Sohn. Es erscheint zweifelhaft, ob man mit Schetter WdF 238 in Agamemnon einen ,von Angst vor der auf ihm lastenden Verantwortung und vor der drohenden Strafe des Schicksals gepeinigten Mann" sehen darf, nur weil er

${ }^{36} \mathrm{Zu}$ der mythischen Version, daß sich Agamemnon gegen die Opferung der Polyxena ausspricht, vgl. Eur. Hek. 116 ff. (von Stephanopoulos 77 zurückgeführt auf die sophokleische Polyxena); die Verküpfung dieser Haltung mit Agamemnons Liebesverhältnis zu Kassandra (Hek. 121 f.) wird in den polemischen Worten des Pyrrhus bei Seneca Tro. 303 ff. reflektiert. 
hervorhebt, daß ihn der Fall Trojas an die Gebrechlichkeit der eigenen Position gemahnt habe und daß unter seinem Oberkommando geschehende Verbrechen auf ihn zurückfallen werden ${ }^{37}$. Die Interpretation Schetters wird in neuerer Zeit weitergeführt von Vielberg 321-323, wo es über die schließliche Unterordnung Agamemnons unter den Willen des Calchas heißt (323): „Der aufgeklärte Egoist hat sich im Netz der eigenen Argumentation gefangen.“. In ähnlicher Richtung auch Steidle $61 \mathrm{f}$., der glaubt, bestimmte rhetorische Vorwürfe des Pyrrhus gegen Agamemnons wohlfundierte Position in Anschlag bringen zu können; gegen Steidle vgl. Müller 461 Anm. 2 =WdF 396 Anm. 38: „Nicht ein schwächlicher Charakter soll im Streit mit dem entschlossenen und brutalen Pyrrhus gezeigt werden ..., sondern die Überwältigung des guten Willens und der Menschlichkeit durch grausame politische Notwendigkeiten“. Fragwürdig erscheint auch das Urteil Vielbergs über die letztliche Herbeiziehung des Sehers Calchas: „Daß der situationsmächtige Heerkönig das grauenhafte Ansinnen nicht klar verbietet, sondern durch Delegation erlaubt, bedeutet, daß er die Tat nach seiner eigenen paradoxen Definition selbst befiehlt (291 Qui non vetat peccare, cum possit, iubet)“. Die Befragung des Calchas bedeutet keine „Delegation“, sondern die Unterordnung unter den göttlichen Willen, dessen Allmacht Agamemnon nicht nur in Aulis (357 f.) zu spüren bekam, sondern auch im Zusammenhang der im ersten Ilias-Buch geschilderten Auseinandersetzung mit Achill, wo er erfahren konnte, zu welchen Folgen es führte, sich göttlichem Willen zu widersetzen; der durch Calchas bekundete Götterwille hebt gerade die Voraussetzung von Agamemnons Leitsatz, das vetare posse, auf. Natürlich ist die plötzliche Einführung des Calchas ungeheuer abrupt, aber ihre Funktion ist vergleichbar der plötzlichen Erkenntnis des Thyest, daß es für Vorsichtsmaßnahmen zu spät ist. Vor allem gibt Agamemnon seine fundierte Opposition gegen die Opferung der Polyxena im Gespräch mit Pyrrhus genauso wenig auf wie Thyest seinen Widerstand gegen die Königsherrschaft im Gespräch mit seinem Sohn Tantalus bzw. mit Atreus.

In beiden Fällen - in den Troerinnen wie im Thyest - wird eine philosophisch äußerst vielversprechend begründete, sich andeutende Handlungsentwicklung jäh durch einen rein äußerlichen Faktor abgebrochen. Ein Vergleich mit der euripideischen deus-ex-machina-Praxis drängt sich auf. Wenn sich Thyest bzw. Agamemenon mit seiner wohlfundierten Position durchsetzen würde, ergäbe sich ein Verstoß gegen den traditionellen Ablauf des Mythos: Das Thyestmahl könnte nicht stattfinden bzw. Polyxena würde nicht geopfert.

Das dritte Chorlied ist das bereits eingangs erwähnte Preislied auf die Bruderliebe, welches der in den vorigen Akten geoffenbarten Wirklichkeit in so eklatanter Weise widerspricht. Die Unwissenheit des Chores mag man sich damit erklären, daß er eben entsprechend seiner immer wieder geäußerten Lebensmaxime tatsächlich nur dem unteren Stand angehört und somit nichts von den Intrigen weiß, die Atreus mit seinem Diener plant, welcher ausdrücklich zum Stillschweigen verpflichtet wird - wobei Seneca jedoch, wie nochmals zu betonen ist, durch nichts eine Abwesenheit des Chors in der Intrigenszene markiert hat. Der zweite Teil des Chorlieds relativiert den anfangs geäußerten Optimismus über die beruhigende Wirkung der Bruderliebe: Es wird hervorgehoben, daß Schmerz und Freude schnell wechseln, besonders für Herrscher, und daß man deshalb niemals auf das augenblickliche Glück vertrauen darf, welches die Fortuna jederzeit wieder zerstören kann. Dieser eher pessimistische Abschluß verhindert, daß der Chor durch den folgenden Bericht vom furchtbaren Verbrechen des Atreus korrigiert und geradezu lächerlich gemacht wird.

Übrigens hat das an der tatsächlichen Situation vorbeigehende Raisonnement des Chors über die versöhnende Wirkung der Bruderliebe eine bemerkenswerte Parallele im vorausgehenden Akt, und zwar im Gespräch zwischen Thyest und seinem Sohn Tantalus. Der Knabe (der ja später dem Verbrechen des Atreus zum Opfer fallen und von seinem Vater verspeist werden wird) richtet gegen die Bedenken seines

37 Die Formulierung in me culpa cunctorum redit (290) kehrt in ähnlicher Form und in gleichem $\mathrm{Zu}$ sammenhang der Opferung Polyxenas später wieder im Munde der als „Brautführerin“ agierenden Helena (870 f.): ad auctorem redit/ Sceleris coacti culpa, wo mit auctor offenbar Calchas gemeint ist, vgl. $938 \mathrm{ff}$. 
Vaters das Argument „die Geschwisterliebe pflegt dorthin zurückzukehren, von wo sie gewichen ist" (Redire pietas unde summota est solet) ${ }^{38}$. Im dritten Akt finden also die Themen der beiden umliegenden Chorgesänge (einerseits das Ideal des bedürfnislosen Lebens und andererseits die versöhnende Wirkung der Pietas) Verwendung, genauer gesagt: sie werden als Argumente im Gespräch zwischen Thyest und Tantalus gegeneinander ausgespielt. Fatalerweise behauptet sich aber nicht die Position Thyests (der in Hinblick auf das Glück seines bescheidenen Exulantendaseins auf die Königsherrschaft verzichten will), sondern die seines Sohns Tantalus, der an die ausgleichende Wirkung der Pietas glaubt (und den dieser Glaube tragischerweise zum Opfer des Thyestmahls machen wird): Es setzt sich in der dramatischen Wirklichkeit also eine Ansicht durch, welche einem ins Leere gehenden Theorem des Chors entspricht, während die Position Thyests, welche dem vom Chor artikulierten Ideal der Bedürfnislosigkeit gleichkäme und faktisch das Unglück verhindern würde, nicht zur Verwirklichung kommt. Hier zeigt sich, wie komplex das Verhältnis zwischen Chorreflexion und dramatischer Handlung bei Seneca sein kann.

Vom vierten Chorlied, welches über den in Anbetracht von Atreus' Greueltat erfolgten Sonnenuntergang reflektiert und diesen mit einem Weltuntergang in Verbindung bringt, können wir hier absehen, da es offensichtlich in unmittelbarem Kontakt zur aktuellen dramatischen Handlung steht.

Davis 1989, 434 sieht in diesem letzten Chorlied eine entscheidende Wandlung in der Haltung des Chors, insofern hier der moralische Optimismus der ersten drei Chorlieder verschwunden sei: „In their first three odes the members of the chorus present themselves as conventional if somewhat sceptical believers in moral guardianship of the gods. They appeal to the gods in Ode 1 for an end to the cycle of crime which had afflicted Argos; in Ode 3 they assert Juppiter's authority over rulers (607 ff.) ... It is in their fourth ode that they come closest to achieving an understanding of the nature of their world. Now they no longer make confident assertions“. Zu beachten ist jedoch der Unterschied, daß das vierte Chorlied Spekulationen über den Grund eines im dramatischen Geschehen plötzlich eingetretenen Naturereignisses (des unnatürlichen Sonnenuntergangs) enthält und somit im Gegensatz zu den ersten drei nicht eigentlich analytisch-kommentierend auf den Gang der Tragödie gerichtet ist.

Zusammenfassend lassen sich die Charakteristika der Rolle des Chors in den fünf betrachteten Tragödien folgendermaßen beschreiben: Die Chorlieder eröffnen jeweils eine jenseits des eigentlichen dramatischen Geschehens liegende Meta-Dimension, die das eintretende Unheil auf einem tieferen reflexiven Wege erklärt: Diese tiefere Dimension kann in dem Drama zeitlich vorausliegenden heroischen Taten einer Person liegen (wie im Hercules — und an einer Stelle der Phaedra - im Hadesgang des Hercules - bzw. des Theseus - oder wie in der Medea in der Meeresbezwingung des Argonauten Jason); solche übermenschlich großen Taten verletzen die Sphären bestimmte Götter — die des Totengotts bzw. die des Meeresgotts. Die tiefere Begründungsdimension kann aber auch in dem vom Handeln der Hauptperson unabhängigen Verhältnis der Stadt — Theben — bzw. ihres Herrschergeschlechts zu den Göttern liegen, wie im Oedipus. Ferner kann eine solche Begründungsdimension auch einer eher philosophischen ${ }^{39}$ Sphäre entstammen, wie in der Phaedra, wo die

\footnotetext{
38 Sen. Thyest. 474.

39 „Philosophisch“ im allgemeinsten Sinne, nämlich in dem der Erklärung des Einzelvorgangs durch allgemein-phänomenologische Beobachtungen (vgl. Davis 1984, 401: ,... the chorus state a quasi-philosophical principal whereby it is possible to interpret the events of the play"). Formal betrachtet ist das erste Chorlied der Phaedra, insofern es über die Gottheit Cupido handelt, in die Kategorie „Mythologie“ einzuordnen.
} 
ersten beiden Lieder über die Allmacht der Liebe und die Vergänglichkeit und Gefährdung von jugendlicher Schönheit handeln. Schließlich können auch verschiedene Sphären ${ }^{40}$ einander ergänzen, wie im Thyest, wo das erste Chorlied auf die genealogische Belastung des argivischen Königshauses hinzielt, also auf eine ähnliche kollektive Belastung wie im Oedipus, das zweite dagegen auf einen philosophischen Argumentationsansatz, nämlich den stoischen Königsbegriff.

Die komplexe Beziehung des Gesprächs zwischen Thyest und seinem Sohn zu den beiden umliegenden Chorliedern macht aber zugleich deutlich, daß man die durch die Chorreflexionen eröffnete tiefere Begründungsdimension nicht grundsätzlich vom dramatischen Geschehen ablösen darf, wie es Bishop 1964 b, 43-45 versucht, wenn er zwei parallel verlaufende Entwicklungslinien in den senecanischen Tragödien unterscheidet, eine „dramatic line“ und eine „odic line“: Die Chorlieder enthalten nicht etwa nur einen in vier Abschnitte zerlegten philosophischen Kommentar zum Stück, sondern stehen zu den benachbarten Akten zumindest teilweise in subtilen Beziehungen, welche jeweils durch Einzelinterpretation zu erschließen sind, wie es hier exemplarisch für den dritten Akt des Thyest angedeutet wurde. Die Disposition des gedanklichen Materials auf die vier Chorlieder ist also durchaus von artistischen Gesichtspunkten bestimmt, wenngleich diese Gesichtspunkte nicht durch die Kategorie „dramaturgische Konsequenz“ im Sinne der aristotelischen Lehre vom Chor als einer an der Handlung teilnehmenden Person zu fassen sind.

Das Unglück, welches durch die in den Chorgesängen eröffneten verschiedenen Begründungsdimensionen erklärt wird, erstreckt sich in keinem der bisher besprochenen fünf Tragödien auf den Chor selbst, sondern immer nur auf die Höhergestellten, und der Chor ist jeweils froh, durch seine programmatisch gepriesene Mittelmäßigkeit solchem Unglück entgehen zu können. In allen fünf Stücken findet der Chor Gelegenheit, sich von den Gefahren der hohen Existenz der Mächtigen zu distanzieren. Nur in der Medea ist die Lage etwas anders, da Jason im Gegensatz zu den Hauptfiguren in den anderen Stücken eigentlich - zumindest vor seiner neuen Hochzeit - noch nicht zur korinthischen Königsfamilie gehört. Hier tritt an die Stelle der großen Macht der Status Jasons als Argonaut, als Meeresbezwinger; von solchen heroischen Taten kann sich der Chor der Medea, gestützt auf das antike Ideal einer seefahrtsfreien Urzeit, genauso nachdrücklich distanzieren wie die Chöre der anderen Stücke etwa vom Hadesgang des Hercules oder von der hohen Stellung der sonstigen Hauptfiguren. Mit dieser Distanzierung von den übergroßen Hauptfiguren und der Berufung auf das Ideal gefahrloser Mittelmäßigkeit ist in allen Stücken tatsächlich eine unbetroffene Stellung des Chors verbunden, der das Unglück der Großen aus den erläuterten verschiedenen Begründungsdimensionen heraus analysieren kann.

Auf die bis jetzt besprochenen fünf Stücke treffen die von Marx $8 \mathrm{f}$. hervorgehobenen Merkmale des senecanischen Chors im wesentlichen zu: „Sein Lied ist kein Akt der Hingabe — es ist eher eine Z u g a b e ; er gewinnt nicht Einsicht — er hat eine A n s i c h t;" er fühlt sich von dem, was geschieht, nicht ,angesprochen und beansprucht“; er „s a g t etwas dazu“. In Hinblick auf die immer wieder bekundete Mittelmäßigkeit seiner Stellung könnte man die von Lefèvre 1969, $155=370$ im Referat über Marx verwendete Formulierung ,er steht über den Ereignissen“ pointiert umkehren zu ,er steht (analysierend) u n t e r den Ereignissen“ (zur Dissertation von Marx vgl. auch Stevens 14). Ähnlich wie Marx charakterisiert R. J. Tarrant 1976 in seiner Vorbemerkung zum ersten Chorlied des Agamemnon (57-107, S. 181) die Funktion des Chores: „not to offer sympathy (and thus additional affectus) but enlightenment“. Wichtig ist im übrigen auch Tarrants Hinweis auf die aesthetische Wir-

40 Davis 1993 unterscheidet durch seine Kapitelüberschriften die Themenbereiche „mythology“, ,philosophy“ und ,prayer“. 
kung des reflexiven Chorlieds als Unterbrechung emotionaler Auseinandersetzung in den einzelnen dramatischen Szenen.

Die in allen fünf Stücken betonte Mittelmäßigkeit der Stellung ist also einerseits die Ausgangsposition, die Perspektive, aus welcher heraus der Chor seine Analysen anstellt; andererseits ist sie aber auch schon das entscheidende gedankliche Instrument, mit dem er das Unglück der hochgestellten Personen des Dramas erklärt: Diese sind eben nicht mittelmäßig, sondern übergroß.

Insofern ist die Position des senecanischen Chors doch nicht so ganz unbestimmt und beliebig, wie Marx 9 formulierte: „Wenn wir also fragen, was denn nun die Realität sozusagen des Chores bei Seneca sei, so lautet die Antwort, daß seine O b lig a t h e i t seine Wirklichkeit ist; a u s g e f ü $11 \mathrm{t}$ wird diese Wirklichkeit durch die dem Dichter gegebene Möglichkeit, zu den im Stück vorkommenden Dingen — sie isolierend — nach Talent und Neigung Dinge beizubringen, die im Rahmen der Handlung keine Stelle haben“. Verallgemeinern auf die bis jetzt besprochenen fünf Tragödien lassen sich einige Aussagen von Jo-Ann Shelton 1978 über den Chor im Hercules: „The identity of this chorus is not defined in terms of age or nationality, but in terms of its approach to life“ (a.a.O. 43). Die Qualität dieses ,approach“ wird kurz zuvor spezifiziert ,,as men of limited perception and simple intelligence whose opinions are shaped primarily by a desire for security“; dabei ist „limited perception and simple intelligence“ allerdings dahingehend zu modifizieren, daß sich die auf diesen „,beschränkten“ Prinzipien gründenden Analysen stets bewahrheiten durch den Gang des dramatischen Geschehens; der Chor vertritt eine Position, die man als oberflächlich und „simple-minded“ ansehen mag, aber sie bewährt sich — in Anbetracht des Unglücks der Großen — stets. „The words of the chorus are the expressions of ordinary men and provide another point of reference from which to judge the events in the play“ (a.a.O. 43; vgl. auch Stevens 332: „The appeal of common sense is held out for us amid the passions and vices of the principals“). Auf S. 48 ist die Rede von ,early resignation to a life of quiet inaction and determination to avoid misfortune and postpone death" und ,philosophy of non-involvement“. „Seneca developed for his chorus the function of a mannerist counterpoint movement" (a.a.O. 48 f.). ,The frightened men of the chorus present a dramatic personality whose participation in the tragedy is essential" (a.a.O. 49).

Man mag diese Standard-Position der senecanischen Chöre (die im System der antiken Philosophie sicher eher in die Rubrik „epikureisch“ als „stoisch“ einzuordnen wäre) billigen oder nicht, man mag streiten, ob Seneca sie selbst billigte bzw. durch sie seine eigene Meinung bekundete - eines wird man nicht abstreiten können: Die auf der Grundlage dieser Position durchgeführte Analyse (,übermäßige Größe führt in den Untergang“) bewährt sich stets in den senecanischen Stücken, insofern die senecanischen Helden $\mathrm{t}$ a $\mathrm{t} \mathrm{s}$ ä $\mathrm{ch} \mathrm{i} \mathrm{ch}$ überproportional groß sind und $\mathrm{t}$ a t s ä c h li ch stürzen. Ob das Ideal des einfachen, mittelmäßigen Lebens Senecas eigenes weltanschauliches Ideal war und dem Leser durch das „Sprachrohr“ des Chors als solches empfohlen werden sollte, wird sich wohl nie sicher entscheiden lassen. Entscheidend ist aber: Das Ideal bewährt sich in den Tragödien als Instrument gedanklicher Analyse, insofern den senecanischen Helden faktisch (nicht schuldhaft) ihre Größe den Untergang einbringt.

In Anbetracht jüngerer Forschungsmeinungen muß dabei Wert auf die Tatsache gelegt werden, daß dieses Großsein in keinem Fall als notwendig mit subjektiver Verschuldung verbunden betrachtet wird. Der Chor geht zwar gelegentlich so weit, hervorzuheben, daß es töricht sei, nach allzu Großem zu streben: Dieses Urteil erklärt sich aber immer durch die in den Tragödien exemplifizierten Folgen des Großseins, nie durch eine moralisierende Ablehnung des Strebens nach Größe. Das Ideal der Mittelmäßigkeit und das Theorem, daß alles Große bedroht ist, bilden eine gedankliche Kategorie, mit der das dramatische Geschehen erklärt wird, nicht eine moralische Norm, mit der die Charaktere bewertet werden ${ }^{41}$.

41 Unklar ist der von Liebermann 227 verwandte Begriff einer „Gegenwelt der Bescheidung, der Philosophie“, welche sich in den Chorliedern eröffnet. Man erfährt nicht genau, ob es sich dabei um eine analytische Kategorie oder um eine moralische Norm handelt. 
Allgemein zu den Implikationen des literarischen Motivs „Der Sturz des Mächtigen“ ist jetzt die von Wolpers herausgegebene Aufsatzsammlung heranzuziehen. In seiner einleitenden Untersuchung (a.a.O. 7-36) geht Wolpers in den Abschnitten 5.1.3 („Menschenauffassung und Art des Stürzens“, S. 22 f.) und 5.1.4 („Das Schuldproblem“, S. 23 f.) auf das Problem der subjektiven Verschuldung des Sturzes durch den Mächtigen ein. Der Sturz eines „,guten Mächtigen“ kommt nach Wolpers nur „,in seltenen Fällen“ (a.a.O. 22) vor, der „moralische Verfall des Stürzenden“ ist dagegen „die Regel“ (a.a.O. 23). Wenn diese statistische Beobachtung zutrifft, so muß man in der Geläufigkeit solchen „moralischen Verfalls“ wohl einen Grund für die in diese Richtung gehende Tendenz der jüngeren Forschung zu den Seneca-Tragödien sehen.

Auf S. 26 f. unterscheidet Wolpers im Bereich der griechischen Tragödie zwei Typen des stürzenden Mächtigen: (1) denjenigen, der schuldhaft seine Macht mißbraucht und somit in Folge seines Fehlverhaltens in untragischer Weise stürzt, und (2) denjenigen, dessen Sturz nicht wesenhaft mit seiner Macht zu tun hat und der ohne wesentliche subjektive Schuld stürzt. Diese Unterscheidung wird im Bereich der attischen Tragödie vertieft in dem Beitrag von Manuwald (a.a.O. 37-62). Hier werden die beiden Gruppen folgendermaßen geschieden: „Auf der einen Seite stehen die Herrscher, die Macht ausüben, sich bei ihrer Machtausübung bzw. -behauptung in vermeidbare Schuld verstricken und darum stürzen (Kreon, Pentheus, Eteokles). Ihr Schicksal erscheint als nachvollziehbare und folgerichtige Konsequenz ihres unangemessenen Verhaltens während der Bühnenhandlung und kann beim Zuschauer eben deswegen nur bedingt Mitgefühl hervorrufen“ (a.a.O. 61). „Ganz anders verhält es sich mit Oidipus, Agamemnon, Aias und Herakles: Ihr Schicksal (bzw. dessen z.T. weit zurückliegende Ursachen) bildet die zentrale Thematik der jeweiligen Tragödie. Es handelt sich bei ihnen zwar um Mächtige, deren Fallhöhe bei ihrem Sturz durch ihren Rang aufs äußerste gesteigert wird, aber die Gegebenheiten, mit denen sie zu tun haben, sind allgemeinerer Art und nur sekundär mit ihrer Stellung verbunden, d.h., sie könnten prinzipiell und ihrer Struktur nach ... jedem Menschen widerfahren. Sofern diese Mächtigen objektiv gegen grundlegende Normen verstoßen, diesen Verstoß jedoch zumindest nicht uneingeschränkt zu verantworten haben oder sie ihr Verhängnis überhaupt ohne jedes Verschulden trifft ..., stellt sich beim Zuschauer Erschütterung ein; und weil ihr Sturz nicht wesentlich an ihrer Macht hängt, berühren ihre Schicksale die Zuschauer in grundsätzlicherer Weise und können ... als Chiffre einer menschlichen Befindlichkeit dienen ..." (a.a.O. 61 f.).

Die moderne Seneca-Forschung, welche oftmals den Hauptpersonen der senecanischen Tragödien in zweifelhaften Fällen schuldhafte Fehlhandlungen (zumeist unter stoischer Betrachtungsweise) zuschreibt, versucht gewissermaßen, den senecanischen Dramen den ersten Typ aufzupressen. Um der Gestaltungsweise Senecas gerecht zu werden, müßte man jedoch eher die zweite Kategorie wesentlich modifizieren: In seinen Tragödien finden sich viele Figuren (Hercules, Jason, Theseus und Hippolytus in der Phaedra, Oedipus ${ }^{42}$, Thyest — zumindest was dessen i m D r a $\mathrm{m}$ a dargestelltes Handeln anbelangt ${ }^{43}$ ), die zwar ohne subjektive Schuld an ihrem Unglück sind und deren Sturz auch nicht wesenhaft mit einem Mißbrauch ihrer exponierten Stellung zusammenhängt, deren Unglück aber vom Chor der jeweiligen Stücke ausdrücklich ihrem Groß-Sein zugeschrieben wird (das sich nicht unbedingt in politischer Macht äußern muß, sondern etwa auch in Jasons Status als Argonaut oder in Hippolytus' übergroßer Schönheit oder in Thyests Zugehörigkeit zum argivischen Herrscherhaus bestehen kann), und zwar nicht im Sinne einer subjektiven Verschuldung, sondern eines objektiven Naturgesetzes, welches — in wesenhaft ungerechter Weise — immer den Sturz der gerade Mächtigen und Großen herbeiführt. Insofern bleiben diese Personen subjektiv unschuldig, aber ihr Untergang steht dennoch in einem objektiv-kausalen Zusammenhang mit ihrer Größe. Wenn man annimmt, daß die in diese Richtung laufende Chorreflexion das Verständnis des Rezipienten fördern soll und nicht etwa die Funktion hat, ihn zu verwirren (worauf manche neuere Deutungen hinauslaufen), so gelangt man zu folgenden Schlußfolgerungen: Wenn der Rezipient der Stücke selbst ein Mächtiger ist (und Birt ist ja in der Tat so weit gegangen, die Tragödien als Abschreckungsbilder für Senecas Zögling Nero zu verstehen), so wird er nicht etwa im Sinne eines Fürstenspiegels moralisch unterwiesen, sondern erhält nur den beängstigenden Hinweis, daß seine Größe geeignet ist, ihn in ähnlich monströses Unglück zu führen, wie es in den Tragödien vorgeführt wird. Wenn es sich dagegen bei den Rezipienten nicht um besonders exponierte Personen, sondern um ,einfache Leute“ handelt, die sich gewissermaßen mit der Chorposition identifizieren können, so erfahren diese, daß Großsein furchtbare Folgen zeitigen kann und daß sie selbst in ihrer mittelmäßigen Position vor solchem

\footnotetext{
42 Vgl. Zwierlein 1984, 41.

43 Vgl. zu letzterem wiederum Zwierlein 1984, 41.
} 
Unglück geradezu gefeit sind. Sie erfahren also das Unglück der senecanischen Helden als etwas, das sie in ihrer mittelmäßigen Position aller Wahrscheinlichkeit nach nicht treffen kann, und erhalten gleichsam die Botschaft, daß sie in ihrer nicht-exponierten Stellung vor solch furchtbarem Geschehen geschützt sind und es nicht auf ihre Situation übertragen können oder — besser gesagt — nicht zu übertragen brauchen (und eine solche Übertragung dürfte in Anbetracht des geradezu gigantisch-monströsen Zuschnitts vieler senecanischer Charaktere in der Tat schwerfallen). Die „Fallhöhe“ ist also nicht nur ein darstellerisches Mittel, welches das Phänomen des Sturzes eindringlicher darstellt, sondern zugleich und vor allem ein Sicherheitsabstand, welcher den Rezipienten vor potentiellen ähnlichen Katastrophen schützt. Eine derartige geradezu erleichternde Erfahrung von fremdem Unglück, welches den Rezipienten ausgesprochenermaßen nicht in ähnlicher Weise treffen kann, also keinerlei Identifikation mit dem Leidenden herbeiführen soll, steht in tiefgreifendem Gegensatz zur aristotelischen Tragödien-Auffassung, die auf ein Mitempfindenkönnen des Zuschauers mit dem Helden ausgerichtet ist.

Dagegen wird die Schuld derjenigen Personen, welche sich in den Seneca-Tragödien tatsächlich subjektiv schuldhaft verhalten, in der Regel durch Szenen des Typs Domina/ Nutrix verdeutlicht, in denen die psychisch krankhafte Verfassung dieser Personen vor der Folie einer moralisch überlegenen Kontrastfigur deutlich gemacht wird: Dies gilt für Medea, Phaedra, Clytemestra im Agamemnon und auch für Atreus im Thyest, dessen Haltung im Gespräch mit seinem zumindest anfangs Widerstand leistenden Satelles beleuchtet wird, ferner auch in den unechten Stücken für Deianira im Hercules Oetaeus und für Nero in der Octavia, der in einer Auseinandersetzung mit Seneca selbst vorgeführt wird.

In gleichem Maße zu meiden wie eine moralisierende Interpretation der Standard-Position des senecanischen Chors ist eine gelegentlich anzutreffende biographistische Deutungsweise, die in der distanziert-mittelmäßigen Positionierung des Chors die persönlichen Erfahrungen und Lehren wiederzufinden sucht, welche Seneca aus seiner erfolglosen Tätigkeit als Prinzenerzieher Neros abgeleitet habe. Denn in keinem Fall wird in den hier besprochenen Stücken das Lebensideal des Chors durch die Korruption der Machthaber oder gar durch ein persönliches Bedrohtsein begründet; eine persönliche Gefährdung liegt nur in der unechten Octavia ${ }^{44}$ vor bei demjenigen Chor, welcher der Titelheldin freundlich gesonnen ist.

Lefèvre 1985, 1268 (über das Chorlied Thyest. 391-403): „Der 'Thyestes’ ist eine Tragödie der Macht, genauer: des Mißbrauchs der Macht, die in eine Zeit gehört, in der das Beharren in einer einfachen Lebensposition oder der rechtzeitige Rückzug dorthin oft die einzige Möglichkeit zum Überleben war. Seneca hat diese Erfahrung am eigenen Leibe machen müssen“. In der von Lefévre zitierten Thyest-Partie ist die Rede von der „schlüpfrigen Höhe des Hofs“ (392) und der friedlichen Ruhe eines bescheidenen Daseins. Daraus folgt, daß die hohe Position wegen der ihr inhaerenten Gefahren gemieden wird und die niedrige wegen der ihr eigenen Friedlichkeit erstrebt wird; der Gedanke an eine Berührung mit korrumpierter Macht, welche einen ursprünglich anders gesinnten Chor umgestimmt hätte, liegt fern. Lefèvre verweist auf Seeck 406 (ebenfalls über den Thyest): „Wenn es sich hierbei auch um eine allgemeine philosophische Lebenslehre handelt, um eine Grundeinstellung, die weitgehend utopischen Charakter trägt, so gewann sie doch gerade in der Zeit Senecas existenzielle Aktualität; nicht über die anderen hinauszuragen konnte bedeuten, zu überleben“. Ein Bekenntnis zu einem bescheidenen, mittelmäßigen Dasein wäre demnach „,nicht Ausdruck bequemer epikureischer Selbstzufriedenheit und Egozentrik, sondern enthielt eventuell eine Entscheidung über Leben und Tod; mancher, der sie zu spät getroffen hatte, mußte es mit dem Leben bezahlen“. Etwas zurückhaltender Blänsdorf 45: „Die Anschauung des Chores von Aufstieg und Sturz des hochgestellten Menschen wird in diesem Drama [im Agamemnon] nicht von den Ereignissen widerlegt und findet ihre Bestätigung in anderen Äußerungen der Dramen über fatum und fortuna. In ihr darf daher eine Grundsatzäußerung Senecas über das Wesen herrscherlicher Existenz gesehen werden. Senecas Tragödien sind zwar nicht

44 Hier fungiert das Motiv vom „Sturz des Mächtigen“ tatsächlich als Motto von Neros Willkürherrschaft, vgl. dessen Ausspruch quidquid excelsum est cadat (471). Nur im Zusammenhang mit dem Chor dieses Stücks kann man (im Gegensatz zu den Chören der echten Tragödien) von einer Haltung inneren Widerstands sprechen, s.u. S. 38. 
verschlüsselte Kommentare zu den Vorgängen am kaiserlichen Hofe, aber doch tiefdringende Stellungnahmen zu den menschlichen Problemen seiner Zeit." - Andererseits sieht Grewe 139 in der Standard-Position des senecanischen Chors gerade einen Gegensatz zur tatsächlichen Haltung Senecas: „Die Wert- und Göttervorstellungen des Chors [in der Medea] widersprechen denen Senecas. Denn nicht träges Verharren in alten, gegebenen Strukturen, sondern Mut zum Wagnis, Bereitschaft, neue Wege zu gehen, machten Senecas Credo aus, und jeder Art von Volksglauben trat der Philosoph in seinen Prosaschriften ausdrücklich entgegen."

In den bis jetzt herangezogenen fünf Stücken erfolgt die Selbst-Positionierung des Chors als bewußte freiwillige Entscheidung in betontem Gegensatz zu der heroischen Größe der Hauptpersonen und in Hinsicht auf die Leiden, Nöte und Gefahren dieser Großen; sie bedeutet jedoch keine moralische Verurteilung und keinen politischen Rückzug.

Was aber ist, wenn der Chor eine derartige Freiheit der analytischen Distanz, die ihn gewissermaßen zum interessiert reflektierenden Beobachter aus dem ungefährdeten Mittelstand heraus macht, nicht erhält und selbst am Unglück der Großen teilhat? Genau diese fundamental verschiedene Situation ist in den Tr o e r i n n e $\mathrm{n}$ des Seneca gegeben, die im folgenden behandelt werden sollen.

\section{Troerin n e n}

Den Chor dieses Stückes bilden die bei der Einnahme Trojas von den Griechen gefangengesetzten trojanischen Frauen. Es handelt sich bei den Troerinnen um das einzige senecanische Stück - abgesehen von den fragmentarisch und ohne Chorpartien überlieferten Phoenissen - , welches nach seinem Chor benannt ist. Daß man in dieser Tatsache schon einen Hinweis auf die besondere und andersartige Rolle sehen darf, die der Chor in diesem Stück spielt, mag man zunächst bezweifeln, da beide Titel Troerinnen und Phoenissen - unverkennbar in euripideischer Tradition stehen. Nicht bestreiten kann man allerdings, daß der Chor — dessen Identität in diesem Fall nicht unprofiliert oder schattenhaft bleibt — in diesem Stück in einem völlig anderen Verhältnis zur dramatischen Handlung steht. Der Chor ist eben nicht ein nur kontemplativ-reflektierend beteiligter Beobachter aus der Stellung des ungefährdeten Mittelstands, wie es in den fünf bisher betrachteten Tragödien der Fall war: Er ist vielmehr durch sein eigenes Geschick genauso von den Kriegsereignissen betroffen wie Hecuba und Andromache und kann sich dementsprechend nicht einer distanzierten Analyse der Handlung hingeben, wie es in den zuvor untersuchten Stücken der Fall war ${ }^{45}$.

Dementsprechend fehlt in den Chorpartien der Troerinnen das Lob der Mittelmäßigkeit und der Hinweis auf die bedrohte Stellung des allzu Großen. Dieser Hinweis wäre völlig unpassend im Munde des Chores: Denn dieser hat einerseits zu viel mit der Bewältigung seines eigenen Leids zu tun, um derart über die Gefahren der Hochgestellten philosophieren zu können; zum anderen wäre der Hinweis aber auch sachlich falsch, da in diesem Fall der Chor - der doch wohl aus Frauen aus dem einfachen Volk besteht - ja zusammen mit den Frauen des $\mathrm{K} \ddot{\mathrm{ni}} \mathrm{gsh}$ a us es ins Elend geraten ist. Der Hinweis auf die Bedrohtheit des Großen erfolgt in den Troerinnen vonseiten anderer Personen des Dramas: einerseits von Hecuba, die im Prolog die Nichtigkeit ihres früheren Status als Königin hervor-

\footnotetext{
45 Angedeutet wird die Sonderstellung des Chors der Troerinnen bereits bei Bishop 1964 b, 47 und 325.
} 
hebt ${ }^{46}$, und andererseits auch vom griechischen Anführer Agamemnon, der in einer Auseinandersetzung mit dem hitzigen Achill-Sohn Pyrrhus eine bemerkenswert gemäßigte Haltung einnimmt: Er will sich durch den Sturz Trojas nicht hochmütig machen lassen, sondern sieht darin nur ein Beispiel für ein allgemeines Phänomen, welches auch ihn selbst betreffen könnte ${ }^{47}$ — worin man vielleicht schon einen vom Autor intendierten Hinweis auf Agamemnons letztliche Ermordung durch Clytemestra erkennen kann.

Der Chor jedoch ist, wie bereits angedeutet, gewissermaßen in seinem eigenen Leid absorbiert. Dies wird der folgende Durchgang durch die Chorlieder der Troerinnen verdeutlichen.

Das erste Lied trägt schon formal Züge, die ungewöhnlich sind für senecanische Chorlieder. Es bedient sich der in der klassischen griechischen Tragödie üblichen Form des Wechselgesangs (Amoibaion) ${ }^{48}$. Inhaltlich handelt es sich um eine Wechselklage zwischen Hecuba und dem Chor, welche zunächst allgemein auf den Untergang Trojas, dann auf Hector und schließlich auf Priamus gerichtet ist. Der Priamus-Teil läuft paradoxerweise in eine Seligpreisung des bei der Eroberung Trojas umgekommenen Herrschers aus:

„Sagt alle „Glücklich ist Priamus“. Er geht als ein freier Mann zu den Geistern der Unterwelt und wird $\mathrm{n}$ i e m a ls auf bezwungenem Halse das griechische Joch tragen. Er sieht $\mathrm{nicht}$ die beiden Atriden [Agamemnon und Menelaus] und erblickt $\mathrm{nicht}$ den trügerischen Odysseus. $\mathrm{Nicht}$ wird er als ein Beutestück eines griechischen Triumphzugs seinen Hals unter den Trophaeen tragen. $\mathrm{Nich} \mathrm{t}$ wird er seine ans Szepter gewöhnten Hände hinter den Rücken [zur Fesselung] richten müssen und, dem Wagen Agamemnons folgend und mit der Rechten goldene Fesseln tragend, einen Triumphzug im weiten Mycene bestreiten“" 49 .

Die verschiedenen Gesichtspunkte, unter denen der tote Priamus glücklichgepriesen wird, sind ausschließlich Negationen von Bedingungen, durch welche die trojanischen Frauen nach der Einnahme Trojas in ihrer Gefangenschaft betroffen sind ${ }^{50}$ : S i e müssen die Unterjochung erdulden, si e müssen die griechischen Feldherrn ertragen, und si e werden bei griechischen Triumphfeierlichkeiten als Kriegsgefangene vorgeführt werden. Wenn der Tod des Priamus als etwas Glückliches angesehen wird, so nur deshalb, weil er in diesem Zustand des Todseins frei ist von all den Leiden, die die trojanischen Frauen ertragen müssen: Der Tod des Königs wird also letztlich nicht um seiner selbst willen gepriesen, sondern nur deshalb, weil in diesen Zustand das Nicht-Vorhandensein der augenblicklichen Leiden der Trojanerinnen hineinprojiziert wird.

Diese Ansicht der Hecuba wird vom Chor aufgegriffen und nur geringfügig modifiziert $^{51}$ : Der Chor preist Priamus selig, weil er seine Königsherrschaft zugleich

\footnotetext{
46 Sen. Tro. $1 \mathrm{ff}$.

47 Sen. Tro. 263 ff. Zur Bewertung von Agamemnons Haltung vgl. oben S. 22 und im folgenden S. $45 \mathrm{f}$.

48 Verfehlt ist jedoch der Versuch von Owen 1970 a, in diesem Chorlied die in der klassischen griechischen Tragödie übliche Form von Strophe und Antistrophe herzustellen, vgl. Zwierlein 1984, 197 Anm. 139.

49 Sen. Tro. 145-155.

$50 \mathrm{Vgl}$. Wilson 50: „the freedom she [Hecuba] extols consists of no more than the absence of life, life which in the case of a defeated and captured king would mean humiliation and disgrace“. Gerade diesen Faktoren sind Hecuba und der Chor aber ausgesetzt.

51 Vgl. Bishop 1964 b, 325: „Hecuba ... at times acts as coryphaeus“; Lawall 1982, 248: „Here the
} 
mit seinem Leben beendete. Dahinter steckt letztlich dieselbe Auffassung vom Totsein des Priamus: Es ist deshalb glücklich, weil es unmittelbar auf das gewaltsame Ende seiner Königsherrschaft folgt und dem Priamus so jene schmerzhafte Erfahrung der Unterwerfung und Sklaverei ersparte, von der jetzt die Trojanerinnen betroffen sind. Dieselbe Haltung, welche hier Hecuba und der Chor im Wechselgesang bekunden, wird später von Andromache in einprägsamen Worten formuliert. Als die kleine Polyxena zur Opferung an Achills Grab abgeführt wird, betont ihre Mutter Hecuba, wie glücklich Cassandra und Andromache über ein solches Geschick wären, und Andromache erwidert bekräftigend: „W i r, Hecuba, w i r, w i r, Hecuba, müssen betrauert werden, die wir von der griechischen Flotte bald hier- und dorthin verstreut werden: Polyxena wird dann ihr geliebtes Land in heimatlicher Erde bergen ${ }^{52}$ “"

Wenn man hinter dem im Wechselgesang zwischen Hecuba und dem Chor geäußerten Makarismos des Priamus diese idealisierende Auffassung vom Tod als Freisein vom gegenwärtigen Leiden erkennt, versteht man das zweite Chorlied der Troerinnen, welches das in seiner Deutung bei weitem umstrittenste und in der Forschungsliteratur am intensivsten behandelte darstellt, viel besser. In der bisherigen Forschung hat man keine rechte Lösung gefunden, wie man die sich hier bekundende scheinbar unpersönliche philosophische Abhandlung über den Tod als absolutes Ende der Seele verstehen kann, zumal sie Widersprüche enthält, sowohl zum ersten Chorlied, wo Priamus im Elysium gesehen wird, als auch zur dramatischen Handlung, in der die Erscheinungen von Toten enorme faktische Wirkung haben: Einerseits fordert der Schatten des Achill erfolgreich die Opferung der Polyxena, und andererseits wird die Andromache-Astyanax-Handlung im dritten Akt durch eine Traumerscheinung des toten Hector in Gang gebracht. Gerade im dramatischen Verlauf der Troerinnen wirken also Totenschatten nachhaltig. Wie kann dann aber der Chor im Widerspruch hierzu jedes Weiterleben der menschlichen Seele nach dem Tod leugnen, und dies noch dazu in einer dramatischen Situation (nach dem zweiten Akt), wo ein persönliches Anteilnehmen am gerade durch die Calchas-Prophezeiung unumstößlich gewordenen Geschick der Polyxena und des Astyanax viel passender erschiene als jener philosophische Traktat über die Sterblichkeit der Seele?

Die Lösung liegt einfach in der Fixierung dieses Chors auf die Bewältigung des eigenen Leidens. Wie in den zuvor abgehandelten fünf Seneca-Tragödien die Reflexionen des Chors oftmals am vorigen Chorlied ansetzen und die im dazwischen liegenden Akt vollzogene dramatische Entwicklung nicht oder nur oberflächlich berücksichtigen, so hat hier der leidende Chor offenbar überhaupt nicht am Geschehen des zweiten Akts Anteil genommen oder es nur vage als periphere Vergrößerung des eigenen Leids empfunden ${ }^{53}$. Er hat am Ende des ersten Chorlieds den Tod des Pria-

chorus is little more than an extension of Hecuba's own overwhelming grief". Die enge Entsprechung zwischen den Empfindungen der Hecuba und denen des Chors beruht natürlich auf der Gleichheit der äußeren Lage: Hecuba ist ja am Anfang der Troerinnen (bevor es zu den Verwicklungen um Polyxena und Astyanax kommt) abgesehen von ihrem Status als ehemalige Königin zunächst eine Kriegsgefangene unter vielen.

52 Sen. Tro. 969-971. Zum Motiv vgl. Eur. Tro. 271 (angedeutet von Talthybios) und 630 f. $636 \mathrm{ff}$. (ausgeführt von Andromache); ferner Eur. Hek. 346 ff.

53 Wilson 32 sucht die Reflexion des Chors als Reaktion auf das Geschehen im vorigen Akt zu deuten: ,their own comforting vision of life after death turns into a startling new source of danger and fear when Talthybius walks in and announces that the hated Achilles has returned from the Underworld, as a ghost, to renew the round of atrocities against Troy“. Doch ist die Reaktion, den Auftritt von Achills Totenschatten in der Oberwelt als eine Gefährdung eines glücklichen elysischen Daseins in der Unter- 
mus als Projektionshintergrund für seinen eigenen Wunsch nach Beendigung der augenblicklichen Leiden genommen. Jetzt wird diese Vorstellung von einem schmerzfreien Todeszustand weitergeführt auf einer mehr philosophischen Ebene: Wenn man den Tod als ein glückliches Nicht-Vorhandensein irdischer Leiden begreift, so gerät man natürlich schnell in unangenehmen Konflikt mit den herkömmlichen antiken Vorstellungen über die Unterwelt, wo ja in Anbetracht von Instanzen wie Totengericht und dem Höllenhund Cerberus eine Schmerzfreiheit durchaus nicht per se gegeben ist. Eben diesen Einwand stellt sich der Chor im zweiten Lied: „Was ist nun aber, wenn der Tod doch nicht die Freiheit von allem Leid bedeutet und gewissermaßen anstelle der irdischen Leiden nur andersartige, unterirdische eintreten?" Dieses angstvolle Bedenken kann der Chor jedoch entkräften mit Hilfe der epikureischen Lehrmeinung, daß der Tod nichts anderes ist als das endgültige Aushauchen der Seele.

$\mathrm{Da}$ das zweite Chorlied diesen Charakter einer psychologischen Selbstbeschwichtigung ${ }^{54}$ und nicht etwa den eines unbeteiligten philosophischen Traktats ${ }^{55}$ hat (der sich dann gegen die Tatsächlichkeit der Erscheinung von Achills Totenseele oder wogegen auch immer richten müßte), läßt sich am Text belegen: Denn die Reflexion beginnt mit den Worten: „Ist es wahr oder nur eine Geschichte, die furchtsame Menschen täuscht, daß die Seelen nach der Bestattung der Körper fortleben?56“. Die Vorstellung, daß eine Fortexistenz der Seele in der Unterwelt nach traditioneller antiker Auffassung stattfindet, hat also den Charakter einer Befürchtung, welche die Sehnsucht des Chors nach dem Tod als Ende aller Leiden in Frage stellen und ihm somit den letzten Ausweg, den Tod, verleiden könnte. Dieselbe bange Befürchtung wird auch wenige Verse später deutlich, wenn der Chor fragt: „Nützt (prodest) es etwa nicht, die Seele dem Tod zu übergeben, sondern bleibt es den unglücklichen Menschen (man könnte auch übersetzen: uns Unglücklichen), noch länger leben zu müssen? ${ }^{57 “}$. Dies ist alles andere als ein unbeteiligter philosophischer Traktat. Der Chor sieht seine Hoffnung, der Tod könne ihm durch Befreiung von allem Leiden „nützen“, plötzlich gefährdet und sucht diesen selbstgestellten Einwand durch eine philosophische Argumentation zu entkräften ${ }^{58}$. Daß er sich dabei um das faktische

welt aufzufassen und stattdessen - in offenkundigem Widerspruch zur Existenz von Achills Totenschatten - ein völliges Nicht-Existieren nach dem Tod anzunehmen, alles andere als leicht nachzuvollziehen. Zudem sagt der Chor am Anfang seiner Ausführungen nichts in diese Richtung Deutendes; im Gegenteil fühlt er sich einfach durch die Vorstellung eines Leben-Müssens (372. 377) nach dem Tod (wobei „Leben“ offenkundig — in Anbetracht der Erfahrungen der Trojanerinnen verständlich — mit „Leiden“ gleichgesetzt wird) in seiner idealisierenden Vorstellung vom Tod als Freisein von Leiden schmerzhaft affiziert.

54 Richtig erkannt von Haywood 415: „The females of the chorus speak with the voice of exquisite lyric despair, trying to assure themselves that they may at least hope for nothingness after death".

55 Vgl. Lawall 1982, 248: „The ode is so private, abstract and self-contained that it can be lifted out of the play and allowed to stand by itself as a poem in its own right“. Ähnlich Pratt 109: „The dramatic format is ruptured to make room for interpretation that Seneca considers essential to the philosophical purposes of his drama“.

56 Sen. Tro. $371 \mathrm{f}$.

57 Sen. Tro. $376 \mathrm{f}$.

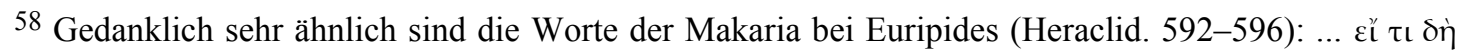

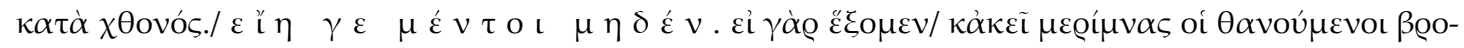

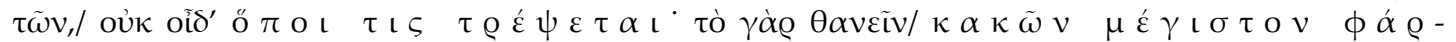
$\mu \alpha \kappa$ o $v$ vo $\mu i \zeta \varepsilon \tau \alpha$. Entsprechend dem zweiten Chorlied der senecanischen Troerinnen veranlaßt die Vorstellung vom Tod als einem „Heilmittel“ gegen Leiden die Sprecherin dazu, ein „Nein“ als Antwort auf die Frage der Fortexistenz nach dem Tod herbeizusehnen. 
Wirken von Totenschatten in der dramatischen Handlung ebensowenig kümmert wie um die Konsistenz mit der früher geäußerten Auffassung, Priamus sei im Elysium, kann nicht überraschen: Beide Vorstellungen (einerseits „Priamus im Elysium“, andererseits „,er Tod als Ende der Seele“) haben letztlich für den Chor keinen Eigenwert, sondern sind nur verschiedene Projektionsflächen für den entscheidenden Gedanken „Tod als Freisein von gegenwärtigen Leiden“59.

In ähnliche Richtung geht die Interpretation von Kugelmeier 2001. Kugelmeier sieht in den verschiedenen philosophischen Konzepten, die sich im ersten und im zweiten Chorlied bekunden, keinen Widerspruch, sondern eine Alternative (,der Todeszustand ist entweder etwas Angenehmes oder eine Nicht-Existenz") und belegt den konsolatorischen Gebrauch dieser Disjunktion bei Seneca und bei anderen Autoren (a.a.O. 35 f.). Die verschiedene Stoßrichtung beider Chorlieder differenziert er hinsichtlich der „Zielgruppe“: Im ersten Chorlied lege der Gedanke an die Verstorbenen Priamus und Hector die Vorstellung eines Elysiums nahe, dagegen werde im zweiten Chorlied „der Blick nach innen gerichtet, auf die persönliche Existenz und ihre Begrenztheit“ (a.a.O. 44). Demgegenüber wird hier entsprechend der oben ausgeführten Interpretation der Chorrolle in den Troerinnen angenommen,

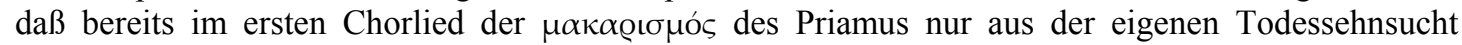
Hecubas und des Chors zu verstehen ist, daß also bereits hier letztlich „der Blick nach innen gerichtet“ ist. Wieder etwas anders sieht Marino den Grund der Diskrepanz zwischen den Vorstellungen „Fortleben im Elysium“ und „Nicht-Sein nach dem Tod“ begründet in der Spannung zwischen intuitiv-glaubenshafter und rational-philosophischer Weltbetrachtung (a.a.O. 72 f. „le due linee, quella filosofica e quella fideistica").

Die übrigen verschiedenen Positionen der neueren Forschung finden sich bei Kugelmeier 2001; eine ältere Doxographie bietet Schetter, besonders im Zusatz „Die Funktion des zweiten Chorliedes in Senecas Troerinnen (371-408)“, WdF 267-271. Der jüngste Kommentator der Troerinnen, Keulen 268-270, wird durch die Kontroverse um Sinn und Funktion des zweiten Chorlieds zu der desperaten Schlußfolgerung getrieben, diese Ode werde von einem Chor griechischer Soldaten gesungen. Der letztliche Grund für die Schwierigkeiten in der Deutung des zweiten Chorlieds liegt wohl darin, daß man immer zunächst nach der Gestaltungsabsicht Senecas und nicht nach dem Sinn der Äußerungen im Munde des Chors, d.h. der leidenden Trojanerinnen, fragt. Angelegt ist diese Betrachtungsweise schon bei Regenbogen Kl. Schr. 445: „Da ist mehr als ästhetisch-anempfindlerisches Spiel. Auch die Stelle im Stück wird ihre Wirkung darauf haben, ob der theoretisch-prinzipielle oder mythisch-anschauliche Ausdruck der Stimmung gewählt wird. Das ist dann also eine wesentlich kompositionelle Rücksicht, die doch auch ihrerseits mehr als ein Äußerliches ist und den Kontrast oder die Affinität der Erschütterung bezeigt. So ist es schwerlich Zufall, daß gerade vor der Szene Andromache-Odysseus (Tro. $371 \mathrm{ff}$.) der Chor das Thema anschlägt: Was ist der Tod? gibt es nach ihm ein anderes Leben? ... Das Gefühl der Nichtigkeit und Vergängnis schärft die Tragik der folgenden großen Szene, indem sie stimmungsmäßig Abstand nimmt von den Hoffnungen, die den Übertritt des Astyanax geleiten: $i$, vade liber, liberos Troas vide.- [791]“. Die Überbetonung dieses kompositionellen Aspekts scheint dagegen überwunden in der japanischen Arbeit von Takahashi, die ich nur durch die englische Zusammenfassung in APh 70, 1999, 459 kenne. Die Ausgangsthese „This view of death [Nicht-Existenz nach dem Tod] is inconsistent with the mood of the chorus in the rest of the play“ " wird durch die oben angestellten Überlegungen widerlegt. Wieder anders versteht Meier 241 die Reflexion des zweiten Chorlieds in autobiographistischer Interpretation als Senecas eigene Lebenserfahrung: „Das Leben war für Seneca eine ständige Bedrohung“. Dagegen glaubt Bishop 1964 b, 331 f. und 340, der Chor spreche im zweiten Lied vom kollektiven Schicksal der Stadt Troja: „Troy is dead and cannot exist again, either here and now or later, or in the hereafter. They [the chorus] are what is left of living Troy, its body - corpus - being the aggregate material life of the city, its soul — anima - being the idea of Troy, the idea that they are Trojans, its total life being the conjunction and interaction of the things and of the minds" (331 f.).

\footnotetext{
${ }^{59}$ Der Gedanke findet sich schon im euripideischen Vorbild, und zwar in den Worten der Hekabe (606

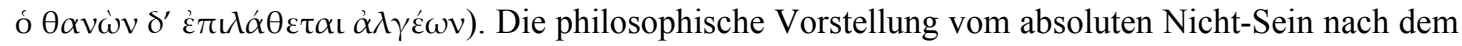

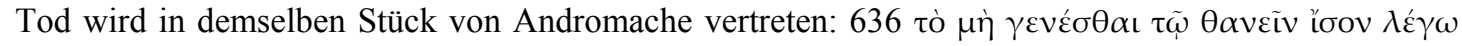
(vgl. 641 f.) $\sim$ Sen. Tro. 407 f. Im euripideischen Zusammenhang dient diese Vorstellung dem Beweisgang, daß die umgekommene Polyxena glücklicher ist als die lebende Andromache (630 f.). Vgl. oben Anm. 52.
} 
Mit der hier gegebenen Deutung verschwindet auch der gelegentlich in der Forschung ${ }^{60}$ monierte Widerspruch zwischen dem philosophischen Chorlied und der unmittelbaren Reaktion der Andromache: „Was zerreißt ihr eure Haare, traurige Phrygierinnenschar, schlagt eure unglückliche Brust und benetzt eure Wangen mit ausströmenden Tränen?" 61 . Andromache faßt den Charakter des Chorlieds völlig richtig und im Sinne des Autors auf: Das Raisonnement über das Wesen des Todseins ist kein unpersönlicher Traktat, sondern eine - freilich philosophisch sublimierte - Trauerhandlung des Chors, eine Selbstbeschwichtigung, die dem Zweck dient, mit dem eigenen Leiden fertig zu werden. Besonders die bangen Fragen am Anfang des Lieds, ob der Tod vielleicht doch nicht die ersehnte Befreiung von allem Elend ist, kann man sich leicht als unter Tränen und Trauergesten gesprochen vorstellen.

Diese auf das eigene Leiden konzentrierte, man könnte fast sagen: autistische Betrachtungsweise zeigt sich auch in den beiden weiteren Chorliedern: Das dritte stellt die Frage nach den zukünftigen griechischen Aufenthaltsorten der Gefangenen $^{62}$, und das vierte befaßt sich mit dem trauer-psychologischen Phänomen, daß „geteiltes Leid halbes Leid ist“", also jeglicher Kummer leichter ertragen wird, wenn die trauernde Person nur von anderen ebenfalls Leidenden umgeben ist ${ }^{63}$. Selbst dieser Vorzug wird den trojanischen Frauen geraubt ${ }^{64}$, indem sie jede einzelne „hierhin und dorthin" ${ }^{65} \mathrm{zu}$ ihren neuen Herrn verschlagen werden, wie im zweiten Teil des letzten Chorlieds ausgeführt wird; damit wird zugleich auch an die geographische Entfaltung des Trennungsgedankens im dritten Chorlied angeknüpft. Der Chor wird also des letzten irdischen Trostmittels, des gemeinsamen Trauerns, beraubt und sieht als Kollektiv seine Auflösung unmittelbar bevorstehen.

Zusammenfassend kann man als durchgehendes Charakteristikum des Chors der Troerinnen eine völlige Fixierung auf das eigene Leiden und dessen Bewältigung festhalten. Diese Tendenz zeigt sich in sämtlichen Chorliedern: Zwar wird im Wechselgesang des ersten Chorlieds zumindest äußerlich Hectors und seines Vaters

$60 \mathrm{Vgl}$. z. B. Owen 1970 b, 122: „Andromache enters upbraiding the chorus for their unrestrained breast-beating and hair-tearing. But the tone and content of Ode II show no indication of choral self-flagellation which would justify Andromache's description“.

61 Sen. Tro. 409-411.

62 Vgl. Eur. Hek. 444 ff. und Tro. 187 ff. In den euripideischen 'Troerinnen' haben die Gefangenen immerhin „Lieblingsorte“ in Griechenland, die sie sich als zukünftigen Aufenthalt wünschen (207 ff.). In der senecanischen Version gibt es keine positiven Wünsche der Gefangenen; diese hoffen nur, daß ihnen die Heimatorte der griechischen Kommandanten (Sparta und Ithaka) erspart bleiben (Sen. Tro. $851 \mathrm{ff}$.).

63 Nicht überzeugend ist die Deutung von Wilson 53 f., der hinter der Herausstellung dieses psychologischen Phänomens Hecubas Verwünschung der griechischen Flotte (1005 ff.) wirksam sieht, die am Leid der Trojanerinnen Anteil haben solle. Daß sich die abschließenden Exempla (1026 ff.) sämtlich auf den Bereich „Schiffahrt und Ertrinken“ beziehen, mag man als subtilen auktorialen Verweis auf den (im Botenbericht des Agamemnon dargestellten) Schiffbruch der Trojasieger auffassen; doch ist die allgemeine Schilderung des psychologischen Phänomens (1009 ff.) sicherlich nur von der eigenen Person des Chors her zu verstehen, und etwa das Exemplum von Reichtum und Armut (1019 ff.) läßt sich in keinerlei sinnvollen Bezug zum Untergang der griechischen Flotte setzen. Das Phänomen der Erleichterung von Trauer durch kollektives Beisammensein mehrerer leidender Personen wird auch von Helena herangezogen, um die Situation der trojanischen Frauen von ihrer eigenen abzusetzen (913 f. vos levat tantus mali/ Comitatus: in me victor et victus furit).

64 Vgl. Motto / Clark 1987, 102: „,The group's talk of being at least cohesive in suffering is so heartily argued because its members are about to be scattered.“

65 Sen. Tro. 1043. 
Priamus gedacht, doch war, wie oben gezeigt, bereits die Seligpreisung des Priamus eigentlich eine negative Projektion des eigenen Leidens; übrigens wird auch Hector weniger als Person denn als Beschützer Trojas beweint, mit dessen Tod das Schicksal Trojas - und damit auch der trojanischen Frauen - letztlich besiegelt war. Im dritten Chorlied wird am Schluß noch kurz die Frage hinterhergeschoben, welchen Herrn denn wohl Hecuba erlosen werde. Doch auf die eigentliche dramatische Handlung des Stücks, den grausamen Tod der Polyxena und des Astyanax, geht der Chor mit keinem Wort ein, und dieses Thema spielt auch in seinen Reflexionen keinerlei erkennbare Rolle ${ }^{66}$.

Also darf man zwei verschiedene Ausformungen der Chorrolle in den senecanischen Tragödien scharf unterscheiden: einerseits einen kontemplativ-reflektierenden Chor im Hercules, in der Medea, in der Phaedra, im Oedipus und im Thyestes und andererseits einen in seinem eigenen Leiden absorbierten Chor in den Troerinnen.

\section{Exkurs: Die Möglichkeit eines bescheidenen Exulanten- daseins im Phoenissenfragment und der Chor in den un- echten Tragödien des Seneca-Corpus}

Die $\mathrm{P}$ h o e $\mathrm{n}$ i s s e $\mathrm{n}$ sind als Fragment ohne Chor erhalten; Spekulationen über die möglicherweise von Seneca geplante äußerliche Gestaltung der Chorpartien bietet Frank 8-10. Ein denkbarer inhaltlicher Ansatzpunkt für eine Chor-Reflexion in herkömmlicher senecanischer Ausprägung (Lob der Mittelmäßigkeit) findet sich in den Worten des Polynices in 591-595. Dort wird rhetorisch der Fall gesetzt, daß Polynices der Aufforderung seiner Mutter Iocasta, vom Kampf um Theben abzulassen, nachkäme: Dann müßte sie ihm wenigstens eine bescheidene Existenz in einer kleinen Hütte ermöglichen können ${ }^{67}$. Tatsächlich aber würde Polynices als „Geschenk“ für seine wohlhabende Gattin Argia (595 f.) und als lixa seines mächtigen Schwiegervaters Adrast (597) leben. Wenn man diese Worte ernstnimmt, folgt daraus, daß Polynices eine mögliche bescheidene Exulanten-Existenz (wie sie etwa Thyest in seinen philosophischen Reflexionen vorschwebt) durch seinen Eintritt in die Königsfamilie des Adrastus verstellt wurde. Insofern könnte ein Chor, den Seneca seinem Stück noch hätte einverleiben müssen, mit Recht die Mittelmäßigkeit seines eigenen Daseins loben: Polynices wäre die Möglichkeit einer solchen Existenz nicht nur durch seine Herkunft aus dem thebanischen Königshaus, sondern auch durch sein Einheiraten in das argivische versperrt, und insofern gehörte auch er zu denjenigen, welche durch ihre äußere Position in unschuldhafter Weise die Sphäre der Mittelmäßigkeit überschritten haben.

Eine ähnliche Andeutung eines alternativen Handlungsverlaufs — mit Verzicht auf die Königsherrschaft — findet sich auch in der Prologrede des Oedipus: Kaum war Oedipus dem Königshaus des Polybus glücklich entflohen (12) und hätte ein gefahrloses Leben als exul vor sich gehabt (13), da geriet er durch seine Bezwingung der Sphinx in eine andere Königsherrschaft, nämlich die thebanische (in regnum incidi 14). Oedipus weiß zu diesem dramatischem Zeitpunkt noch nicht, wie wahr seine Überlegung ist: Wäre er ein bescheidener Exulant geblieben und hätte er auf die thebanische Königsherrschaft verzichtet, so wäre ihm zumindest die inzestuöse Ehe mit seiner Mutter erspart geblieben, und die Tötung seines Vaters wäre wohl niemals aufgeklärt worden. Die Verknüpfung von Oedipus' tragischem Unglück mit seiner Stellung als Herrscher von Theben wird aufgegriffen im dritten Akt in der Auseinandersetzung mit Creon. Daß der Vorwurf, Creon habe die Nekyomantie zusammen mit Tiresias fingiert, völlig in die Irre geht, weiß jeder Rezipient des Stückes von Anfang an — dies geht einerseits aus dem bekannten Ablauf des mythischen Geschehens, andererseits aus dem literarischen Hintergrund der Auseinandersetzung (Soph. Oid. 513 ff.) zwingend hervor. Damit ist es von Anfang an wahrscheinlich, daß der Verteidigung Creons gegen den Vorwurf

\footnotetext{
66 Richtig Gil 179: „Ihr [der Troerinnen] Los ist für sie das Vordergründige trotz des Grauens der unmittelbaren Verhaftung des Astyanax“.

67 Die Diktion mit den Ausdrücken parva ... casa (593) und exiguo lare (594) erinnert an die Chorreflexionen in Herc. 197 f. und Phaedr. 1127; vgl. auch Thyest. 451.
} 
ein hohes Maß an Wahrheitsgehalt zukommt. Der senecanische Creon geht nun aber über die Argumente seines sophokleischen Vorgängers hinaus, insofern er nicht nur die Vorteile in seiner eigenen bisherigen Position ausführt (Quasi-Herrscher ohne die belastenden Gesichtspunkte faktischer Herrschaft, Sen. 687 ff. Soph. 584 ff.), sondern es auch als für Oedipus wünschenswert herausstellt, die Herrschaft niederzulegen (675-677 liceat hoc tuto tibi/ Exuere pondus nec recedentem opprimat:/ Iam te minore tutior pones loco). Als Oedipus hierauf mit Empörung reagiert (678 f.), betont Creon, sein Rat gelte nur für solche Personen, die sich noch frei zwischen Herrschen und Nicht-Herrschen entscheiden können (679 f.); Oedipus habe diese Wahl nicht mehr (681 Tibi iam necesse est ferre fortunam tuam). Aus diesen (von Seneca seinem sophokleischen Vorbild hinzugesetzten) Worten ergibt sich für einen den Gesamtablauf des Mythos überblickenden Rezipienten zweierlei:

1. der bereits von Oedipus selbst im Prolog angedeutete Gedanke, daß die thebanische Königsherrschaft für ihn ein Unglück bedeutet: Ohne sie hätte Oedipus wenn auch nicht den Vatermord, so doch wenigstens den Inzest vermieden, und vor allem müßte er jetzt nicht durch eigene Ermittlungen seinen Untergang selbsttätig herbeiführen.

2. die Erkenntnis, daß Oedipus seinem Geschick jetzt nicht mehr entgehen kann: Er steckt viel zu tief in seinen Nachforschungen, als daß er nach Creons Empfehlung jetzt einfach die Herrschaft ablegen und alles weitere einem anderen überlassen könnte — damit ist sein durch seine eigenen Nachforschungen angesteuertes Schicksal besiegelt.

Im Oedipus wird wie im Thyest (s.o.) und in den Phoenissen eine Möglichkeit angedeutet, wie eine Person ihrem Verhängnis hätte entkommen können, nämlich durch eine bescheidene Exulanten-Existenz: Oedipus hätte seine Mutter nicht geheiratet, Polynices hätte nicht mit argivischer Hilfe einen Bruderkrieg geführt, und Thyest hätte seine Söhne nicht der Intrige des Atreus ausgeliefert. Indem diese Figuren faktisch nicht den Weg der bescheidenen Mittelmäßigkeit wählen, handeln sie zwar subjektiv in keiner Weise schuldhaft: Oedipus tut nichts Verwerfliches, indem er als Belohnung für seine Bezwingung der Sphinx die thebanische Königsherrschaft annimmt (Oed. 104 f.) — und damit auch die Ehe mit Iocasta — , ebensowenig Polynices, wenn er sich mit Argia vermählt und mit Unterstützung seines Schwiegervaters Adrastus die ihm zustehende Herrschaft einfordert; Thyest schließlich verstößt bei seiner Einwilligung, an der argivischen Herrschaft teilzuhaben, gegen seine eigenen (stoischen) Prinzipien in keiner Weise (s.o. S. 20 ff.), und nicht einmal stoischer Rigorismus verbietet, eine angebotene Herrschaft anzunehmen, wie Thyests Sohn Tantalus hervorhebt (471). Keine dieser Personen handelt also persönlich schuldhaft, und doch hätte sich jede durch einen konsequenten Verzicht auf die Rückkehr in eine exponierte Stellung faktisch vor schlimmem Unglück schützen können. Die von diesen Personen erstrebte oder akzeptierte Größe bedeutet keinen Charakterfehler, wohl aber eine faktische Voraussetzung ihres schließlichen Sturzes.

Die unechten St ücke im Corpus der Seneca-Tragödie n haben — wie der im Folgenden zu behandelnde Agamemnon — je zwei Chöre, von denen jeweils der Hauptchor im Prinzip die reflexiv-analytische Grundhaltung einnimmt, wie sie als typisch für die echten Stücke (außer Troerinnen und Agamemnon) herausgearbeitet wurde. Allerdings unterscheidet sich der Hauptchor von dieser Grundhaltung in beiden Fällen durch eine besondere persönliche Beziehung zu einer Hauptfigur.

Das erste Chorlied des $\mathrm{Her} \mathrm{c} \mathrm{u} \mathrm{l}$ e s $\mathrm{O}$ e t a e u s wird von einem Nebenchor gefangener Frauen aus Oechalia gesungen. Dessen Haltung entspricht bis in Details dem leidenden Chor der Troerinnen: Glücklich ist der, dessen Leben zugleich mit seinem Glück endet (104 ff. — wie Priamus in den Troerinnen). Wer tot ist, braucht das Unglück der gefangenen Frauen nicht mehr zu ertragen (107 ff. - mit einer ähnlichen Negationsanapher wie im ersten Chorgesang der Troerinnen). Der Chor reflektiert über mögliche künftige Aufenthaltsorte der versklavten Frauen (135 ff.) — wie im dritten Chorlied der Troerinnen. Formal endet das erste Chorlied in einem Wechselgesang zwischen Iole und dem Chor, was wiederum seine Entsprechung im ersten Chorgesang der Troerinnen hat. Motivisch neu gegenüber den Troerinnen ist eigentlich nur eine ausführliche Schmähung der Unerbittlichkeit des Hercules (147 ff.).

Die übrigen drei Chorlieder werden von einem Deinanira nahestehenden Chor calydonischer Frauen gesungen gemäß dem Vorbild der sophokleischen Trachinierinnen. Aus dieser engen Verbundenheit resultiert auch der wesentliche Unterschied gegenüber der senecanischen Standard-Ausprägung des reflektierend-distanzierten Chors: Die Frauen sind die Gespielinnen der Deianira und mit ihr durch Jugenderinnerungen aus der Zeit am Achelous-Strom (der zugleich als Flußgott Deianiras Vater ist) eng verbunden (586 ff.). Eine solch praezise personale Identifikation des Chors findet sich in keiner echten Seneca-Tragödie, ebensowenig eine derartig enge Verbundenheit mit einer Hauptperson. Dementsprechend bekommt der topische Gedanke vom Unglück der Mächtigen eine spezifische Ausprägung: Dieses Unglück besteht darin, daß die Mächtigen keine wirklich verläßlichen Freunde 
haben; die Menschen verehren sie ausschließlich aus egoistischen Beweggründen (604 ff.). Solchen unlauteren Motiven steht entgegen die rara fides (602), welche der Chor aufweist, wie er ausdrücklich bekundet (vorbereitet wird das Motiv schon durch die Anrede Deianiras an Lichas, 569 f. O quod superbae non habent umquam domus, / Fidele semper regibus nomen Licha). Der Chor sieht sich also selbst als Pendant zum allgemeinen Mißstand mangelnder Loyalität mit ins Unglück geratenden Mächtigen. Im weiteren Verlauf des Lieds tritt dieser Aspekt jedoch zurück, und der Topos vom Unglück der Mächtigen und das Ideal vom mittelmäßigen Leben wird in herkömmlicher Weise entwickelt (648 ff.).

Die sich hier bekundende Gesamthaltung des calydonischen Chor ist eine eigentümliche Mischung zwischen typisch senecanischer Distanziertheit im Sinne mittelmäßiger, von den Mächtigen abgewandter Existenz (am Ende des Lieds) und an die griechische Tragödie erinnernder enger, persönlich motivierter Bindung an Deianira (am Anfang).

Die beiden letzten Chorlieder sind motivisch deutlich von bestimmten Vorbildern im senecanischen Hercules geprägt: Im dritten Chorlied (1031 ff.) wird der Unterweltsgang des Orpheus ausführlich beschrieben und am Ende der Erzählung eine knappe Verbindung zu Hercules hergestellt. Dieses Verfahren greift auf das zweite Chorlied des Hercules (569 ff.) zurück; allerdings ist das Tertium comparationis diesmal nicht der Erfolg des Hadesgangs, sondern die Lehre von der allgemeinen Vergänglichkeit, welche der vom erneuten Verlust der Eurydice enttäuschte Orpheus in einem Gesang äußert und welche nach Ansicht des Chors durch den Untergang des Hercules verifiziert wird; aus der Orpheus-Geschichte wird diesmal nicht eine günstige, sondern eine unglückliche Moral für Hercules abgeleitet (allerdings über den Umweg eines orphischen Gesangs). Die abschließende Reflexion über einen Weltuntergang (1102 ff.) erinnert dagegen an das letzte Lied des Thyest.

Das letzte Lied im Hercules Oetaeus, welches sich hauptsächlich mit dem Fortleben des Hercules in der Unterwelt oder am Sternenhimmel beschäftigt, ist zumindest in seinem Ansatzpunkt vom letzten Chorlied des senecanischen Hercules beeinflußt: Der als Titan angesprochene Sonnengott soll die Kunde von Hercules' Tod in der ganzen Welt verbreiten (1518 ff.), ähnlich wie in dem senecanischen Stück derselbe Sonnengott zur Teilnahme an der kosmischen Trauer um das Unglück des in Wahnsinn versetzten Hercules gebeten wurde (1057 ff.).

In auffälligem Mißverhältnis zu der Standard-Position der echt-senecanischen Chöre steht der Abgesang des Chors im Herculeus Oetaeus (auch formal ohne Parallele in den echten Tragödien): In Anbetracht der Apotheose des Hercules werden die Menschen zur Tapferkeit ermuntert, die auch sie zu den Sternen führen könne: 1984 f. vivite fortes/ Nec Lethaeos saeva per amnes/Vos fata trahent. Dieser Protreptik ist die Warnung entgegenzustellen, die der echt-senecanische Chor der Medea in Anbetracht des Schicksals der Argonauten in der Form eines ironischen Imperativs an die fortes richtet (650 f.): Ite nunc, fortes, perarate pontum/ Fonte timendo. In der Medea führt die überdimensionale Größe in den Untergang, im Hercules Oetaeus zu den Göttern.

Der Hauptchor der O c t a v i a steht in dem HO entsprechender Weise innerlich auf der Seite der Titelheldin. Im ersten Chorlied (273 ff.) reagiert er mit deutlich spürbarem Widerwillen auf die Nachricht von der Vermählung zwischen Nero und Poppaea, welche eine Ausstoßung der Octavia aus ihrer Ehe bedeutet. Der Chor beklagt geradezu, daß er selbst nicht zugunsten Octavias tätig wird (288-290), und stellt der eigenen Passivität die durch einige Exempla beleuchtete altrömische virtus entgegen (291 ff.). Der Rest des Chorlieds ist der Ermordung der Agrippina durch Nero gewidmet (309 ff.).

Das zweite Chorlied beginnt mit einer Äußerung Octavias angesichts ihrer Verstoßung aus der Ehe (646 ff.): Sie fordert den Chor auf, von seinen Tränen um sie abzulassen, um nicht am Tag der feierlichen Hochzeit die Aufmerksamkeit Neros auf sich zu ziehen; in diesem Fall könnte Octavia (genauer gesagt: die Loyalität zu Octavia) für den Chor „ein Grund des Unglücks“ (650) sein. Damit wird die äußere Bedrohung als Motiv des Chors für die mangelnde Bekundung seiner Loyalität zu Octavia deutlich. In der Antwort des Chors heißt es dementsprechend: „Unsere Fürsorge und unser träger Schmerz zögert, durch schwere Furcht bedrückt“ (674 f.). Dieser Passivität wird wiederum die Tatkraft des altrömischen Volkes entgegengestellt (676 ff.); eine Schmähung der Poppaea schließt sich an.

Das dritte Chorlied (762 ff.) wird von einem aus Anhängerinnen der Poppaea bestehenden Nebenchor gesungen, der die übermenschliche Schönheit seiner Herrin preist. Das Motiv hat eine auffällige Parallele im zweiten Chorlied der Phaedra auf die Schönheit des Hippolytus; zugleich erinnert die Parteinahme zugunsten der neuen Braut an das erste Chorlied der Medea. Derselbe Nebenchor reagiert auf den Bericht eines Boten über die sich in einem Aufstand bekundende Sympathie des Volkes für Octavia mit einer Apostrophe an ebendieses Volk: Cupido (d.h. die Liebe Neros zu Poppaea) werde mit seinen Flammen dieses Kriegsfeuer löschen, und die Allmacht des 
Liebesgotts wird durch einige mythische Exempla belegt (806 ff.) wie im ersten Chorlied der Phaedra.

Das vierte Chorlied besteht aus einem Wechselgesang zwischen einem Octavia wohlgesonnenen Chor und Octavia selbst; unterdessen wird diese von den Schergen Neros fortgezerrt. Der Chor leitet sein obligatorisches Standard-Motiv (Lob der niedrigen Stellung, Bedrohtheit der Hochstehenden, 896 ff.) in diesem Fall aus der Wechselhaftigkeit der Gunst des Volks ab, das trotz seines vorigen Eintretens für Octavia jetzt ihre Festnahme mit ansieht; solche Wechselhaftigkeit wird durch mehrere Exempla aus der römischen Geschichte belegt ( $877 \mathrm{ff}$.). Wenn es sich hierbei um denselben Chor handelt, der die ersten beiden Lieder sang (und einen dritten Chor wird man nur ungern annehmen), so müßte diese Reflexion letztlich wieder auf die bereits dort beklagte Illoyalität des eigenen Verhaltens gehe, obwohl hier das Volk nicht mit dem Chor identifiziert wird: Zumindest eignet dem Octavia wohlgesonnenen Chor genau die Haltung des Volkes (183. 187. 572 f.), und das rebellierende Volk führt gemäß dem Botenbericht (794 ff.) genau die Handlungen aus, welche der Chor am Ende des zweiten Gesangs gegen die Bildnisse der Poppaea plante (685 ff.); insofern müßte das jetzt nicht mehr an seiner Octavia-freundlichen Handlungsweise festhaltende Volk (892 ff.) eigentlich auch mit dem Chor identisch sein.

Die hier gegebene Zuordnung der Chorpartien entspricht im wesentlichen den Ausführungen von Rebekka Junge 216-218. Junge versucht die Schwierigkeit, daß der Schlußchor in der dritten Person vom Volk redet, folgendermaßen zu erklären: „Daß dieser Chor hier nicht mehr in der 1. Person von sich spricht, ist am ehesten als Zeichen dafür zu deuten, daß der populus, dem nach dem Scheitern des Aufstandes jede Möglichkeit zu aktivem Handeln genommen ist, resigniert und im Bewußtsein der eigenen Machtlosigkeit sich auf allgemeine philosophische Topoi zurückzieht, in denen eine engere persönliche Beteiligung unpassend wäre“ (a.a.O. 217); Lammers 137 wollte die zu offenkundigen Inkonsequenzen führende Resignation des Chors dadurch erklären, daß dieser „wohl aus älteren Leuten besteht". Hier bleiben ersichtlich gewisse Schwierigkeiten zurück, die sogar die (von Junge auf Giancotti 228 zurückgeführte) Drei-Chöre-Theorie nicht völlig abwegig erscheinen lassen (umfassender Forschungsbericht: Gesine Manuwald 294 Anmm. 77 und 79). Erklären sich die Schwierigkeiten vielleicht dadurch, daß der Octavia-Dichter die Konzeption eines als prinzipiell handlungsfähiges Volk in das Geschehen eingreifenden Chors (Lieder I und II) und diejenige eines reflektierend-distanzierten Chors, wie er in den echten Seneca-Stücken immer wieder begegnet, (Lied IV) nicht zu einem überzeugenden Ausgleich miteinander brachte? Durchschlagend erscheint jedenfalls Junges Kritik gegen Peter L. Schmidt 1431 f., der die ersten beiden Lieder einem aktiven und die zweiten beiden einem ausschließlich reagierenden Chor zuweisen will. Fortgeführt wird Schmidts Auffassung neuerdings von Gesine Manuwald 292-296, die die ersten beiden Chorlieder einem aktiv an der politischen Handlung beteiligten „Praetextachor“ (a.a.O. 293) und die letzten beiden einem allgemein menschlich reflektierenden, aber nicht aktiv in die politische Handlung eingreifenden „Tragödienchor“ (a.a.O. 295) zuweist. Doch läßt sich die geradezu adulatorische Bewunderung von Poppaeas Schönheit (762 ff.) und die Auffassung vom Aufstand des Volkes als einem vergeblichen Aufbegehren gegen die Allmacht Amors (806 ff.) schwerlich derselben Personengruppe zuschreiben, die später Octavia - wenn auch in irreal-eskapistischem Wunschdenken - unversehrt wünscht (971 ff.) und das Nachlassen der Sympathie für Octavia als Beispiel für den Wankelmut des Volkes beklagt (877 ff.).

Zusammenfassend läßt sich über den Hauptchor der Octavia sagen, daß er einerseits zwar im letzten Chorlied die typische reflexiv-distanzierte Haltung einnimmt, andererseits aber — wie besonders die ersten beiden Lieder zeigen — politisch ohne Zweifel auf der Seite der Titelheldin steht; doch vermag er eingestandenermaßen unter dem äußeren Druck der Gewaltherrschaft Neros seine Sympathie für die Titelheldin nicht in Taten umzusetzen. Wie der Hauptchor im Hercules Oetaeus ist auch dieser Chor in einer Weise Partei, die den reflektierend-analytischen Chören des echten Seneca fremd zu sein pflegt. Seine Parteinahme wird indes durch die äußere Gewalt des Regimes verhindert; insofern kann man im Fall dieses unechten Stücks tatsächlich von einer Haltung des inneren Widerstands sprechen: Die Passivität ist von außen erzwungen.

\section{A ga m e m n on}

Das einzige bis jetzt ausgelassene echtheitskritisch unanfechtbare Stück Senecas, der A g a $\mathrm{m}$ e $\mathrm{m} \mathrm{n}$ o $\mathrm{n}$, bietet nun interessanterweise, wie bereits anfangs angedeutet, eine 
Mischform zwischen den beiden bisher herausgestellten Gestaltungsweisen (einerseits analytisch-reflektierender und andererseits in seinem Leiden absorbierter Chor ${ }^{68}$.

Der Agamemnon beginnt in exakter Entsprechung zum bereits besprochenen Thyest mit dem Prolog einer Vorfahrenseele, welche die Unterwelt verlassen hat und eine grauenvolle Atmosphäre am Ort des künftigen Verbrechens verbreitet: Der Schatten Thyests erscheint am argivischen Königspalast und freut sich auf ein neues Schreckensmahl — nämlich das, bei welchem der aus Troja heimgekehrte Griechenführer Agamemnon von seiner Ehefrau Clytemestra und ihrem Geliebten Aegisth ermordet werden soll. Der Chor (über dessen Identität sich nichts sagen läßt, außer daß es sich wohl um Argiver handelt) wendet sich gleich im ersten Lied einer ausführlichen Erörterung des Standardthemas „Gefährdung der Hochstehenden“ zu: Alles Hochragende ist bedroht, und wenn es nicht durch äußere Gewaltanwendung zerstört wird, so bricht es unter seinem bloßen Gewicht zusammen.

Die Interpretation von Lefèvre 1973, 66-74 betont das Element persönlicher Schuld, welches angeblich den Fall des Hochstehenden herbeiführt. In einer früheren Arbeit Lefèvres zur Phaedra aus dem Jahr 1969 wird die Nuance subjektiver Verschuldung noch weniger als semantisches Element der Chorlieder verstanden denn als etwas mit Notwendigkeit Darhinterstehendes (vgl. oben S. 12), a.a.O. 159 f. = 374: „Diese 'Kausalität' des menschlichen Handelns hat sich im 'Agamemnon', einem der letzten Stücke, so verdichtet, daß Seneca das Handeln des subjektiv voll verantwortlichen Menschen unter dem Wirken eines sich mit Notwendigkeit vollziehenden objektiven Prozesses sieht: sidunt i p s o pondere magna/ ceditque oneri Fortuna suo (88 f.)“. In der Arbeit von 1973 legt Lefèvre Wert auf den Mittelteil des Chorlieds (Agam. 77-89), konzediert aber im übrigen auch hier mehrfach, daß seine Deutung so nicht unmittelbar dem lateinischen Text zu entnehmen ist, a.a.O. 69: Seneca „,verkürzt“ meist seine Konzeption der Verschuldung des Mächtigen „im Sinne der poetischen Evidenz in der Form, daß er sagt, der Arme bekomme Fortunas Macht nicht so zu spüren wie der Mächtige“; a.a.O. 73: „Gerade darin liegt die schneidende Pointe der Verse Agam. 87 ff., daß sie so formuliert sind, als handele es sich um einen objektiven Vorgang, d.h.: die Konsequenz der subjektiven Verschuldung tritt mit objektiv anmutender Notwendigkeit ein“.

In Agam. 57-76 ist nicht von Verbrechen die Rede, sondern nur von den Gefahren, Sorgen und Nöten, welche die Hochstehenden bedrängen. Im folgenden Abschnitt tritt dann neben diese Bedrängnisse als ein neues Phänomen des Unglücks der Mächtigen das Verbrechen, wobei von scelus alternum (77) die Rede ist, also an äußere Prozesse gegenseitiger Aufschaukelung der Gewalt, vorzugsweise wohl zwischen verschiedenen Mitgliedern von Herrscherfamilien, gedacht ist, nicht aber an einseitige subjektive Schuldhaftigkeit des Herrschenden: scelus alternum betont eindeutig das Phänomenologische des äußeren Prozesses, nicht das Moment subjektiver Schuld. Sprachlich ist in den Versen 77-86 stets die Umschreibung des Begriffs „Verbrechen“ Subjekt, und das Herrscherhaus ist stets Objekt, wird also als die betroffene und nicht als die schuldige Instanz angesehen.

Im übrigen zeigt schon die nicht zu übersehende Beziehung 79-81 iura pudorque/ Et coniugii sacrata fides/ Fugiunt aulas $112 \mathrm{f}$. (Worte Clytemestras über ihre eigene Lage) Periere mores ius decus pietas fides/ Et qui redire cum perit nescit pudor, daß bei den im Chorlied erwähnten „Verbrechen“" primär an Clytemestra und nicht an Agamemnon selbst zu denken ist.

In den Versen 87-89 wird hervorgehoben, daß ein Sturz des Mächtigen aber sehr wohl auch ohne solche äußeren verbrecherischen Gewalttaten möglich ist - es handelt sich gewissermaßen um eine gedankliche Absicherung, die verdeutlicht, daß das Verbrechen im Herrscherhaus (selbst wenn

68 Die in der vorliegenden Arbeit entwickelte Typologie der senecanischen Chöre spielt in der speziell dem Phänomen ,senecanischer Chor“" gewidmeten Forschungsliteratur kaum eine Rolle. Sie wird aber angedeutet von Tarrant 1976 in seiner Vorbemerkung zum ersten Chorlied des Agamemnon (57-107, S. 181): „Given the function of the chorus just described [, not to offer sympathy ... but enlightenment"], it is not surprising that the ode on mutability is a hall-mark of Senecan tragedy. A distinct sub-group is made up of odes in which captive women lament the change of fortune which has caused their present misery: 589 ff. below, Tro. 67 ff., and HO 104 ff. In these choral songs general observations are combined with, and usually overshadowed by, personal expressions of grief. Agamemnon alone contains odes of both the generic and the personal type; structure thus reflects content, since the play is built around two related falls from fortune — Troy's and Agamemnon's." 
man es als subjektive Schuld des Herrschenden ansehen sollte, was die oben gegebene Deutung der Verse 77-86 unwahrscheinlich macht) letztlich nicht konstitutiv ist für den geradezu naturnotwendigen Sturz des Hochgestellten. In der Struktur des Chorlieds wird der Gedanke eines möglichen Sturzes durch verbrecherische Gewalttaten beidseitig ( $57 \mathrm{ff}$., $87 \mathrm{ff}$.) eingeschlossen durch das Theorem, daß alles Hochragende ohnehin (also auch ohne solche Gewalttaten) zu Fall kommen muß.

Der Gegensatz zu den äußeren verbrecherischen Gewalttaten ist der Sturz ,unter dem bloßen Gewicht“ (ipso pondere 88), nicht aber die innerliche Verschuldung, die Lefèvre 1973, 72 als zentral ansieht. Ähnlich wie Lefèvre argumentiert auch Boyle 204, wo Fortuna im ersten Chorlied angesehen wird als ,a quasi-moral force that punishes excess and the vices that attend power and wealth“; Pratt 112: „Chorus I gives the counterview that Fortune, if not controlled Stoic ally by the moderate $1 \mathrm{ife}$, brings exposure to insecurity and crime and an excess that destroys itself“, vgl. auch dens. 163. Im Anschluß an Lefèvre jetzt auch Blänsdorf 43, der im ersten Chorlied „die im Wesen des Menschen liegende moralische Entartung der Herrschenden durch Furcht und Verbrechen“ beschrieben sieht: „Selbst wenn Waffen und verbrecherische Listen, also das, was den Untergang in der zweiten Stufe des Gedankens auslöste, fehlen, muß das Hohe durch sein eigenes Wesen zu Fall kommen: sidunt ipso pondere magna/ ceditque oneri Fortuna suo“ (a.a.O. 43 f.). Aber ipso pondere heißt ja gerade nicht „durch sein eigenes Wesen“, sondern „durch sein bloßes Gewicht“, d.h. „nur durch den Umstand seines Groß-Seins“. Ähnlich wie Lefèvre und Blänsdorf auch Shelton 1983, 162 f., die den Sturz der Mächtigen auf deren fehlende Erkenntnis äußerer Güter als $\alpha \delta$ ı́ $\phi o \varrho \alpha$ zurückgeführt sieht. Sheltons Wiedergabe des entscheidenden Satzes lautet „even if treachery and strife do not destroy prosperous men, these men may sink under the weight of $\mathrm{th}$ e i $\mathrm{r}$ p r o s p e r i t y “ (a.a.O. 163), womit wiederum ein im lateinischen ipso pondere (,durch das bloße Gewicht“, d.h. „,durch den bloßen Umstand des Großseins“) nicht enthaltener Begriff eingeführt wird. Eine etwas andere Fehldeutung findet sich bei Fantham 128: „fortune's humiliation of e v e $n$ i n n o c e n t greatness (licet arma vacant, cessentque doli $87 \mathrm{f}$ )“. In Wirklichkeit beziehen sich arma und doli nicht auf das, was die Mächtigen schuldhaft tun, sondern auf das, dem sie ausgesetzt sind; dies zeigt auch impia quas (sc. arces) non/ Arma fa t i g a $n$ t? (78 f.): Die Gewaltverbrechen werden als Phänomen der ungünstigen Position der Herrschenden aufgefaßt. Vgl. hierzu Thyest. 451453 scelera non intrant casas,/ T u t u s que mensa capitur angusta scyphus;/ Venenum in auro bibitur, wo ebenfalls der Aspekt der G e fä h r d u ng der Hochstehenden durch Verbrechen im Mittelpunkt steht; gleiches gilt für HO 610-612 Et quom magnae patuere fores,/ Intrant fraudes cautique doli/ Ferrumque latens, wo der Fortgang eindeutig auf die Bedrohung der Hochstehenden (u.a. durch invidia) abzielt. Natürlich ist es legitim zu fragen, ob solche Verbrechen nicht auch oder sogar hauptsächlich durch die Mächtigen selbst verschuldet werden. Aber der Text berührt dieses Problem eben überhaupt nicht. Warum sollte in den Worten des Chors der entscheidende Punkt verschwiegen werden, der nach Lefèvres Deutung im ganzen Agamemnon zentral wäre?

Gegen Lefèvre vgl. Zwierlein 1970, 197 f. Anm. 1. Kritisch gegenüber einer moralisierenden Deutung des ersten Chorlieds im Agamemnon verhält sich auch Liebermann 226 f. Anm. 78, der den Schuldgedanken jedoch nicht eliminiert, sondern auf die „Lebenswahl“ zurückführt: Die subjektive Verantwortlichkeit ,liegt bereits bei der Lebenswahl. Da entscheidet sich eben falsch, wer sich für die Macht (oder den Reichtum) entscheidet“. Ob Agamemnon jemals in seinem Leben eine solche Entscheidungsmöglichkeit hatte, ist fraglich (in einigen senecanischen Stücken werden solche Entscheidungsmöglichkeiten angedeutet, vgl. oben den Exkurs „Die Möglichkeit eines bescheidenen Exulantendaseins in den Phoenissen“); jedenfalls findet sich keine Spur davon im senecanischen „Agamemnon“.

Stevens 203 will Ag. 87-89 ironisch verstehen: „The irony of these words is particularly acute because Thyestes has enumerated both the arma and the doli which will be present at the murder of Agamemnon: enses secures tela (45); and iam scelera prope sunt, iam dolus caedes cruor (47)“. Doch wird aus den vorausgehenden Versen Ag. 77-86 (vgl. besonders die Verallgemeinerung durch quas non in $77 \mathrm{f}$. und semper 84) deutlich, daß der gewaltsam durch arma und doli herbeigeführte Sturz die Regel ist und der Alternativfall eines Sturzes ipso pondere die Ausnahme bildet. Insofern kann von einer ironisch wirkenden Diskrepanz der Chorreflexion zur dramatischen Wirklichkeit keine Rede sein.

Am Schluß steht das obligatorische Bekenntnis zur Mittelmäßigkeit: „Maßvolle Dinge haben ein längeres Leben: Glücklich ist, wer, sich mit dem Lose der mittleren Schicht beruhigend, mit sicherem Wind an der Küste entlangstreift und, voller Furcht, 
sein Schiff der hohen See anzuvertrauen, am Land entlangfährt, ohne die Ruder weit zu entfernen. 69“6

Dieser Chor mit seiner typisch distanziert-reflektierenden Betrachtungsweise, die auf die erschreckende Erscheinung von Thyestes' Totenseele in keiner Weise reagiert und nur in allgemeinsten Tönen das bevorstehende Unheil anklingen läßt, entspricht genau der Haltung, die man als typisch für alle übrigen senecanischen Chöre, abgesehen von den Troerinnen, betrachten kann.

Das zweite Chorlied enthält einen sich an verschiedene Götter richtenden Festgesang in Anbetracht der bevorstehenden Rückkehr Agamemnons und schließt mit einer Bitte an Juppiter, gnädig auf seine Nachkommen (gemeint sind die argivischen Herrscher) zu blicken. Hier liegt also eine stärkere Einbindung in das dramatische Geschehen des Stücks vor.

Entscheidend ist für die hier angestellten Betrachtungen der Umstand, daß Seneca beim dritten Chorgesang einen zweiten Chor ${ }^{70}$ einführt, nämlich eine Gruppe zusammen mit der Seherin Cassandra vom griechischen Heer nach Argos geschaffter trojanischer Kriegsgefangener ${ }^{71}$. Die Verwendung zweier verschiedener Chöre in einer Tragödie hat Vorbilder bei Euripides. Zwierlein hat gezeigt, daß Seneca - ganz im Gegensatz zu dem griechischen Tragiker - nicht im geringsten bemüht ist, das Nebeneinander zweier Chöre bühnentechnisch zu organisieren ${ }^{72}$. Wichtig ist für unseren Zusammenhang die Ähnlichkeit dieses Chors mit dem Chor in den Troerinnen: Er begibt sich in ein teilweise in lyrischen Maßen gehaltenes Wechselgespräch mit Cassandra - vergleichbar dem Wechselgesang zwischen Chor und Hecuba in den Troerinnen.

Neben diese formale Gemeinsamkeit treten auffällige inhaltliche Parallelen. Das Lied beginnt mit einer tiefsinnigen Bemerkung über den sonderbaren Überlebenswillen, der die Menschen dazu bewegt, an ihrem Leben festzuhalten, obwohl doch eigentlich der Tod als sichere Zuflucht vor allen Leiden offensteht. Dies wird verdeutlicht durch eine metaphorische Sprechweise: Der Tod wird als ein "von ewiger Ruhe friedlicher Hafen“" (Portus aeterna placidus quiete ${ }^{73}$ ) bezeichnet.

„Diesen bewegt weder ein Schrecken $\mathrm{noch}$ ein Sturm der unbeherrschten Fortuna oder der Blitzschlag des zornigen Juppiter. Dieser tiefe Frieden fürchtet ke i n e Scharen von Bürgern oder drohenden Zorn von Kriegssiegern, $\mathrm{n} \mathrm{icht} \mathrm{Meere,} \mathrm{die} \mathrm{wahnsinnig} \mathrm{toben} \mathrm{von} \mathrm{rauhen} \mathrm{Winden,} \mathrm{n} \mathrm{i} \mathrm{cht}$ wilde Heerscharen oder eine staubige Wolke, die aufgewirbelt wird von barbarischen Reiterscharen, n i c h t Völker, die mitsamt einer ganzen Stadt zu Boden stürzen, während das feindliche Kriegsfeuer die Mauern verheert, und ungebändigten Krieg“74.

Offenkundig beschreiben die in einer negativen Aufzählung aneinanderge-

\footnotetext{
69 Sen. Agam. 102-107.

70 Vgl. die Abhandlung von Lammers (zu den Senecatragödien a.a.O. 130 ff.). Weitere Bibliographie zum Thema „Doppelchor“ bei Gesine Manuwald 295 f. Anm. 83.

71 Der Besonderheit dieses Chors kommt Marx 10 nahe: Er „mutet von allen Senecaliedern am 'griechischsten' an“; ,es ist eben ein Sonderchor: im Griechischen sind a $11 \mathrm{e}$ Chöre eigenartig charakterisiert, d.h. in besonderer Weise mit den Personen verbunden“. Gerade dies verbindet ihn aber mit dem Chor der Troerinnen.

72 Zwierlein 1966, 80-85. Der Versuch von Calder, das Bühnenspiel (im Rahmen einer privaten Aufführung) $\mathrm{zu}$ rekonstruieren, erfordert als Voraussetzung u.a. ,an extraordinary divergence from classical Greek practice“ und die Möglichkeit, daß „the Senecan chorus here and elsewhere exits and re-enters fare more often then a classical Greek chorus“" (a.a.O. 35).

73 Sen. Agam. 592.

74 Sen. Agam. 593-603.
} 
reihten Faktoren alles das, was die trojanischen Kriegsgefangenen zu erdulden hatten, und zwar in umgekehrter zeitlicher Reihenfolge: 1. die schmähliche Mißhandlung in der Stadt des Siegers, 2. die Überfahrt über das von einem Seesturm aufgewühlte Meer (die im Botenbericht des Eurybates im dritten Akt geschildert wird) und 3. die Verwüstung ihrer Heimatstadt Troja. Diese negative Aufzählung von Faktoren, die „der ruhige Hafen Tod“ nicht zu fürchten hat, entspricht genau der oben zitierten negativen Aufzählung in der ersten Chorpartie der Troerinnen, die all das umfaßte, was der bei der Zerstörung von Troja umgekommene Priamus nicht mehr erleben mußte. In beiden Fällen wird es von den Überlebenden als glückliches Merkmal des Todes gewertet, daß dieser Zustand unberührt ist von dem Leiden, welches die Überlebenden gerade erdulden müssen. Freilich dient die Summe dieser negativen Faktoren im Agamemnon nicht zur Glücklichpreisung einer speziellen Person wie in den Troerinnen (nämlich des Priamus), sondern charakterisiert eine abstrakt-metaphorische Vorstellung, nämlich den „stillen Hafen Tod“. In dieser philosophischen Abstraktheit kommt das besprochene Chorlied des Agamemnon dem zweiten Chorgesang der Troerinnen nahe ${ }^{75}$. Doch gilt es den Unterschied zu beachten, daß im Agamemnon der Todeszustand nur durch eine negative Aufzählung von belastenden Faktoren gekennzeichnet wird. Im übrigen wird er eben nur durch die Metapher des „ruhigen Hafens“ charakterisiert. Das Fehlen von leidvollen Erfahrungen wird weder auf die elysische Fortexistenz einer bestimmten Person - wie im ersten Chorlied der Troerinnen noch auf einen philosophisch bestimmten Todeszustand der Seele - wie im zweiten Lied desselben Stücks - projiziert. Der Chor im Agamemnon reflektiert nicht, was der Tod eigentlich ist, sondern charakterisiert ihn ausschließlich durch das Fehlen der gegenwärtigen Leiden. Dagegen bekundet der Chor der Troerinnen in etwas anderer Weise, aber doch mit gleicher Tendenz seine Gleichgültigkeit in bezug auf das Wesen des Todes gewissermaßen durch die Diskrepanz zwischen erstem und zweitem Chorlied, ungefähr nach der Maxime: „Nur kein weiteres Leiden mehr, mag der Tod entweder ins Elysium oder auch ins absolute Nichtsein führen“. Damit bestätigt sich durch den Agamemnon die oben gegebene Interpretation der ersten beiden Chorlieder der Troerinnen.

Franz Egermann, besonders WdF 44 f., betont in seiner Deutung der Lieder der trojanischen Frauen in 'Troerinnen' und 'Agamemnon' allzu sehr den Aspekt der „Erkenntnis“; es handelt sich in erster Linie um die Schmerzensbekundungen leidender Individuen und erst in zweiter Linie um stoische Lehrsätze. Allgemein zur Rolle des Chors vgl. Egermann WdF 43, der den Chor im wesentlichen als Sprachrohr des die dramatischen Personen bewertenden „Dichterphilosophen“ betrachtet. Kritisch zu dieser „Sprachrohrthese“ jetzt Grewe 117-119.

Die Todesthematik wird im dritten Chorlied des Agamemnon fortgesetzt durch eine — stoisch geprägte - Glücklichpreisung desjenigen Menschen, der zu sterben versteht, d.h. der im Moment allzu belastender äußerer Bedrängnis sich kurzerhand durch Selbstmord vom Leben zu trennen weiß. Von diesem Menschen heißt es, daß „er allein jegliche Sklaverei durchbrechen wird“76. Da hier ausdrücklich von „Sklaverei“ (servitium) die Rede ist, kann kaum ein Zweifel bestehen, daß diese Worte auf den Chor selbst gemünzt sind. Dieser hatte ja am Anfang der Ode sein Erstaunen über den

\footnotetext{
75 Wilson 50 verwendet in seiner Paraphrase des zweiten Chorgesangs der Troerinnen — wohl unabhängig vom Text des Agamemnon — den Begriff „Hafen“: „The Trojan women, in the second choral ode, continue to regard death as a haven“.

76 Sen. Agam. 604.
} 
unüberwindlichen Lebenstrieb bekundet, der den Menschen am Leben erhält, auch wenn eigentlich alle äußeren Bedingungen für den Tod sprechen. Die verschiedenen, negativ formulierten Faktoren, welche den ,ruhigen Hafen Tod“" auszeichneten, bezogen sich sämtlich, wie gezeigt, auf die trojanischen Frauen. Da sich nun auch die „Sklaverei“ — zumindest im wörtlichen Sinne - nur von derselben Personengruppe verstehen läßt, so muß man schlußfolgern, daß sich die ganze Reflexion primär auf die Leidenssituation des Chors selbst bezieht ${ }^{77}$.

Die Verschiedenheit der Rolle dieses leidend betroffenen Chors (die genau derjenigen des Chors in den Troerinnen entspricht) läßt sich im Kontrast zu der reflexiv-distanzierten Chorfunktion in den übrigen Seneca-Tragödien noch deutlicher fassen: Über denjenigen, der seinem Leben durch Selbstmord ein Ende zu machen weiß, heißt es in typisch stoisch-paradoxer Umwertung äußerer Status-Begriffe, er sei „einem König gleich“ (Par ille regi) ${ }^{78}$. Dieselbe paradoxe Verwendung des Königsbegriffs im stoischen Sinne konnte bereits im zweiten Chorlied des Thyest beobachtet werden, wo es hieß, der wahre König zeichne sich nicht durch äußere Macht, sondern durch Bedürfnislosigkeit, Freiheit von Affekten und auch nötigenfalls die Bereitschaft zum freiwilligen Austritt aus dem Leben aus. Dort war diese popularphilosophische Betrachtung aber, wie die Übereinstimmung mit den Äußerungen des Thyest im folgenden Akt zeigte, eindeutig auf die Hauptpersonen des Stückes gemünzt. Damit greift man den fundamentalen Unterschied zwischen der reflexiv-distanzierten Spielart des senecanischen Chors und der leidend betroffenen: Beide philosophieren mit Hilfe vorzugsweise stoischer Theoreme, aber im ersteren Fall handelt es sich um Reflexionen, die den dramatischen Ablauf des Stückes analysieren und kommentieren, im letzteren um ein Ringen um die Bewältigung des eigenen Schicksals.

Der weitere Fortgang des besprochenen dritten Chorlieds des Agamemnon ist vor allem den Ereignissen vor und während der Einnahme Trojas gewidmet; wie in den Troerinnen wird Priamus beweint. An das Lied schließt sich ein Zwiegespräch des Chors mit Cassandra an, welche die Teilnahme des Chors an ihrer persönlichen Trauer zunächst nicht erwünscht. In seiner Erwiderung verweist der Chor auf das psychologische Phänomen, daß geteiltes Leid weniger schmerzt; damit entsteht eine enge Verbindung auch zum letzten Chorlied der Troerinnen.

Die Stellung des trojanischen Nebenchors zur dramatischen Handlung entspricht also bis in Einzelheiten dem Chor der Troerinnen. Vor allem ist in beiden Fällen ein ähnliches Absorbiertsein im eigenen Leiden und den Bedingungen dieses Leidens $\mathrm{zu}$ beobachten, welches einen fundamentalen Unterschied darstellt $\mathrm{zu}$ der kontemplativ-reflexiven Grundhaltung, welche den Chören der übrigen Seneca-Tragödien zueigen ist.

Das letzte Chorlied des Agamemnon singt wieder der argivische Chor. Dies geht zwingend aus dem Inhalt der Ode hervor: Es handelt sich um ein Preislied auf die edlen Sprößlinge von Argos, insbesondere Hercules ${ }^{79}$. Die ausführliche Darstellung von dessen Leistungen gipfelt in der Erwähnung der um eine Generation frühe-

\footnotetext{
77 Richtig Gil 98 f.: „Der Inhalt ... erwächst aus der Situation der Sklavinnen und nicht als Erläuterung eines in der vorigen Handlung besprochenen Themas“.

78 Sen. Agam. 609.

79 Abwegig ist die Auffassung von Stevens 274 f. (vgl. auch a.a.O. 279. 289), wegen der dem Chorlied unmittelbar folgenden Worte Res agitur intus magna (867) müßten die im Chorlied erwähnten Arbeiten des Hercules auf Clytemestra und Aegisth bezogen werden (,,The ode is intended not to compare Agamemnon but Clytemestra and Aegisthus, to Hercules“). Zum Verhältnis des Chorlieds zur umliegenden dramatischen Handlung s.o.
} 
ren Eroberung von Troja unter Laomedon und Hercules ${ }^{80}$ : „Unter dir [Hercules] als Anführer fiel das trügerischere Haus des Laomedon und spürte den Bogen, den es ein zweites Mal [durch Philoctet] fürchten sollte; unter dir als Anführer fiel Troja in eben soviel Tagen, wie es jetzt Jahre dauerte ${ }^{81 " “}$.

Die Plazierung dieser in einer fast prahlerischen Bemerkung über den früheren Sturz Trojas kulminierenden Glorifizierung argivischer Heldentugend kann im Rahmen des ganzen Dramas nur ironisch verstanden werden. Unmittelbar zuvor hat Cassandra dem Agamemnon seinen bevorstehenden Untergang in verdeckter Weise angekündigt; unmittelbar danach wird seine gleichzeitig im Palast stattfindende Ermordung durch eine seherische Vision der Cassandra geschildert. Ein zwischen diesen Szenen stehendes stolzes Chorlied über die Größe argivischer Heldentugend widerspricht dem tatsächlichen Ereignisgang in einem derartigen Maße, daß man die Haltung dieses argivischen Chors nicht anders denn als eine völlig verfehlte hybris-artige Überschätzung der eigenen Position ansehen kann. Daß die Tendenz des dramatischen Geschehens in solcher Weise einem Chorlied Hohn spricht, ist im senecanischen Dramencorpus singulär; etwa die Verirrung des Chors im Thyest, der den Streit zwischen den Brüdern durch die brüderliche Liebe, die Pietas, beendet glaubt, wird erheblich gemildert durch die folgenden Reflexionen über die Wechselhaftigkeit des Geschicks. Offenkundig soll dieser argivische Chor mit seinem Nationalstolz durch die Tötung des Agamemnon faktisch widerlegt werden. Er entwächst der reflektierend-analytischen Haltung, die er am Anfang des Stückes einnimmt, und verfällt der Hybris $^{82}$.

Man kann noch weitergehen: Die Ermordung Agamemnons wird von Seneca geschildert als eine Art Ausgleich zwischen trojanischem Leiden und griechischer Hybris $^{83}$. Cassandra hat in einer früheren Vision gesehen, wie der Nachen Charons den Totenfluß mit zwei königlichen Seelen überqueren wird, einer besiegten (ihrer eigenen) und einer siegreichen (Agamemnons) ${ }^{84}$. Derselbe Ausgleichsgedanke bestimmte die Diktion der späteren Vision, in welcher Cassandra die im Palast vor sich gehende Ermordung Agamemnons schildert ${ }^{85}$ : Das am Boden liegende Troja reißt gewissermaßen seinen Bezwinger mit sich nieder. Es findet ein königliches Gastmahl statt wie in der letzten Nacht in Troja vor der Eroberung durch die Griechen. Agamemnon ist von trojanischen Spolien umgeben: er ruht auf trojanischem Purpur, trägt

\footnotetext{
80 Zum Rückgriff auf die frühere Eroberung von Troja im Zusammenhang des späteren trojanischen Kriegs vgl. das euripideische Chorlied Tro. $799 \mathrm{ff}$.

81 Sen. Agam. 862-866.

82 Nicht zu halten ist die Deutung von Gil 161, der die Funktion der Herakles-Figur im vierten Chorlied des Agamemnon folgendermaßen bestimmt: „Die im ersten Chorlied ausgesprochenen Gedanken der Gefährdung des Herausragenden ... werden dem Leser mit diesem Beispiel verdeutlicht“. Von einer Gefährdung des Hercules ist keine Rede, und Gils Ausdruck „die Katastrophe der Alkiden“ (a.a.O. 161) scheint einem mythologischen Mißverständnis zu entstammen.

83 Angelegt ist diese Vorstellung bereits in den Visionen der Kassandra bei Euripides (Tro. 359 f.):

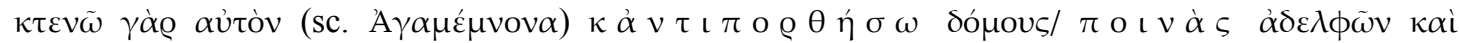
$\pi \alpha \tau$ ¡ò $\lambda \alpha \beta$ о $\tilde{v} \sigma^{\prime} \dot{\varepsilon} \mu$ ov (vgl. auch 404 f.). Der „Ausgleich“, der zum dramatischen Zeitpunkt der euripideischen Troerinnen nur rhetorisch vollzogen werden kann, nämlich in dem paradoxen Nachweis Kassandras, daß die Trojaner glücklicher seien als die Griechen (365 ff.), wird durch die Cassandra-Prophezeiung im senecanischen Agamemnon, welche die gleichzeitig stattfindende Ermordung des Atriden mit dem Tod des Priamus visionär in Verbindung bringt, in der dramatischen Faktizität realisiert.

84 Sen. Agam. 752-754.

85 Zur seherischen Prophezeiung als dramaturgischem Mittel (welches hier letztlich einen Botenbericht ersetzt) vgl. R. J. Tarrant 1978, 253 f., und dens. 1976, 335 f. (zu v. 867 ff).
} 
die erbeuteten Kleider des Priamus und trinkt erbeuteten trojanischen Wein. Die Todesszene Agamemnons wird also ganz in trojanischen Farben gezeichnet ${ }^{86}$.

Dieser Gedanke eines finalen Ausgleichs zwischen trojanischem Leiden und griechischer Hybris läßt sich auch durch ein sprachliches Detail belegen, welches die beiden letzten Chorlieder, das des leidenden trojanischen und das des übermütigen argivischen Chors, verbindet: Der argivische Chor hat in seinen letzten Worten seine Hybris gewissermaßen konzentriert in einer Bemerkung über Hercules' Sieg gegen Troja: Dieser Erfolg dauerte nur soviel Tage, wie der jetzige unter Agamemnon Jahre. Auf diesen kurzen, mit der zehnjährigen Belagerungszeit kontrastierten Zeitabschnitt wird gewissermaßen die griechische Überlegenheit in der historisch-mythischen Retrospektive fokussiert. Der trojanische Chor hat dagegen in seiner Schilderung des schließlichen Untergangs der Stadt auf den vergeblichen erbitterten zehnjährigen Widerstand hingewiesen und diesen mit dem kurzen Zeitraum des letztlichen Untergangs kontrastiert: „Troja widersetzte sich zehn Jahre lang, um schließlich durch den Betrug einer einzigen Nacht unterzugehen ${ }^{87 “}$. Damit ist auch das trojanische Leiden auf einen knappen Zeitabschnitt, nämlich die letzte Nacht, fokussiert; wenige Verse zuvor war übrigens von der in offenem Kampf erfolgenden ersten Bezwingung Trojas unter Hercules die Rede ${ }^{88}$. In einen den beiden Chorliedern genau entsprechenden Gegensatz zu den zehn Kriegsjahren tritt nun aber auch die Ermordung Agamemnons in der Vision Cassandras. Die trojanische Prophetin beginnt ihre Ausführungen unmittelbar nach den prahlerischen Worten des argivischen Chors über den schnellen Sieg des Hercules mit den Worten: „Drinnen [im Palast] geschieht ein großes Ereignis, welches die zehn Jahre aufwiegt (Res agitur intus magna par annis decem) ${ }^{89 " ،}$. Dem Zuhörer bzw. Zuschauer muß das Schlußwort des argivischen Chors „,in sovielen Tagen, wie jetzt Jahren“ (totidem diebus/ ... quot annis) ${ }^{90}$ noch im Ohr $\operatorname{sein}^{91}$. Diese dreimal verwendete Technik, die zehn Jahre des trojanischen Kriegs auf einen viel kürzeren Zeitraum zu fokussieren, zunächst aus der Sicht des leidenden trojanischen Chors, dann von der Warte des triumphierenden argivischen Chors und schließlich im Munde der einen talions-artigen Ausgleich zwischen beiden Parteien schildernden Prophetin, macht die vom Autor intendierte Vergeltungsvorstellung mehr als deutlich.

Vielleicht darf man sogar eine Intertextualität zwischen verschiedenen Tragödien Senecas annehmen und diese drei Formulierungen mit einer Äußerung Agamemnons in den Troerinnen zusammenstellen. Dort wird der argivische Feldherr in der Auseinandersetzung mit Pyrrhus als erstaunlich besonnen gezeichnet: Er verweist darauf, daß der Fall des Priamus ihm vor allem zeige, wie schnell die Königsherrschaft verloren gehen kann: „Dies alles [Szepter und äußeren Glanz] wird ein kurzer Zufall wegreißen, vielleicht nicht einmal mit tausend Schiffen oder in zehn Jahren ${ }^{92 “}$. Genauso kommt es schließlich: Agamemnons eigene Ermordung durch Clytemestra und Aegisth dauert nur wenige Augenblicke, kommt aber nach den Worten Cas-

\footnotetext{
86 Vgl. den Aufsatz von Lohikoski.

87 Sen. Agam. 623 f.

88 Sen. Agam. 613 f.

89 Sen. Agam. 867.

90 Sen. Agam. 865 f.

91 Statt dieser sich aufdrängenden sprachlichen Berührung zwischen dem Ende des Chorlieds und dem Auftakt des letzten Akts stellt Seidensticker 131 f. Anm. 163 eine nicht im Text stehende, vom Leser hinzuzudenkende Korrespondenz zwischen den Liebschaften des Hercules (Iole) und des Agamemnon (Cassandra) in den Mittelpunkt. Dagegen vgl. Liebermann 230 f. Anm. 93.

92 Sen. Tro. $273 \mathrm{f}$.
} 
sandras in ihrer Bedeutung „den zehn Jahren gleich“. Der Agamemnon der Troerinnen ${ }^{93}$ bildet gewissermaßen ein Korrektiv, vor dessen Hintergrund man die hybrishafte Überhebung derselben Person im Schlußteil des Agamemnon erkennt: In den Troerinnen sagt Agamemnon, das Geschick des gestürzten Priamus mache ihn nicht hochmütig, sondern vielmehr f u $\mathrm{r} \mathrm{ch} \mathrm{t} \mathrm{s}$ a $\mathrm{m}$ (Tu me superbum, Priame? tu t $\mathrm{i}$ m $i$ d u $m$ facis ${ }^{94}$ ). Dagegen richtet er im Agamemnon kurz vor dem letzten Chorlied an Cassandra, welche ihm das bevorstehende Unheil andeutet, die von völliger Verblendung zeugende Frage „Was kann ein Sieger schon fü r c h t e n ?" (Victor ti m e re quid potest $\left.{ }^{95}\right)$. Cassandras Antwort quod non timet kann man auf zwei Weisen übersetzen: entweder „das, was er nicht fü r chte t“ oder „die Tatsache, daß er nicht fü r ch te t". Dem Agamemnon im gleichnamigen Stück fehlt also die zur Selbstmäßigung führende Voraussicht, welche dieselbe Figur in den Troerinnen auszeichnet: D i e s e r Agamemnon tritt ebenbürtig neben den der Hybris verfallenden argivischen Chor.

Eine solche ausgleichende Vergeltung, wie sie im Agamemnon beobachtet werden kann, findet sich am Schluß keiner der anderen Seneca-Tragödien, an deren Ende sonst immer Leiden und Unglück ohne rächenden Ausgleich steht. Selbst der Selbstmord der Phaedra, den man als ausgleichende Vergeltung für den Tod des Hippolytus auffassen könnte, wird nicht in dieser Weise dargestellt, sondern eher als ein zusätzlich über Theseus hereinbrechendes Unglück. Der in der Schlußszene des Agamemnon geschilderte Ausgleich zwischen trojanischem Elend und argivischer Hybris ist also ein singuläres Phänomen in den Seneca-Tragödien. Um diese spezielle Gestaltung sinnfällig zu machen, liefert die ebenfalls singuläre Technik, zwei konträre Chöre, einen leidenden trojanischen und einen übermütigen argivischen, einander gegenüberzustellen, den entscheidenden dramaturgisch-tektonischen Beitrag.

Daß im Schlußteil des Agamemnon ein neuer Gedanke hervortritt, wird richtig herausgestellt von Lefèvre 1966, 491 = 469 f.: ,Während die erste Hälfte des Stücks ... nur auf das Individuum Agamemnon bezogen ist, wird er in der zweiten Hälfte in seiner Eigenschaft als Eroberer Trojas meist nur noch als Teil seines Volkes gesehen. Bedingt wird dieser Wechsel einerseits natürlich durch die Konfrontation mit Cassandra und dem Chorus Iliadum, der ein ganzes Volk repräsentiert, andererseits aber ist hier eine besondere Konzeption Senecas deutlich zu erkennen: der Sieger als Besiegter“. Damit ist der Auftritt des trojanischen Chors als Wendepunkt im Agamemnon erkannt: In der ersten Hälfte liegt der Schwerpunkt bei Agamemnons bevorstehendem persönlichen Schicksal, welches der argivische Chor in seinem ersten Lied in typischer Weise analysiert, in der zweiten dagegen auf Konfrontation und Ausgleich zwischen griechischer Hybris und trojanischem Leiden und der Repräsentation dieser beiden politischen Gruppen durch die beiden konträren Chöre. Auf S. 494 f. = 474 qualifiziert Lefèvre den ersten Teil als „Leidenschaftstragödie“ in Hinsicht auf Agamemnon, den zweiten Teil als „Fatumstragödie“ in Hinsicht auf Cassandra. Über die Chorlieder heißt es (a.a.O. $495=475)$ : „In dem Maße, wie das erste Chorlied der troischen Mädchen (589 ff.) für die Haltung Cassandras programmatisch ist (der contemptor levium deorum könne sich jederzeit durch den Freitod den Schlägen des Schicksals entziehen), nimmt das erste Chorlied des Stücks auf Agamemnon Bezug“. Nach der oben gegebenen Deutung bezieht sich der Gesang des trojanischen Chors jedoch weniger auf Cassandra als auf die Bedingungen des eigenen Leidens.

Zur Zweiteilung des Agamemnon vgl. auch Müller 462 f. = 398 f.: „,Doch scheint mir eine Zwiespältigkeit darin gegeben, daß nach der glänzenden psychologischen Analyse des 2. Aktes die Tat der Klytaemnestra und des Ägisth nicht mehr weiter an ihren Tätern psychologisch studiert, sondern

\footnotetext{
93 In der modernen Forschung wird der Agamemnon der Troerinnen eigentümlich ungünstig bewertet, vgl. oben S. 22.

94 Sen. Tro. 270.

95 Sen. Agam. 799. Die Haltung des Agamemnon an dieser Stelle entspricht ziemlich genau derjenigen seines Widersachers Pyrrhus in den Troerinnen (335 Quodcumque libuit facere victori licet).
} 
nur von außen in der Schau der triumphierenden Cassandra dargestellt wird, also als Vollzug des Fatums ...“. Ähnlich Anlikers Anhang „Zum Agamemno“ (98-103 = WdF 450-456). 98 = WdF 450: „Klytämnestra und Aegisth ... handeln am Schlusse gleichsam nicht mehr in eigener Sache, sondern erscheinen nur noch als Werkzeuge in der großen Abrechnung zwischen Troja und Griechenland (Argos) ...“; $101=\mathrm{WdF}$ 455: „Zugleich wird so das Stück aus der Enge eines „Familiendramas“ herausgehoben und in in einen weltweiten Rahmen und Schicksalszusammenhang gestellt". Zur Korrespondenz der beiden letzten Chorlieder vgl. Anliker 96 und $100=\mathrm{WdF} 453$. Liebermann $229 \mathrm{f}$. sieht — weniger überzeugend - einen Kontrast zwischen zweitem und drittem Chorlied und versteht das vierte vor allem „retardierend“. Shelton 1983, 171 will Bezüge zwischen dem Gesang der Troerinnen über die Vorzüge des Tods (589-611) und dem ersten Lied des argivischen Chors erkennen.

Die Feststellung von D. \& E. Henry 90 (,The Chorus saw that „,great things sink down by their own weight" (87-9) but the fate of the humble Trojan women has demonstrated that Fortune is destructive of the unassuming as well as the ambitious“) zeigt den sich in den konträren Chorgestaltungen (einerseits analytisch-reflektierend in bezug auf das Unglück der Großen, andererseits vom eigenen Leiden betroffen) bekundenden entgegengesetzten Charakter der beiden Hälften des Stücks.

Die vorangegangenen Überlegungen haben zwei grundverschiedene Typen der Chorgestaltung in der senecanischen Tragödie deutlich gemacht: auf der einen Seite den unbeteiligt aus seiner eigenen Mittelmäßigkeit heraus das Geschehen um die hochgestellten Helden beobachtenden und analysierenden Chor, auf der anderen die konträre Spielform eines selbst am Leiden der Großen beteiligten und in der Bewältigung dieses Leidens absorbierten Chors. Beide Spielformen laufen Gefahr, verkannt zu werden in der modernen Forschung, die noch immer das philosophisch-didaktische Element in Senecas Schrifttum auch in den Tragödien in den Mittelpunkt rückt (letztlich ist Egermanns ${ }^{96}$ Vorstellung von "Seneca als Dichterphilosoph“ noch immer wirksam): Die analytische Ausprägung, die immer wieder auf das Axiom rekurriert, alles Hochstehende sei gefährdet, wird mißverstanden in dem Sinne, daß Seneca zeigen wolle, daß Macht und Größe automatisch zu Hybris und Korruption führe; die leidende Variante wird noch krasser fehlgedeutet, indem man das, was in Wirklichkeit philosophisch sublimierte Leidensbekundungen des Chors sind, als philosophische Theoreme auffaßt, welche der „Dichterphilosoph“ dem Chor zur Belehrung des Lesers in den Mund lege.

Zudem eröffnete sich ein Blick darauf, wie die Mischung beider Spielformen in der in vieler Hinsicht zwitterhaften Tragödie Agamemnon ${ }^{97}$ den im zweiten Teil des Stückes zentralen Gedanken der zwischen Trojanern und Griechen ausgleichenden Vergeltung sinnfällig macht. Wenn man aus den zum Agamemnon angestellten Beobachtungen eine chronologische Konsequenz ziehen will, wird es die sein, daß man den heterogene Elemente kombinierenden Agamemnon eher an das Ende der senecanischen Tragödiendichtung setzen wird, zumindest hinter die Troerinnen. Die in der Forschung unternommenen Versuche, das fast aussichtslose Problem einer Chronologie der Seneca-Tragödien anzugehen, haben zumindest nichts hervorgebracht, was einer derartigen Datierung widerspräche.

\footnotetext{
96 Bereits vor Egermann hat Birt den Primat des Moralisch-Philosophischen betont. Laut Birt liegt in den Tragödien „,das einheitliche Dichterprogramm des Autors De ira“ vor (a.a.O. 349); ,,alle übrigen [Dramen] sollen Abschreckungsbilder sein, der Herkules [Oetaeus] ist dagegen ein Vorbild“ (a.a.O. 337).

$97 \mathrm{Zu}$ einem anderen Gesichtspunkt vgl. die Abhandlung von Riemer, der zeigt, daß im senecanischen Agamemnon zwei in der vorgängigen mythischen Tradition getrennte Konzeptionen (einerseits Aegisth, andererseits Clytemestra als hauptsächlich schuldige Person) konsequent miteinander kombiniert werden.
} 
Zur Schwierigkeit einer Datierung der Seneca-Tragödien vgl. die Doxographie bei Grewe 9 Anm. 11. Der letzte zu positiven Ergebnissen führende Anlauf stammt von Nisbet. Demnach wären die Troerinnen durch die Anspielung auf den lusus Troiae (Saekularspiele im Jahr 47) in Tro. 777 ff. (entspricht formal Eur. Tro. $1210 \mathrm{f}$.) zu datieren: „Seneca is likely to have made his tactful allusion after he became the boy's mentor in 49. A few years later Nero would no longer be flattered by references to the accomplishments of his childhood, and that would certainly be true after he became emperor in 54" (a.a.O. $96=294$ ); Keulen 8 f. datiert die Troerinnen auf 51-54. Andererseits soll nach Nisbet auch der Agamemnon noch in die Zeit vor Neros Regierungsantritt gehören: „The early years of Nero were not the time to write about a forceful wife who killed a triumphant king“" (a.a.O. 99 = 297).

Speziell zur relativen Datierung von Troerinnen und Agamemnon vgl. den Aufsatz von Fantham: a.a.O. 118 allgemein zur Frage nach Intertextualität (,cross-relationship“) zwischen den beiden Tragödien; 123 zur verschiedenen Zeichnung der Agamemnon-Figur (,whereas the onstage Agamemnon of Troades is a sadder and wiser man for his victory, there is no acknowledgement in his returning speech in Agamemnon of the need for restraint"); $125 \mathrm{f}$. zum Nebenchor des Agamemnon. Fantham kommt ebenfalls zu dem Ergebnis, daß die Troerinnen dem Agamemnon chronologisch vorausgehen.

Privatdozent Dr. Thomas Gärtner

Universität zu Köln, Institut für Altertumskunde

th-gaertner@gmx.de 


\section{Literaturverzeichnis}

Kurt Anliker, Prologe und Akteinteilung in Senecas Tragödien, Noctes Romanae 9, Bern 1960

Margarethe BILLERBECK, Seneca. Hercules furens. Einleitung, Text, Übersetzung und Kommentar, Mnem. Suppl. 187, Leiden 1999

Giuseppe Gilberto BIONDI, Il mito argonautico nella Medea. Lo stile 'filosofico' del drammatico Seneca, Dioniso 52, 1981, 421-445

Giuseppe Gilberto BIONDI, Il nefas Argonautico. Mythos e logos nella Medea di Seneca, Bologna 1984

Theodor BIRT, Was hat Seneca mit seinen Tragödien gewollt?, Neue Jahrbücher für das Klassische Altertum, Geschichte und deutsche Literatur 14, 1911, 336364

J. David Bishop, The Choral Odes of Seneca's Medea, CJ 60, 1964, 313-316 [1964 a]

J. David Bishop, The Choral Odes of Seneca: Theme and Development, Diss. University of Pennsylvania 1964 [1964 b]

J. David BisHop, Seneca's Hercules furens: Tragedy from modus vitae, C \& M 27, 1966, 216-224

Jürgen BLÄNSDORF, Senecas Kritik am Menschenbild des Horaz, in: Candide iudex. Beiträge zur augusteischen Dichtung,. Festschrift für Walter Wimmel zum 75. Geburtstag (ed. A. E. Radke), Stuttgart 1998, 35-46

A. J. BoYle, Hic epulis locus: The Tragic worlds of Seneca's Agamemnon and Thyestes, in: Seneca tragicus. Ramus Essays on Senecan Drama, ed. A. J. Boyle, Australia 1983, 199-228

Johanna BRANDT, Argumentative Struktur in Senecas Tragödien. Eine Untersuchung anhand der „Phaedra“ und des „Agamemnon“, Beiträge zur Altertumswissenschaft 5, Hildesheim 1986

William M. CALDER III, The size of the chorus in Seneca's Agamemnon, CPh 70, 1975, 32-35

Luigi CASTAGNA, Nove studi sui cori tragici di Seneca, Biblioteca di aevum antiquum 8, Mailand 1996

Thomas F. CURLEY, The Nature od Senecan Drama, Instrumentum Litterarum 4, Rom 1986

Peter J. DAVIS, Vindicat omnes natura sibi: A Reading of Seneca's Phaedra, in: Seneca tragicus. Ramus Essays on Senecan Drama, ed. A. J. Boyle, Australia 1983, 114-127

Peter J. DAVIS, The first chorus of Seneca's Phaedra, Latomus 43, 1984, 396-401

Peter J. DAVIS, The Chorus in Seneca's Thyestes, CQ 39, 1989, 421-435

Peter J. DAVIS, Fate and Human Responsibility in Seneca's Oedipus, Latomus 50, 1991, 150-163

Peter J. DAVIS, Shifting Song: The Chorus in Seneca's Tragedies, Altertumswissenschaftliche Texte und Studien 26, Hildesheim 1993

Joachim DiNGEL, Seneca und die Dichtung, Heidelberg 1974

Franz EgERMANN, Seneca als Dichterphilosoph, Neue Jahrbücher für Antike und deutsche Bildung 3, 115, 1940, 18-36 = Senecas Tragödien, ed. Eckard Lefèvre, WdF 310, Darmstadt 1972, 33-57

Elaine FAnTHAM, Seneca's Troades and Agamemnon: Continuity and Sequence, CJ 
$77,1981,118-129$

John G. Fitch, Seneca's Hercules Furens. A Critical Text with Introduction and Commentary, Ithaca 1987

Marica FrANK, Seneca's Phoenissae. Introduction and Commentary, Mnem. Suppl. 138, Leiden 1995

Irene FRINGS, Odia fraterna als manieristisches Motiv - Betrachtungen zu Senecas Thyest und Statius' Thebais, Abh. der Akad. Mainz 1992 (Nr. 2)

Helen FyFE, An analysis of Seneca's Medea, in: Seneca tragicus. Ramus Essays on Senecan Drama, ed. A. J. Boyle, Australia 1983, 77-93

Francesco GiAnCOTTI, L'„Octavia“ attribuita a Seneca, Turin 1954

Alberto GIL, Die Chorlieder in Senecas Tragödien. Eine Untersuchung zu Senecas Philosophie und Chorthemen, Diss. Köln 1979

Stefanie GREWE, Die politische Bedeutung der Senecatragödien und Senecas politisches Denken zur Zeit der Abfassung der Medea, Identitäten und Alteritäten 6, Würzburg 2001

Richard M. HAYwOOD, The Poetry of the Choruses of Seneca's Troades, in: Hommages à Marcel Renard I, Brüssel 1969, 415-420

Konrad Heldmann, Untersuchungen zu den Tragödien Senecas, Hermes Einzelschriften 31, Wiesbaden 1974

John Henderson, Poetic Technique and Rhetorical Amplification: Seneca Medea 579-669, in: Seneca tragicus. Ramus Essays on Senecan Drama, ed. A. J. Boyle, Australia 1983, 94-113

Denis \& Elisabeth Henry, The Mask of Power. Seneca's Tragedies and Imperial Rome, Warminster 1985

Otto HiLtBRUNNER, Seneca als Tragödiendichter in der Forschung von 1965 bis 1975, ANRW II 32, 2 (1985) 969-1051

Rita degl'InNOCENTI PIERINI, Venit ad pigros cana senectus (Sen. Herc. f. 198). Un motivo dei cori Senecani tra filosofia ed attualità, in: Nove studi sui cori tragici di Seneca (ed. L. Castagna), Biblioteca di aevum antiquum 8, Mailand 1996, 37-56

Rebekka Junge, Nicholas Trevet und die Octavia Praetexta. Editio princeps des mittelalterlichen Kommentars und Untersuchungen zum pseudosenecanischen Drama, Studien zur Geschichte und Kultur des Altertums 14, Paderborn 1999 (Diss. Bonn 1998)

Atze J. Keulen, L. Annaeus Seneca. Troades. Introduction, text and commentary, Mnem. Suppl. 212, Leiden 2001

Ulrich KNOCHE, Senecas Atreus. Ein Beispiel, Antike 17, 1941, 66-76 = Senecas Tragödien, ed. Eckard Lefèvre, WdF 310, Darmstadt 1972, 477-489

Christoph KugelmeIER, Chorische Reflexion und dramatische Handlung bei Seneca - einige Beobachtungen zur Phaedra, in: Peter Riemer/ Bernhard Zimmermann (edd.), Der Chor im antiken und modernen Drama (Drama, Band 7), Stuttgart 1999, 139-169

Christoph KUgelmeIER, Zweierlei Tod. Philosophische Konzepte und ihr Verhältnis zur Handlung in Senecas Troades, Prometheus 27, 2001, 25-47

Joseph LAMMERS, Die Doppel- und Halbchöre in der antiken Tragödie, Diss. Münster 1929, Paderborn 1931

Gilbert LAWALL, Death and Perspective in Seneca's Troades, CJ 77, 1982, 244-252

Gilbert LAwALL, Virtus and Pietas in Seneca's Hercules furens, in: Seneca tragicus. Ramus Essays on Senecan Drama, ed. A. J. Boyle, Australia 1983, 6-26 
Eckard LEFÈVRE, Schicksal und Selbstverschuldung in Senecas Agamemnon, H. 94, 1966, 482-496 = Senecas Tragödien, ed. Eckard Lefèvre, WdF 310, Darmstadt 1972, 457-476

Eckard LEFÈVRE, Quid ratio possit? Senecas Phaedra als stoisches Drama, WS 82, 1969, 131-160 = Senecas Tragödien, ed. Eckard Lefèvre, WdF 310, Darmstadt 1972, 343-375

Eckard LefÈvre, Die Schuld des Agamemnon. Das Schicksal des Troja-Siegers in stoischer Sicht, H. 101, 1973, 64-91

Eckard LeFÈVRE, Das erste Chorlied in Senecas Oedipus - Ein innerer Monolog?, Orpheus 1, 1980, 293-304

Eckard LefĖvre, L'Edipo di Seneca: Problemi di drammaturgia Greca e Latina, Dioniso 52, 1981, 243-259

Eckard LEFÈVRE, Senecas 'Thyestes', ANRW II 32, 2 (1985), 1263-1283

Eckard LEFÈVRE, Götter, Schicksal und Handlungsfreiheit in Senecas Tragödien, in: B. Kühnert et alii (edd.), Prinzipat und Kultur im 1. und 2. Jahrhundert, Bonn 1995, 164-185

Eckard LEFĖVRE, Senecas Atreus - die Negation des stoischen Weisen?, in: Griechisch-römische Komödie und Tragödie II, ed. B. Zimmermann, Stuttgart 1997 (Drama, Band 5), 119-134

Friedrich LEO, Die Composition der Chorlieder Senecas, RhM 52, 1897, 509-518

Wolf-Lüder LIEBERMANN, Studien zu Senecas Tragödien, Beiträge zur Klassischen Philologie 39, Meisenheim 1974

Klaus Krister LoHIKoski, Der Parallelismus Mykene-Troja in Senecas „Agamemnon", Arctos 4, 1966, 63-70

Gottfried MADER, Form and meaning in Seneca's 'dawn song' (H.F. 125-201), Acta Classica 33, 1990, 1-32

Gottfried MADER, Quis queat digne eloqui? Speech, Gesture and the Grammar of the mundus inversus in Seneca's Thyestes, A\&A 46, 2000, 153-172

Bernd MaNUwALD, Der 'Sturz des Mächtigen' in der griechischen Tragödie, in: WOLPERS 37-62

Gesine MaNuWALD, Fabulae praetextae. Spuren einer literarischen Gattung der Römer, Zetemata 108, München 2001

Rosanna MARINO, Il secondo coro delle Troades e il destino dell'anima dopo la morte, in: Nove studi sui cori tragici di Seneca (ed. L. Castagna), Biblioteca di aevum antiquum 8, Mailand 1996, 57-73

Wilhelm MARX, Funktion und Form der Chorlieder in den Seneca-Tragödien, Diss. Heidelberg 1928, Köln 1932

Donald J. Mastronarde, Seneca's Oedipus: The drama in the word, TAPhA 101, 1970, 291-315

Gregor MAURACH, Jason und Medea bei Seneca, A \& A 12, 1966, 125-140= Senecas Tragödien, ed. Eckard Lefèvre, WdF 310, Darmstadt 1972, 292-320

Giancarlo MAzzoli, Funzioni e strategie dei cori in Seneca tragico, Quaderni di cultura e di tradizione classica 4/5, 1986/7, 99-112

Barbara MEIER, Furcht und Hoffnung der Besiegten, Anregung. Zeitschrift für Gymnasialpädagogik 42, 1996, 238-241

Anna Lydia MotTo / John R. Clark, Maxima virtus in Seneca's Hercules furens, $\mathrm{CPh} 76,1981,101-117$

Anna Lydia MotTo / John R. Clark, Paradox, Reversal \& Mental Disorder in the Senecan Troades, The Classical Bulletin 63, 1987, 99-103 
Gerhard MüLLER, Senecas Oedipus als Drama, H. 81, 1953, 447-464 = Senecas Tragödien, ed. Eckard Lefèvre, WdF 310, Darmstadt 1972, 376-401

Heinz-Günther NeSSELRATH, Herakles als tragischer Held in und seit der Antike, in: Tragödie. Idee und Transformation, ed. H. Flashar (Colloquium Rauricum Band 5), Stuttgart/ Leipzig 1997, 307-331

R. G. M. NisBet, The Dating of Seneca's Tragedies, with Special Reference to Thyestes, Proceedings of the Leeds International Latin Seminar 6, 1990, 95-114= Collected Papers on Latin Literature (ed. S. J. Harrison), Oxford 1995, 293311

William H. Owen, The Excerpta Thuanea and the Form of Seneca Tro. 67-164, H. 98, 1970, 361-368 [1970 a]

William H. Owen, Time and Event in Seneca's Troades, WS 83, 1970, 118-137 $[1970 \mathrm{~b}]$

Alessandro Perutelli, Il primo coro della Medea di Seneca, Materiali e discussioni per l'analisi dei testi classici 23, 1989, 98-117

Giusto PICONE, La fabula e il regno. Studi sul Thyestes di Seneca, Palumbo 1984

Viktor PösCHL, Bemerkungen zum Thyest des Seneca, in: Latinität und alte Kirche, Festschrift für Rudolf Hanslik zum 70. Geburtstag, Wien 1977, 224-234

Norman T. PRATT, Seneca's Drama, Chapel Hill 1983

Otto Regenbogen, Schmerz und Tod in den Tragödien Senecas, Vorträge der Bibliothek Warburg VII, Leipzig 1930, 167-218 = Kleine Schriften (ed. Franz Dirlmeier) München 1961, 409-462

Peter RIEMER, Zur dramaturgischen Konzeption von Senecas Agamemnon, in: Griechisch-römische Komödie und Tragödie II, ed. B. Zimmermann, Stuttgart 1997 (Drama, Band 5), 135-151

Amy R. Rose, Seneca's HF: A politico-didactic reading, CJ 75, 1980, 135-142

Amy R. Rose, Seneca's Dawn Song (Hercules Furens, 125-58) and the Imagery of Cosmic Disruption, Latomus 44, 1985, 101-123

Willy SchetTer, Zum Aufbau von Senecas Troerinnen, in: Senecas Tragödien, ed. Eckard Lefèvre, WdF 310, Darmstadt 1972, 230-271 (italienische Originalpublikation in RFC 93, 1965, 396-429)

Jens-Uwe SchmidT, Phaedra und der Einfluß ihrer Amme. Zum Sieg des mythischen Weltbilds über die Philosophie in Senecas „Phaedra“, Phil. 139, 1995, 274323

Jens-Uwe SCHMIDT, Im Banne der Verbrechen. Überlegungen zu aktuellen Einflüssen auf Senecas Konzeption der 'Medea', GB 22, 1998, 145-175

Peter L. SCHMIDT, Die Poetisierung und Mythisierung der Geschichte in der Tragödie 'Octavia', ANRW II 32, 2 (1985), 1421-1453

Christine SchmiTZ, Die kosmische Dimension in den Tragödien Senecas, Untersuchungen zur antiken Literatur und Geschichte 39, Berlin 1993

Gustav Adolf SEECK, Senecas Tragödien, in: Das römische Drama, ed. E. Lefèvre, Darmstadt 1978, 378-426

Bernd SeIDENSTICKER, Die Gesprächsverdichtung in den Tragödien Senecas, Heidelberg 1969

Jo-Ann SHELton, Seneca's Hercules Furens. Theme, Structure and Style, Hypomnemata 50, Göttingen 1978

Jo-Ann Shelton, Revenge or Resignation: Seneca's Agamemnon, in: Seneca tragicus. Ramus Essays on Senecan Drama, ed. A. J. Boyle, Australia 1983, 159183 
Gregory A. STALEY, Seneca's Thyestes: Quantum mali habeat ira, GB 10, 1981, 233 246

Wolf STEIDLE, Studien zum antiken Drama, München 1968

Theodoros K. Stephanopoulos, Umgestaltung des Mythos durch Euripides, Athen 1980 (Diss. Berlin 1977)

John Alan Stevens, The chorus in Senecan tragedy: The uninformed informer, Diss. Duke University 1992

Dana Ferrin SuTTON, Seneca's Hercules furens: One chorus or two?, AJPh 105, 1984, 301-305

Dana Ferrin SutTon, Seneca on the stage, Mnem. Suppl. 96, Leiden 1986

Hiroyuki TAKAHASHI, On the second choral ode of Seneca's Troades, Classical Studies 11, 1994, 151-184

Richard John TARRANT, Seneca Agamemnon, Cambridge 1976

Richard John TARRANT, Senecan Drama and its Antecedents, HSCPh 82, 1978, 213 263

Meinolf VielBerg, Necessitas in Senecas Troades, Phil. 138, 1994, 315-334

Marcus WILSON, The tragic mode of Seneca's Troades, in: Seneca tragicus. Ramus Essays on Senecan Drama, ed. A. J. Boyle, Australia 1983, 27-60

Theodor Wolpers (ed.), Der Sturz des Mächtigen. Zu Struktur, Funktion und Geschichte eines literarischen Motivs, Abhandlungen der Akad. d. Wiss. Göttingen, Phil.-Hist. Klasse, 3. Folge, Nr. 234, Göttingen 2000

Clemens ZinTZEN, Alte virtus animosa cadit. Gedanken zur Darstellung des Tragischen in Senecas 'Hercules furens', in: Senecas Tragödien, ed. Eckard Lefèvre, WdF 310, Darmstadt 1972, 149-209 = Athen - Rom - Florenz. Ausgewählte Kleine Schriften, edd. D. Gall et P. Riemer, Hildesheim 2000, $243-283$

Otto ZWIERLEIN, Die Rezitationsdramen Senecas, Beiträge zur klassischen Philologie 20, Meisenheim am Glan 1966

Otto ZwIERLEIN, Rezension zu: Wolf Steidle, Studien zum antiken Drama, München 1968, GGA 222, 1970, 196-227

Otto ZwIERLEIN, Die Tragik in den Medea-Dramen, Literaturwissenschaftliches Jahrbuch 19, 1978, 27-63

Otto ZWIERLEIN, Prolegomena zu einer kritischen Ausgabe der Tragödien Senecas, Abh. der Akad. Mainz 1983 (Nr. 3), Wiesbaden 1984

Otto ZWIERLEIN, Senecas Hercules im Lichte kaiserzeitlicher und spätantiker Dichtung, Abh. der Akad. Mainz 1984 (Nr. 6)

Otto ZwIERLEIN, Senecas Phaedra und ihre Vorbilder, Abh. der Akad. Mainz 1987 (Nr. 5)

Otto ZwIERLEIN, Rezension zu FitCH, Gn. 60, 1988, 333-342 